\title{
GENDER AND ICTS IN BHUTAN: A COMPARATIVE CASE STUDY OF TANGMACHU AND THIMPHU
}

\author{
by \\ CHAITALI SINHA, B.Comm. \\ A thesis submitted to \\ The Faculty of Graduate Studies and Research \\ in partial fulfilment of \\ the requirements for the degree of
}

Master of Arts

The Norman Paterson School of International Affairs

Carleton University

Ottawa, Ontario

August 15, 2007

(C) 2007, Chaitali Sinha 


$\begin{array}{ll}\begin{array}{l}\text { Library and } \\ \text { Archives Canada }\end{array} & \begin{array}{l}\text { Bibliothèque et } \\ \text { Archives Canada }\end{array} \\ \begin{array}{l}\text { Published Heritage } \\ \text { Branch }\end{array} & \begin{array}{l}\text { Direction du } \\ \text { Patrimoine de l'édition }\end{array} \\ \begin{array}{l}\text { 395 Wellington Street } \\ \text { Ottawa ON K1A ON4 }\end{array} & \begin{array}{l}\text { 395, rue Wellington } \\ \text { Ottawa ON K1A ON4 } \\ \text { Canada }\end{array}\end{array}$

Your file Votre référence ISBN: 978-0-494-33769-1 Our file Notre référence ISBN: 978-0-494-33769-1

NOTICE:

The author has granted a nonexclusive license allowing Library and Archives Canada to reproduce, publish, archive, preserve, conserve, communicate to the public by telecommunication or on the Internet, loan, distribute and sell theses worldwide, for commercial or noncommercial purposes, in microform, paper, electronic and/or any other formats.

The author retains copyright ownership and moral rights in this thesis. Neither the thesis nor substantial extracts from it may be printed or otherwise reproduced without the author's permission.
AVIS:

L'auteur a accordé une licence non exclusive permettant à la Bibliothèque et Archives Canada de reproduire, publier, archiver, sauvegarder, conserver, transmettre au public par télécommunication ou par l'Internet, prêter, distribuer et vendre des thèses partout dans le monde, à des fins commerciales ou autres, sur support microforme, papier, électronique et/ou autres formats.

L'auteur conserve la propriété du droit d'auteur et des droits moraux qui protège cette thèse. $\mathrm{Ni}$ la thèse ni des extraits substantiels de celle-ci ne doivent être imprimés ou autrement reproduits sans son autorisation.
In compliance with the Canadian

Privacy Act some supporting forms may have been removed from this thesis.

While these forms may be included in the document page count, their removal does not represent any loss of content from the thesis.
Conformément à la loi canadienne sur la protection de la vie privée, quelques formulaires secondaires ont été enlevés de cette thèse.

Bien que ces formulaires aient inclus dans la pagination, il n'y aura aucun contenu manquant.

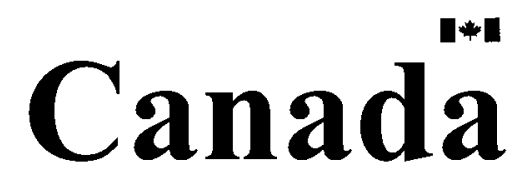




\begin{abstract}
The introduction of Information and Communications Technologies (ICTs) in developing countries is commonly linked with improved livelihoods and increased social inclusion. In Bhutan, a country isolated by its natural geography and deliberate national policy, ICTs have been introduced in a relatively cautious and controlled manner. This thesis uses a comparative case study model to examine how fixed telephones, mobile telephones, and the Internet are perceived and used by women and men in the urban community of Thimphu, and those in the remote rural community of Tangmachu. Based on library research and original fieldwork, it explores ICTs and gender relations as mutually shaped, significant at both material and symbolic levels, and situated within existing social and technological continua. Additional findings reveal access as a physical and social phenomenon, differences in text- versus voice-intensive ICTs, and a nuanced understanding of ICT users and non-users.
\end{abstract}




\section{ACKNOWLEDGMENTS}

I would like to extend my deepest gratitude to those who helped me complete this thesis. My supervisor, Dr. Jared Keil, never ceased to amaze me with his unlimited source of enthusiasm, support and friendship - I greatly appreciate his generosity and kindness. I would also like to thank Dr. David Long for his kind support and guidance as my thesis advisor.

I am indebted to my colleagues at IDRC who allowed me the time and space to undertake this endeavour. Specifically, Maria $\mathrm{Ng}$, who connected me with individuals at the Department of Information Technology (DIT) in Thimphu and helped me realize my dream of conducting field research in Bhutan. Others at IDRC, such as Kathleen FlynnDapaah, Laurent Elder and Rich Fuchs, were extremely supportive and helpful over the course of writing this work. I would also like to thank the management at IDRC for allowing me to take a leave of absence to collect primary data in the Thimphu and Tangmachu.

I was fortunate to have met several individuals at DIT in Bhutan who helped me immensely during my field visit. Director Chhoeda, Sangay Wangchuck, Sangay Wangmo, Namgay Wangchuk and Lektsho Dorji are among the many individuals who facilitated my learning process. I would also like to thank my interpreters in Thimphu and Tangmachu - Dolkar Lham and Pema Lhazin respectively.

Finally, I would like to thank my family and friends without whose love and support I would not have been able to write this thesis. My parents and brothers provided a great deal of strength and support along the way. I would particularly like to thank Mark Uygur, whose kindness, love and care were often the sole source of my energy and motivation to persevere. To all of these individuals, I dedicate this thesis. 


\section{TABLE OF CONTENTS}

ABSTRACT ........................................................................................................................

ACKNOWLEDGMENTS .........................................................................................iii

TABLE OF CONTENTS ............................................................................................. iv

LIST OF ACRONYMS .................................................................................................. vi

GLOSSARY ................................................................................................... vii

MAP 1: BHUTAN .............................................................................................................. viii

MAP 2: THIMPHU \& TANGMACHU .................................................................................. ix

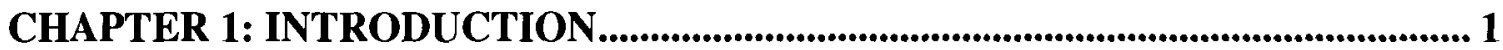

CHAPTER 2: GENDER AND TECHNOLOGY ...................................................... 8

2.1 Situating Key Terms: Context and Definitions.............................................................. 8

2.2 Literature Review: Gender and Technology .......................................................... 12

2.2.1 Mutual Shaping of Gender and Technology ................................................ 13

2.2.2 Gender and Technology: Material \& Symbolic Significance............................ 18

2.2.3 ICTs as part of Social and Technological Continua ........................................ 23

2.3 Gender and ICTs in the Third World...................................................................... 27

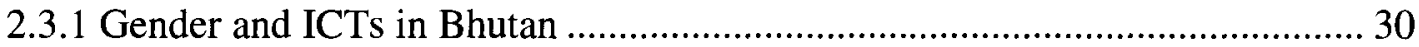

2.4 Conclusion ............................................................................................................................. 33

CHAPTER 3: RESEARCH METHODOLOGY ............................................................. 35

3.1 Defining the Boundaries and Scope .................................................................................. 35

3.1.1 Searching for a Suitable Methodology ....................................................... 37

3.2 Actual Research Process............................................................................................... 39

3.2.1 Site Selection .................................................................................. 41

3.2.2 Situating Myself in the Research Process ...................................................... 43

3.2.3 Research Methods and Instruments ............................................................ 44

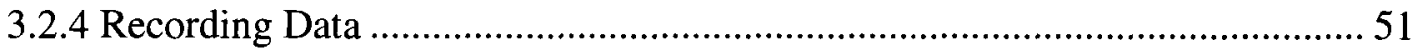

3.3 Reflecting on the Research Process ............................................................................. 52

3.3.1 Paramount Importance of Social Networks ..................................................... 53

3.3.2 Overcoming Faulty Assumptions ………………………………………....... 54

3.3.3 Balancing Flexibility and Integrity within the Research Design ..................... 56

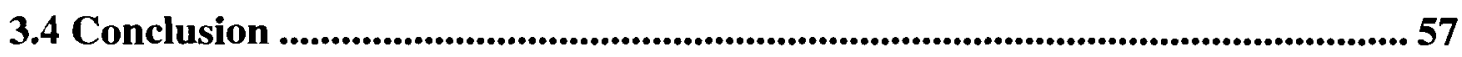

CHAPTER 4: GENDER IN BHUTAN: THIMPHU AND TANGMACHU ...............58

4.1 Rural and Urban Communities in Bhutan ..........................................................58

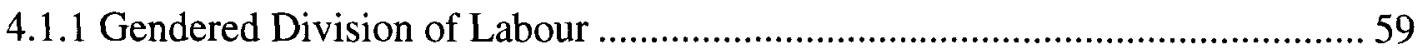

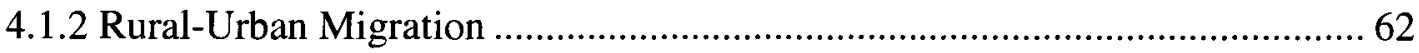

4.1.3 Legal and Customary Norms: Inheritance and Residence ...................................... 64

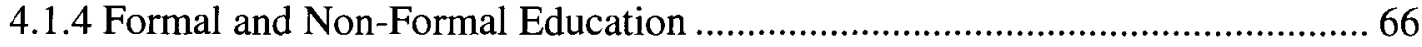


4.1.5 ICT: Introduction, Access and Usage 68

4.2 Thimphu \& Tangmachu: Demographic and Contextual Information ............ 69

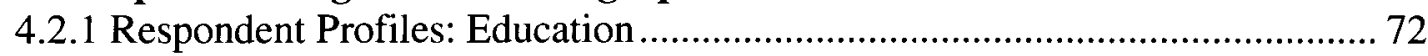

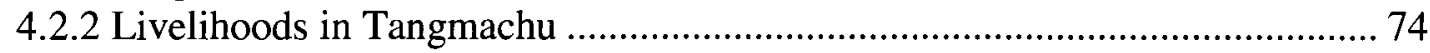

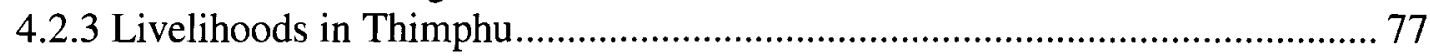

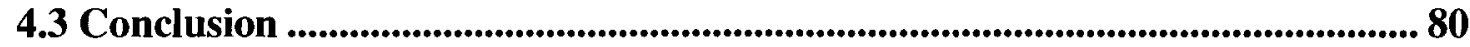

CHAPTER 5: GENDERED PERCEPTIONS AND USE OF ICTS IN

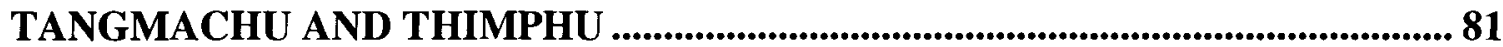

5.1 Gendered Perceptions of ICTs in Tangmachu and Thimphu .......................... 82

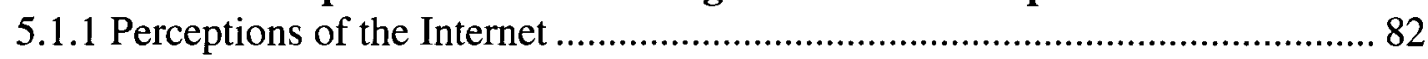

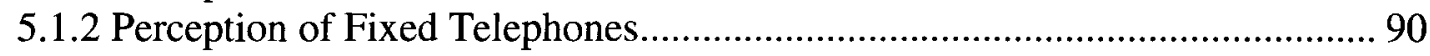

5.1.3 Perception of Mobile Telephones .............................................................. 93

5.2 Gendered Use of ICTs in Tangmachu and Thimphu ....................................... 99

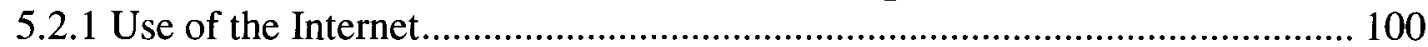

5.2.2 Fixed Telephone \& Mobile Telephone Use................................................ 104

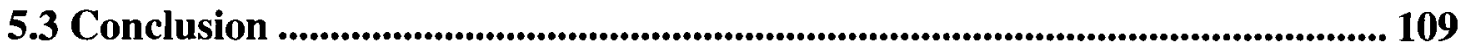

CHAPTER 6: SUMMARY AND CONCLUSIONS ...................................................... 110

6.1 Revisiting the Scope, Objectives and Limitations............................................. 110

6.2 Perceptions of ICTs in Thimphu and Tangmachu: Findings.......................... 111

6.3 Use of ICTs in Thimphu and Tangmachu: Findings................................... 115

6.4 Thesis Assertions: Findings....................................................................... 117

6.4.1 Mutual Shaping of Gender and ICTs ...................................................... 118

6.4.2 Gender and ICTs: Material and Symbolic Significance ............................. 120

6.4.3 Social and Technological Continua ........................................................... 122

6.5 Summary and Areas Flagged for Future Research .......................................... 124

6.5.1 Text- versus Voice-Intensity of ICTs .................................................. 125

6.5.2 Spectra of Users and Non-Users ....................................................... 127

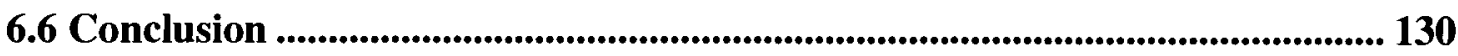

Appendix A: Household Survey ......................................................................... 131

Appendix B: Semi-Structured Interview Plan for Thimphu ................................... 132

Appendix C: Semi-Structured Interview Plan for Tangmachu ............................... 140

Appendix D - List of Key Informant Interviewees............................................... 146

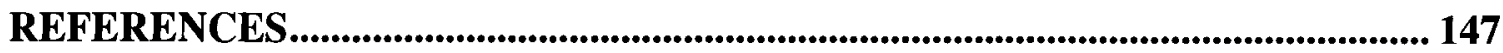




\section{LIST OF ACRONYMS}

$\begin{array}{ll}\text { BBS } & \text { Bhutan Broadcasting Service } \\ \text { BHU } & \text { Basic Health Unit } \\ \text { CBS } & \text { Centre for Bhutan Studies } \\ \text { CEDAW } & \text { Convention on the Elimination of All forms of Discrimination } \\ \text { CIC } & \text { Community Information Center } \\ \text { DIT } & \text { Department of Information Technology } \\ \text { FAO } & \text { Food and Agriculture Organization } \\ \text { FYP } & \text { Five Year Plan } \\ \text { GNH } & \text { Gross National Happiness } \\ \text { ICT } & \text { Information and Communication Technology } \\ \text { ICT4D } & \text { Information and Communication Technology for Development } \\ \text { IDRC } & \text { International Development Research Centre } \\ \text { ITU } & \text { International Telecommunications Union } \\ \text { MoIC } & \text { Ministry of Information and Communication } \\ \text { NCWC } & \text { National Commission for Women and Children } \\ \text { NFE } & \text { Non-Formal Education } \\ \text { NGO } & \text { Non-Governmental Organization } \\ \text { NWAB } & \text { National Women's Association of Bhutan } \\ \text { PAN } & \text { Pan Asia Networking } \\ \text { RUB } & \text { Royal University of Bhutan } \\ \text { RENEW } & \text { Respect, Education Nurture \& Empower Women } \\ \text { RGoB } & \text { Royal Government of Bhutan } \\ \text { SCOT } & \text { Social Construction of Technology } \\ \text { SMS } & \text { Short Message Service } \\ \text { TD } & \text { Technological Determinism } \\ \text { USD } & \text { US Dollar } \\ \text { VOIP } & \text { Voice over Internet Protocol } \\ \text { WiFi } & \text { Wireless Fidelity } \\ \end{array}$




\section{GLOSSARY}

Ara

Chocangacakha

Chökey

Driglam Namzha

Drukpa

Dzong

Dzongkha

Dzongkhag

Gewog

Gup

Kishuthara

Kurtoep

Lhotshampa

Lhuntse

Ngalong

Ngultrum (Nu)

Sharchop

Sharchopkha

Thimphu

Tangmachu

Thagla bela
Rice wine

Language spoken in Tangmachu

Alphabet used to write Dzongkha, originated from Tibet

A national decree that translates to "One nation. One People."

Term generally used to refer to people of Bhutan

Fortress - there is one located in every district

National language of Bhutan

District - there are 20 districts in Bhutan

Block - each district is comprised of blocks

Equivalent to a town mayor

Type of intricately woven textile

Language spoken in Tangmachu

Translated literally from Dzongkha as 'people of the south'. It is broadly used to refer to people of Nepali descent

District in eastern Bhutan containing Tangmachu

People originally from western Bhutan

Currency in Bhutan (30 Nu $=\sim 0.70$ USD)

People originally from eastern Bhutan

Language spoken by many people in eastern Bhutan

Name of a district and of Bhutan's capital city

A collection of villages, forming a community in Lhuntse district

Work related to wool and weaving 
MAP 1: BHUTAN

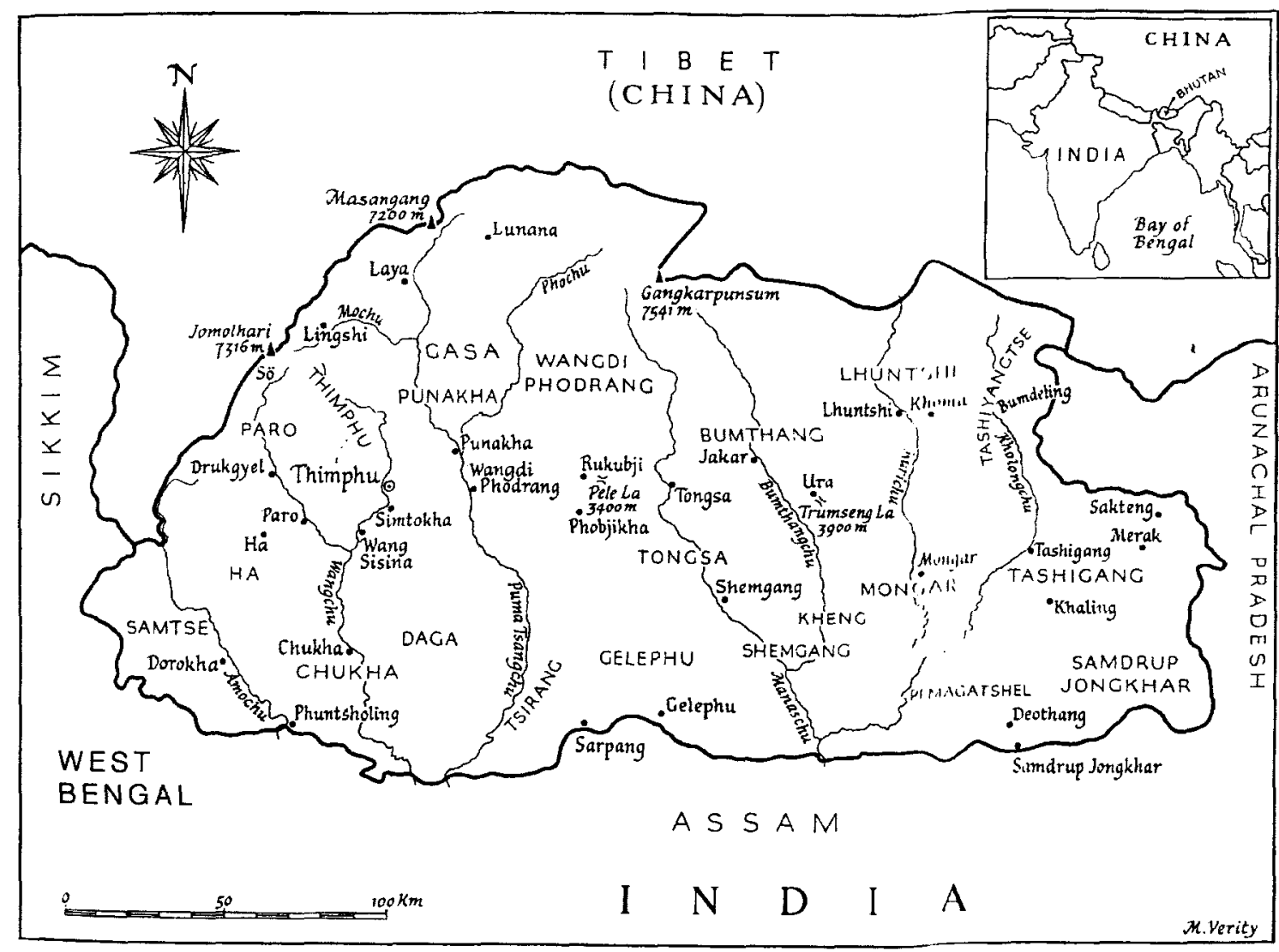

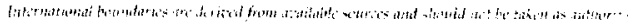

Map of Bhutan

Source: Bhutan: Mountain Fortress of the Gods (Schicklgruber \& Pommaret 1997: 11) 
MAP 2: THIMPHU \& TANGMACHU
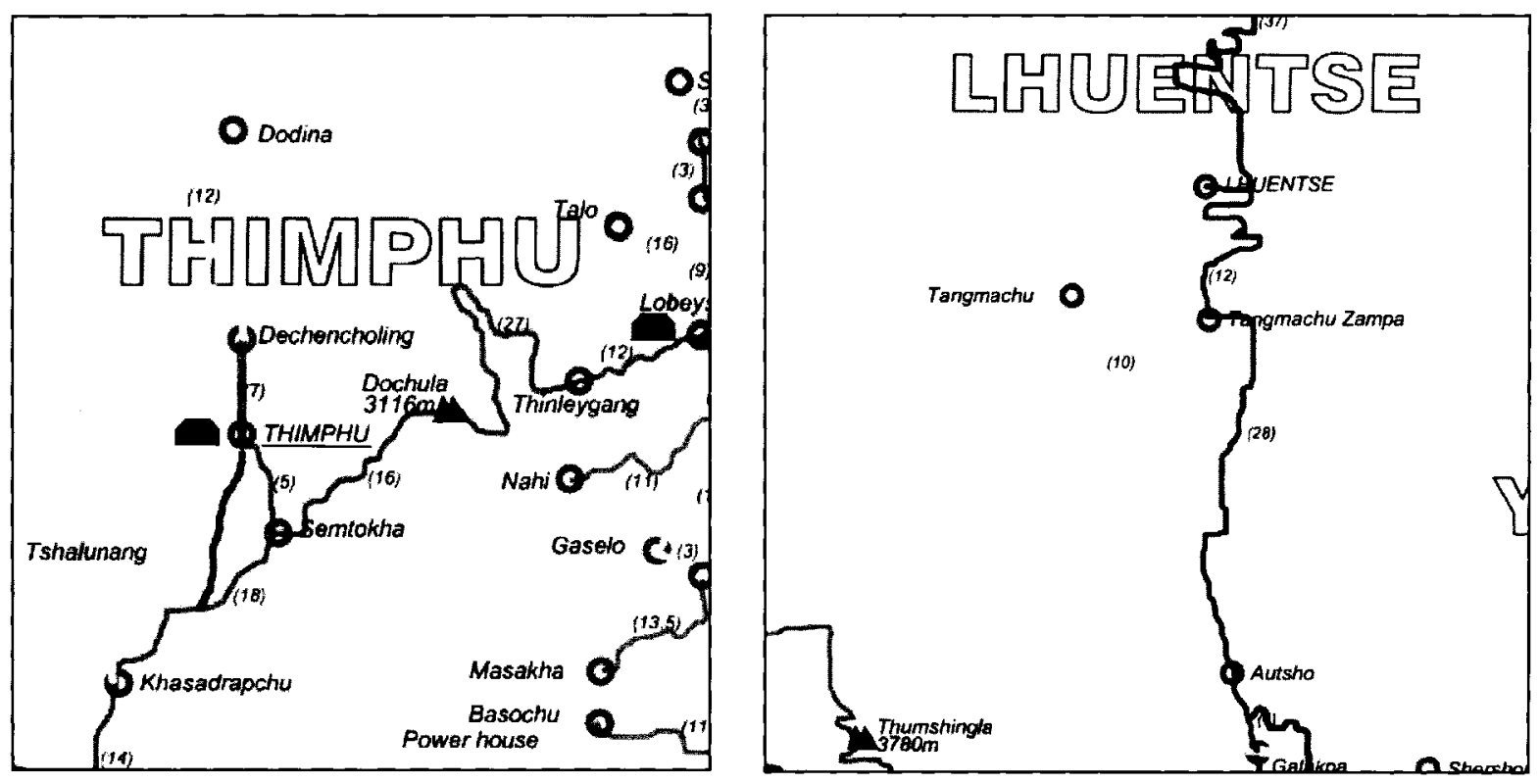

Source: RGoB (Department of Roads Ministry of Works \& Human Settlement), Updated: 01/12/2005: http://www.dor.gov.bt/graphics/ROADNET.pdf. 


\section{CHAPTER 1: INTRODUCTION}

This thesis examines the recent introduction of information and communications technologies (ICTs) - notably the Internet, fixed telephones and mobile telephones - in the Himalayan kingdom of Bhutan. Based on library research and original fieldwork, the inductive study considers different elements of the "digital divide" by exploring perceptions and use of the aforementioned ICTs among women and men from different classes, ethnicities and generation in the urban community of Thimphu and the rural community of Tangmachu [see Map 2]. ${ }^{2}$

Bhutan is a relatively remote nation-state (both physically and politically) that emerged from self-imposed isolation in 1961. Since then, the country has observed controlled and gradual exposure to foreign influences and technologies, while actively protecting Drukpa ${ }^{3}$ societal values and norms (Hutt 2003; Pain \& Pema 2000). Examining gender relations and ICTs in Bhutan provides a unique opportunity to explore the issue in a country with relatively progressive legal gender norms (Schicklgruber 1997; Brauen 1997; Crins 2004) and one that has recently been introduced to several new ICTs - including television (1999), the Internet (1999), and mobile telephony (2003). ${ }^{4}$ My field research in October-November 2006 was propitiously timed to follow the release of Bhutan's first internationally recognized census (for 2005, released in 2006),

\footnotetext{
${ }^{1}$ The 'digital divide' describes the gaps between those with access to ICTs and those without.

${ }^{2}$ Thimphu is both a district and a city (the country's capital) in western Bhutan. Tangmachu is located in Lhuntse district in eastern Bhutan. At the time of this research, Tangmachu did not have any mobile telephony service.

${ }^{3}$ Drukpa is a term used to refer to people of Ngalong and Sharchop descent in Bhutan. Sometimes it is used synonymously with 'citizen of Bhutan'. These terms are defined in the glossary and discussed in more detail later in the thesis.

${ }_{4}^{4}$ In June 1999, coinciding with the silver jubilee celebrations for King Jigme Singye Wangchuck, the fourth monarch unveiled Bhutan's first television broadcast service (BBS: Bhutan Broadcasting Service) and Internet service provider (Druknet). Bhutan launched its first mobile telephony service (B-Mobile) in November 2003.
} 
the official launch of a wireless fidelity $(\mathrm{WiFi})^{5}$-enabled Internet connection and local telephone system in the rural community of Tangmachu, and the announcement of the country's first national elections to be held in $2008 .^{6}$

Commonly referred to as Druk Yul - land of the Thunder Dragon - Bhutan's unique geopolitical situation as a country nestled between China (Tibet) and India [see Map 1] influences many of its policies toward security, trade, development and diplomacy. ${ }^{7}$ The country's population, which is comparable to that of Qatar or Luxemburg, is dispersed throughout a landmass that is more akin to Switzerland in size. A large proportion of Bhutan's populace ${ }^{8}$ lives in sparsely inhabited communities, which are scattered throughout the predominantly mountainous terrain. The people of Bhutan are multi-ethnic, multi-religious, and multi-lingual (Pommaret 1997; Mathou 2000; Giri 2004; Aris 1994). There are three main ethnic groups: the Ngalong, originally from western Bhutan; the Sharchop, originally from eastern Bhutan; and the Lhotshampa, originally from southern Bhutan. ${ }^{9}$ People of Ngalong and Sharchop descent are known collectively as Drukpa.

Bhutan's state religion is Drukpa Kagyupa Mahayana Buddhism. In a country that identifies closely with its religious history (Rose 1977), Drukpa norms have been

\footnotetext{
${ }^{5} \mathrm{Wi}-\mathrm{Fi}$ (or Wi-fi, WiFi, Wifi, wifi), short for "Wireless Fidelity", is a set of product compatibility standards for wireless local area networks (WLAN) based on the IEEE 802.11 specifications. New standards beyond the 802.11 specifications, such as 802.16 (WiMAX), are currently in the works and offer many enhancements, anywhere from longer range to greater transfer speeds. (en. wikipedia.org/wiki/WiFi)

${ }^{6}$ The proposed governmental changes mark the end of approximately 100 years under an absolute hereditary monarch - which began in 1907 with the crowning of Bhutan's first king Ugyen Wangchuck.

${ }^{7}$ Indian assistance accounted for a substantial outlay during all Five Year Plans (FYPs) to date and India continues to be the major donor to Bhutan (CBS \& IDE/JETRO 2004). The kingdom's amicable relationship with India, which is both its largest official development assistance provider and principal trade partner, is starkly juxtaposed with the frigid diplomatic relations it has with China. (Pain 2004).

${ }^{8}$ According to the 2005 national consensus, the population is 634,982 , which comprises 333,595 males and 301,387 females (RGoB 2005a).

${ }^{9}$ The Lhotshampa - literally translated from Dzongkha as "people of the southern border" - are essentially those of Nepali origin. Many other ethnic groups inhabit Bhutan, above and beyond these three dominant groups, such as the Brokpa, Kurteop, Bumthangpa, Doya, Lepcha, Kheng, Monpa, Adivasis and Gongduk.
} 
institutionalized through, among other avenues, the driglam namzha ("one nation, one people") decree. ${ }^{10}$ Present day dzongs (district headquarters) continue to house spiritual and administrative orders of governance side-by-side. Dzongkha, which literally translates to "language of the dzong", is the mother tongue of Ngalong Drukpas and was proclaimed the national language of Bhutan in 1961 (with an estimated 160,000 speakers). ${ }^{11}$

Bhutan is predominantly an agrarian society - albeit with limited arable land. ${ }^{12}$ Due to the mountainous terrain, the majority of cultivated land is terraced on steep slopes, thus precluding large-scale mechanization and generally limiting efficiency and crop yield. Subsistence farming and animal husbandry prevail as the dominant form of livelihood throughout Bhutan; however the proportion of cash cropping has been gradually increasing over the past few decades (Tobgay 2005; Choden 1997; Pain \& Pema 2004; RGoB 2005b). Cash cropping in previously subsistence-based communities has been accompanied by a corresponding increase in rural-urban migration. ${ }^{13}$ According to the latest census, (RGoB 2005a), 69\% of Bhutan's population live in rural areas, indicating a decline from previously reported figures of approximately $80 \% .{ }^{14}$ Growing

\footnotetext{
${ }^{10}$ In 1989 , the fourth king issued a cultural decree termed "driglam namzha" ("one nation, one people"), which actively promotes a distinct national identity for the kingdom and requires that all people of Bhutan follow the Drukpa code of ethics.

${ }^{11}$ The estimates are based on a total population of 600,000. According to George Van Driem's Languages of the Greater Himalayan Region published in 1998, Leiden University, Dzongkha is native to eight out of twenty dzongkhags - all of which are found in western Bhutan. Statistics for other languages include 156,000 for Nepali (spoken predominantly by Lhotshampa) and 138,000 for Sharchopkha (spoken predominantly by Sharchop).

${ }^{12}$ A mere $7.8 \%$ of the country's land area is suitable for cultivation (Tobgay 2005).

${ }^{13}$ The RGoB's Ministry of Agriculture commissioned the first systematic study conducted on rural-urban migration. According to the study, titled "Rural-Urban Migration in Bhutan: Walking the Extra Mile", the profile of most migrants is predominantly literate males, between the ages of 16 and 30 (RGoB 2006).

${ }^{14}$ Statement by H.E. Lyonpo Om Pradhan Chairman Of The Delegation Of The Kingdom Of Bhutan To The Twenty Fifth Special Session Of The General Assembly For An Overall Review And Appraisal Of The Implementation Of The Habitat Agenda, New York, 6-8 June 2001. http://www.un.org/ga/habitat/statements/docs/bhutanE.html.
} 
rural-urban migration, changes in the gendered division of labour, and other phenomena influencing overall gender relations in Bhutan have not gone unnoticed. According to a Gender Pilot Study commissioned by the Royal Government of Bhutan (RGoB et al. 2001: 2):

[t] he country today recognizes the challenge of balancing modern and traditional values and that socioeconomic changes influence gender relations. Changes such as increased mobility, rising educational requirements, new opportunities for employment, urbanization, and access to and use of technology, may have differential impacts on women and men.

Despite a growing recognition of the link between socioeconomic changes and gender relations in Bhutanese society, there exists a limited body of research examining these relationships. This is due to a combination of scarce sex-disaggregated data, the relatively recent introduction of several ICTs, the incipient body of social science literature, and the country's strict visa acquisition policies. ${ }^{15}$

Western Bhutan is home to most urban settlements, while most rural settlements are located in the central and eastern parts of the country. Dissimilarities in natural geography between the western and eastern parts of Bhutan directly influence their access to roads, electricity, and communications infrastructure. ${ }^{16}$ Despite Bhutan's comparative advantage in producing hydroelectricity, several communities face challenges vis-a-vis

\footnotetext{
${ }^{15}$ According to Francoise Pommaret (2006), "The discipline of Social Science was therefore unknown in [Bhutan] ... [r]ight till the 1980s." http://www.reseau-asie.com/rf/ed en 0 2027.html. Daily tariffs render Bhutan inaccessible to many non-Indian researchers without explicit permission (200 USD daily tariff from Jan-June; 165 USD otherwise). These prices include services for land transport, accommodation, food, sightseeing, guides and cultural programs (Dorji 2001: 85).

${ }^{16}$ Valleys in the west are relatively broad and 'u-shaped', having valley floors up to a kilometre wide, whereas valleys located in the eastern parts are particularly steep and possess very narrow valley floors (Pain 2004; Pommaret 1997).
} 
electrification. ${ }^{17}$ Moreover, the uneven terrain makes laying cable for ICT infrastructure relatively labour- and resource-intensive. Wireless ICT solutions are being increasingly deployed to overcome many of these physical challenges - especially in rural areas, which possess limited legacy wired infrastructure (Tobgyl 2003; Wangmo 2004; Dubgyur 2002). Few studies have been conducted to assess the way in which women and men of different age groups, classes, and ethnicities utilize ICTs in rural and urban milieus; and fewer still on the effects ICT access and use can have on reinforcing or challenging existing gender relations (RGoB et al. 2001). ${ }^{18}$

Relative to other South Asian countries, the legal status of Bhutanese women is perceived to be progressive (Wangmo 2004: 27; Crins 2004: 581). ${ }^{19}$ Many cite Bhutan's preclusion of overt legal and social discrimination against women, and the dominant role women often play in inheritance law (Schicklgruber 1997; Brauen 1997; RGoB et al. 2001; Crins 2004). However, the relative paucity of sex-disaggregated data and a corresponding dearth of evidence based on sound gender analysis give rise to several unanswered questions about the rhetoric versus the reality of present day gender relations among the urban and rural populace of Bhutan. Moreover, these norms and practices have yet to be discussed vis-à-vis if and how they are influenced by (or influence) ICT perception, access and use. Examining ICTs and gender relations in Bhutan makes for a particularly interesting case study because of the country's relatively recent exposure to several ICTs, and its limited role in the design and production phases.

\footnotetext{
${ }^{17}$ Approximately $30 \%$ of the country has access to electricity and most of it lies in urban areas (RGoB 2004). Moreover, Bhutan exports a growing amount of the hydroelectricity it generates to neighbouring India.

${ }^{18}$ The literature review in Chapter Two will discuss much of the existing literature written about gender relations and ICTs in Bhutan.

${ }^{19}$ Bhutan is home to many different people and cultures. References made with regards to gender relations generally refer to Drukpa norms.
} 
Three assertions, which flow from the literature review in Chapter Two, help frame the rationale and approach taken in this thesis: i) gender relations and ICTs are socially constructed and mutually shaped categories (Wajcman 2004; MacKenzie \& Wajcman 1985); ii) interactions between ICTs and gender relations are both material and symbolic in nature (Plant 2002; Turkle 1984); and iii) ICTs are complex, dynamic and flexible, situated within broader social and technological continua (Heeks 2002; Warschauer 2003). These assertions shaped the research questions and were used as guiding pillars in this exploratory study. As such, the objective of this work is not to provide answers to predefined questions or hypotheses, but rather to furnish a stronger understanding of how ICTs and gender relations converge and interact with one another in particular urban and rural communities.

Chapter Two reviews the relevant literature on gender and technology, including gender and ICTs in the Third World and in Bhutan, and draws on germane theories to develop a suitable conceptual design for the study. Chapter Three discusses the research design and methodology before, during and after my field research. Using feminist inquiry and drawing on elements from actor-oriented approaches, a tripartite range of research instruments (semi-structured interviews, participant observation and key informant interviews) was developed for the two sites. Chapter Four considers gender relations, rural-urban migration, and ICTs among urban and rural communities of Bhutan, and presents specific demographic information about the respondents from Thimphu and Tangmachu. Chapter Five analyzes the data collected during the eight and a half weeks of fieldwork and reveals findings related to gender identities, roles and relations. As a 
conclusion to this thesis, Chapter Six summarizes the findings and presents recommendations pertaining to the research on gender relations and ICTs in rural and urban communities of Bhutan. 


\section{CHAPTER 2: GENDER AND TECHNOLOGY}

This chapter situates the thesis topic among the existing literature on gender and technology, including gender and ICTs in the Third World and in Bhutan. Divided in three sections, the first section provides context and definitions for frequently used terms throughout the thesis. The following section presents a concise literature review of works examining gender and technology, including its discourse, origins and assumptions; as well as a more specific body of literature on the topic of gender and ICTs in the Third World and in Bhutan. This exercise uncovers a number of deficiencies and raises several questions pertaining to the research topic. The final section of the chapter examines relevant literature and empirical examples in order to develop a framework to adequately address these areas in the study.

\subsection{Situating Key Terms: Context and Definitions}

Several recurring terms and concepts underlie this study including gender, gender relations, technology, ICT, digital divide and gender digital divide. These terms carry diverse meanings, which are often contingent on historic, geographic, political, economic and/or social contexts. In order to furnish a common conceptual springboard to conduct a literature review, develop a methodology and analyze data collected in Thimphu and Tangmachu, this section presents a set of definitions that will be drawn upon throughout the thesis.

While often used interchangeably, gender and sex are inextricably related but theoretically distinct concepts. Sex relates to biological and anatomical characteristics, whereas gender refers to a broader array of socially constructed roles, relationships, attitudes, values and behaviours ascribed to the male and female sex. The concept of 
gender is relational, including the relationship between and among women and men, as well as the socially constructed meanings of femininity and masculinity. According to Reeves and Baden (2000: 30), "to understand and challenge the cultural value placed on someone's biological sex and unequal power hierarchies, we need the relational concept of 'gender'." They also define gender relations to constitute and be constituted by an array of structures and institutions, such as the family, the market and legal systems (ibid: 18). Both gender and gender relations are central concepts in this study. With respect to the research topic examining gender relations includes the range of perceived and actual circumstances and opportunities influencing physical and social access by men and women to different ICTs.

Technology is a broad term that can refer to material objects, systems or techniques. For the purposes of this study, technology is defined as "human-made artefacts/processes and their social contexts that are geared towards enhancing human capabilities" (Everts 1998: 6). Richard Heeks provides a framework to distinguish between different information-handling technologies. He presents four categories: i) digital technology, such as computers which handle data as $1 \mathrm{~s}$ and 0 , ii) intermediate technology based on analog information and electromagnetic waves, such as analog radio, television and telephones; iii) literate technology based on information as written word, such as books and newspapers; and iv) organic technology, which is based solely on the human body, including the brain and sound waves (Heeks 2002: 3). This taxonomy is useful in situating ICTs among other information-handling technologies; however Heeks' classification of ICTs as either digital or analog technology is found to be rather narrow for the purpose of this thesis. A more inclusive definition is provided by 
Cees J. Hamelink (1997: 3), who defines ICTs as "all those technologies that enable the handling of information and facilitate different forms of communication among human actors, between human beings and electronic systems, and among electronic systems".

As a term comprised of three multi-faceted components, ICTs have been classified differently over the years. For example, UNDP (2001: 2) defines ICTs as "information-handling tools - a varied set of goods, applications and services that are used to produce, store, process, distribute and exchange information ... [including] 'old' ICTs of radio, television and telephone, and the 'new' ICTs of computers, satellite and wireless technology and the Internet". ${ }^{20}$ ICTs examined in this study - notably the Internet (as accessed via computers), fixed telephones and mobile telephones - are henceforth referred to as 'interactive ICTs'. This qualification distinguishes between: i) ICTs with lower levels of interaction with the user, which generally limits the user's role as a passive recipient (e.g. televisions and analog radios), and ii) ICTs with higher levels of interaction, which generally include some form of voice or data input device and expands the user's role as both a recipient and a producer of information and knowledge (e.g. telephones and computers). The distinction between old and new ICTs is common in the literature; however its implicit chronology is found to be incongruous with this study. By categorizing ICTs by their level of interactivity, both new and old ICTs are examined side-by-side and evaluated according to specific conditions and motivations extant in Thimphu and in Tangmachu. This is done to avoid assigning value to ICTs based on functionality or complexity of design or use; but rather to garner a deeper understanding

\footnotetext{
${ }^{20}$ The distinction between old and new ICTs generally relate to the nature of data transmission - where analog transmission generally relates to old ICTs and digital transmission generally relates to new ICTs.
} 
of how women and men perceive and use these technologies in their daily lives to access information, share knowledge and communicate with one another.

Differences in ICT access and use among different parties are commonly referred to as a "digital divide". The OECD report titled "Understanding the Digital Divide" (2001: 5) defines the digital divide as "the gap between individuals, households, businesses and geographic areas at different socio-economic levels with regard both to their opportunities to access information and communication technologies (ICTs) and to their use of the Internet for a wide variety of activities". Anthony Wilhelm nuances this definition in a manner that is more pertinent to this study. He defines the digital divide as "the gap between those who have access to and can effectively use information technologies and those who cannot" (emphasis added). ${ }^{21}$ Wilhelm's emphasis on effective use of ICTs is germane to this thesis because it contextualizes ICT access and use within specific realities, which includes both opportunities and challenges. As access can be perceived as a social phenomenon (Liff \& Shepherd 2004: 2 ), ${ }^{22}$ the digital divide comprises divides that are specific to social relations, such as gender. The "gender digital divide" is defined as gaps in access between men and women, which can manifest itself through various societal axes such as race, ethnicity, class and age (Hafkin \& Taggart 2001; Gurumurthy 2004). ${ }^{23}$ The set of definitions provided thus far is meant to furnish a common foundation to approach the remainder of this thesis.

\footnotetext{
21 "They Threw Me a Computer...But What I Really Needed was a Life Preserver. First Monday, 6 (4). Retrieved June 1, 2007, from http://www.firstmonday.org/issues/issue6_4/wilhelm/

${ }^{22}$ Liff and Shepherd (2004) describe the social nature of access by indicating its connection with one's awareness of, interest in, and motivation to use an ICT (in the case of the article, this ICT happens to be the Internet). In addition, the authors discuss the link between ICT access and how the technology is integrated in to one's regular day-to-day activities.

${ }^{23}$ Slight variations on this definition can be found in Huyer et al. (2005) Marcelle (2000) Mitter and Rowbotham (1995); Huyer and Mitter (2003), among others.
} 


\subsection{Literature Review: Gender and Technology}

In light of the three assertions stated at the outset of this study, this section reviews literature relating to: i) gender relations and ICTs as socially constructed and mutually shaped; ii) the interactions between ICTs and gender relations as both material and symbolic in nature; and iii) ICTs are complex, dynamic and flexible, situated within broader social and technological continua. The first assertion of technology and gender as mutually shaped categories is discussed on the one hand by examining the influence of gender relations on technology design, production, and deployment; and on the other hand by examining the influence of technology on reinforcing or altering gender relations. Considering material and symbolic elements of gender and technology involves exploring the range of processes and practices in technology access and use (material elements), as well as related perceptions, vocabulary and meanings (symbolic elements). The third assertion situates different ICTs and the notion of a digital divide within social and technological continua. Challenging the 'leapfrogging, ${ }^{24}$ hypothesis, it examines the prerequisite social and technological changes that are often taken for granted in parts of the First World (Raiti 2007; Heeks 2002; Warschauer 2003). The final two sections of the literature review are devoted specifically to examining gender relations and ICTs in the Third World and Bhutanese contexts.

Gender and technology as a social science research question is a post-1980 phenomenon (Sorenson 2000: 9). Its roots can be traced back to the "Women in Technology" movement, which advocates equal opportunity among women and men to access technologies that are neutral in their design, production and diffusion (Cockburn

\footnotetext{
${ }^{24}$ Leapfrogging in this sense can be defined as "bypassing stages in capability building or investment through which countries were previously required to pass during the process of economic development" (Steinmueller 2001: 194).
} 
1986; Henwood 1993). This position in feminist technology studies has since been challenged as one that situates the necessary change(s) in women (their socialization, aspirations and values), instead of asking the broader questions of whether, and in what way, technology and its institutions could be reshaped to accommodate women and men (Wajcman 2004: 14). Alternatively, the gender and technology discourse acknowledges the gendered nature of technological innovations and the reciprocal relationship between the categories of gender and technology (Mitter 2004; Huyer 1997; Wajcman 1991; Gurumurthy 2004). A growing body of literature written about gender and technology examines their mutually constructed and contested relationship - often referred to as mutual shaping (Mackenzie \& Wajcman 1985).

\subsubsection{Mutual Shaping of Gender and Technology}

Mutual shaping of gender and technology refers to the co-influence, coproduction and co-dependence of the two. By examining the impacts and outcomes of technological change, in addition to the intent behind technology design, production and content creation, this approach posits technology and society as mutually shaped by one another (Mackenzie \& Wajcman 1985; Wajcman 2004).

In Feminism Confronts Technology (1991), Judy Wajcman provides an impressive account of feminist critiques of technology. She documents the evolution of the gender and technology debate and poses questions about the role of technology in emancipating women and encouraging gender equality, versus reinforcing existing sexual divisions or creating new forms of societal inequity. More than a decade later, Wajcman's Technofeminism (2004) examines 'frontier technologies' such as the Internet, and considers two extreme positions in the gender and technology discourse - utopian 
and dystopian. The utopian position is optimistic and focuses on the potential for technologies to liberate women, while the dystopian perspective is pessimistic and charges gendered technologies with maintaining or exacerbating existing gender hierarchies and power imbalances. ${ }^{25}$ Wajcman offers the 'technofeminism' approach, as a happy medium between the two. Technological Determinism (TD) promotes the view that technology and technological capacity determine history and forces for change within a given society; on the other hand, Social Construction of Technology (SCOT) (sometimes referred to as social determinism) claims that technologies are shaped predominantly by human interactions and negotiations. Transcending technological determinism and social determinism, mutual shaping of gender and technology (or 'technofeminism') perceives 'technology as both a source and a consequence of gender relations" (Wajcman 2004: 107); this conceptually positions it somewhere between technological determinism and social determinism.

Several examples illustrating the co-construction of gender and technology have surfaced over the years; the following pages discuss two specific instances relating to i) the QWERTY keyboard ${ }^{26}$ and ii) the microwave. These examples pay particular attention to the mutual shaping of gender and technology as it pertains to the gendered division of labour. Examining the initial intent behind designing a technology, the method of production and deployment, and the nature of access and use among men and women, the

\footnotetext{
${ }^{25}$ Wajcman argues that early writings about gender and technology (in the 1980s) were far too fatalistic and dystopian in their perspective. She situates more recent contributions by scholars such as Donna Haraway (1985) and Sadie Plant (1996) in the utopian - or cyberfeminism - camp. Wajcman states "cyberfeminist discourse is particularly appealing to a new young generation, who have grown up with computers and pop culture in the 1990s, with their themes of 'grrrl power' and 'wired worlds'." (Wajcman 2004: 63)

${ }^{26}$ The QWERTY keyboard refers to the second from top left hand row on a standard English language keyboard, which spell Q-W-E-R-T-Y.
} 
following discussion interrogates the relationships between technological change and socially constructed meanings of femininity and masculinity.

Technology has historically been an arena that attaches considerable value to physical strength and masculinity. Cynthia Cockburn (1985) demonstrates how men have historically positioned themselves in key technological roles, including metal working in feudal eras and operating heavy machinery in industrial eras. She contends, "many machines have been developed precisely to substitute for human physical strength" (Cockburn: 1985: 56). As technologies often take the form of machines, many technological innovations can result in the exclusion, deskilling and/or devaluation of women's work. Although different technologies necessitate varying levels of physical strength, the strong connection between (perceived or actual) masculinity and technology adoption begs further examination in relation to socially ascribed perceptions, motivations and competencies associated with technology.

One seldom thinks about the gendered politics behind the present day layout of keys on a typewriter or computer keyboard. The QWERTY keyboard layout was designed in the 1860 s as a configuration that would minimize the entangling of metal bars when one typed quickly. Cynthia Cockburn $(1983,1985)$ captures the history of typesetting and its influence on culture and gender relations in Britain. At the time, men using Linotype machines had monopolized typesetting activities in the printing industry. In addition to being the highest paid craftsmen, these male labourers were responsible for both elements of typesetting: composition/casting (generally perceived as skilled labour) and distribution/keyboarding (generally perceived as unskilled labour). Operating a Linotype machine required lifting a 50 pound metal piece (a forme). The weight of the 
forme, which according to Cockburn (1983) was arbitrary and a question of custom rather than function, was heavy enough to exclude most women from typesetting.

In order to break the monopoly of male typesetting labourers in the printing industry, which had a strong workers union, employers decided to split the two activities (composition and distribution) onto different machines. The composition would remain on the Linotype machine and the distribution would take place on the newly designed QWERTY keyboard. The introduction of this keyboard marked a significant change from the existing Linotype key layout. For example, the QWERTY keyboard has fewer and smaller keys (44 versus 90 for the Linotype) that are situated closer to one another, different relative positioning of the keys, and precludes contact with heavy metals. Most typists at the time were female stenographers who were generally perceived as 'unskilled labourers'. By introducing a new technology, employers managed to de-skill the male Linotype workers and provide more opportunities for lower-paid female typists to enter the printing industry.

The QWERTY keyboard represents a technology that was introduced as a means to disrupt the existing male-dominated division of labour. However, as changes in technology enabled more women to enter the industry, shifting from a male-dominated to female-dominated, previously high wages began to fall - signaling the industry's gradual feminization (Cockburn 1985). The introduction of female labour in this example accompanied a downgrading of perceived skill content and a consequent fall in pay (Wajcman 1991: 37).

Susan Omrod's paper "Let's nuke the dinner: Discursive practice of gender in the creation of a new cooking process" (1994) discusses the technological, social and cultural 
history of the microwave. Originating under the auspices of 'masculine' engineering and designed for single male users, Omrod's account of the microwave reveals the fluid and responsive nature of technology to gender relations and vice versa. The microwave was later redesigned, advertised and retailed as a 'feminine' technology for the domestic activity of cooking. According to the author, the gendered intentional design and production of the microwave stemmed from prior use of microwave technology to heat food in US navy submarines. As such, microwaves were initially sold next to hi-fi equipment and televisions (generally referred to as 'brown goods' related to leisure and entertainment), only to be redesigned, repackaged and re-retailed in response to the strong appeal to housewives. The microwave's role in the domestic sphere triggered a redesign that would 'feminize' the technology and allow it to be sold next to washing machines and freezers (related to domestic appliances and generally referred to as "white goods').

Wacjman (1991: 22-23) discusses the role of power in controlling technological change and asserts, “... technologies bear the imprint of the people and social context in which they are developed". In Gender and Technology in the Making (1993), Cockburn and Ormrod combine their past experience and expertise in researching gender and technology. They discuss gender symbolism in relation to technology and uncover "ways in which gender gains expression in technology relations and technology acquires meaning in gender relations" (Cockburn \& Ormrod 1993: 7). In the aforementioned examples, one can see the tension between technological and social forces, and how the individual and reciprocal agency shapes the design, production, retailing and use of the microwave and QWERTY keyboard. 


\subsubsection{Gender and Technology: Material \& Symbolic Significance}

[A technological] innovation is not only materially produced but is also 'loaded' with all kinds of symbolic meanings by producers, designers, marketers etc., and users have to interact with these meanings when considering to buy ICTs or when using ICTs in their everyday life (Frissen \& Punie 2001: 25-26).

Technologies and gender relations manifest both materially and symbolically within a given societal context. Material elements relate to physical access and use, while symbolic elements pertain to perceptions and semiotics. One key aspect of a technology's symbolic influence of technologies is aptly summarized by Fischer (1999: 135), who states "[t]he real technology - behind all of our other technologies - is language. It actually creates the world our consciousness lives in." This section explores the material and symbolic aspects of gender and technology by revisiting the microwave and QWERTY keyboard examples discussed earlier, and examining gendered elements of computer culture and mobile telephony.

The microwave's shift from a 'brown good' (associated with masculine symbolism) to a 'white good' (associated with feminine symbolism) exemplifies the interrelated material and symbolic nature of gender and technology (Cockburn \& Ormrod 1993). Originally marketed as a technology to satisfy men's leisure and entertainment needs, the microwave is currently found "alongside washing machines, fridges and freezers as a humdrum domestic appliance" (Wajcman 2004: 37). Machines arrive in the household already imprinted with 'gender scripts' that define their intended operators (Wajcman 2004: 47). Domestic technologies such as washing machines, refrigerators and microwaves are seldom considered in the same category or complexity as 'masculine' technologies such as televisions, radios or computers (Cockburn 1985; Gray 1987). The 
femininity or masculinity of a certain technology is found to influence its relative value in society.

In the case of the QWERTY keyboard, feminine and masculine identity initially played a key role in the design phase, and was then reinforced symbolically by the associated gendered perceptions and meanings. The 50-pound forme used in the maledominated Linotype typesetting machine represents a material artifact that excludes most women. In this case, the material restrictions are associated with masculinity and physical strength, and thus used to construct a symbolically privileged position of men in the paid labour force. However, once the QWERTY keyboard enabled greater numbers of women to participate in typesetting, the industry became increasingly associated as a symbol of femininity, and eventually led to its feminization. Other examples of co-existing symbolic and material aspects of gender and technology include Sherry Turkle's (1984) examination of computer culture, and Geser (2004) and Plant's (2002) discussion of mobile telephones in society.

In "Computational Reticence: Why Women Fear the Intimate Machine" (1988), Sherry Turkle examines how women and men perceive computer culture and why female computer programmers generally opt not to engage with computers as much as their typical male counterparts. Her findings indicate that computers are socially constructed as a male domain and are traditionally associated with symbols and language related to competition, sports and violence (Turkle 1998). Turkle concludes that women's low level of engagement with computers is related closely with symbolic issues (computer reticence) and less so with material ones (computerphobia). ${ }^{27}$ She describes this reticent

\footnotetext{
27 Turkle's study included interviews with 25 female students successfully completing computer programming courses at Harvard and MIT. Turkle defines computerphobia as "needing to stay away
} 
position of women vis-à-vis computers as a rejection of computers as intimate machines. Moreover, many of the interviewed women perceived computers as a masculine symbol and chose to distance themselves from this image.$^{28}$ In contrast to Turkle's findings about the masculine symbolism often attached to computers, several studies have indicated the mobile phone's ability to transcend differences in age, gender, cultural background, income or hierarchical position (Puro 2002: 20-21) and more specifically provide means to personalize according to particular gender identities (Skog 2002: 255). ${ }^{29}$

In "Towards a Sociological Theory of the Mobile Phone" (2004), Hans Geser provides a prolific literature review spanning developed and developing countries. Geser discusses a breadth of issues including mobile phones as status symbols, guardians of private spaces, catalysts for new vocabulary, and domains of personal and social control. The popularity of mobile phones has shown to spill over into relatively "technophobic contexts" such as Italy, where several modern technologies such as computers were not widely adopted at the early stages of their introduction (Fortunati 2002: 53), Scandinavian countries where people are traditionally perceived as introverted (Puro 2002), and illiterate mass populations in the Third World, where individuals rarely have the means to access a computer or fixed telephones (Townsend 2000). Studies in Europe

because of fear and panic; lack of ability" and computer reticence as "deciding / wanting to stay away because the computer becomes a personal and cultural symbol of what a woman is not; reticence to become more deeply involved with an object experienced as threatening" (Turkle 1988: 46).

${ }^{28}$ The origins of the Internet can be traced to the U.S. Department of Defense, which developed Advanced Research Projects Agency Network (ARPANET) - the world's first operational network that used packet switching technology, and was the predecessor to the Internet. The first ARPANET link was made in January 1969 between four nodes, located at University of California, Los Angeles (UCLA), Stanford Research Institute, the University of California, Santa Barbara, and the University of Utah. The militaristic roots of the Internet are often pointed to when discussing the common masculine perceptions of the Internet and computer programming.

${ }^{29}$ Skog contrasts the degree of personalization afforded by mobile phones in relation to other ICTs such as computers and televisions. Mobile phones allow users to personalize colours, outer casing, ring tones, display images etc. 
indicate the early users of mobile phones were among the elite, educated middle- and upper-class males, who typically used them for instrumental (especially professional) purposes (Roos 1993; Lasen 2001a). ${ }^{30}$ The unanticipated shift in user base has been accompanied by corresponding changes in symbolic associations.

Status symbols related to mobile telephones are found to extend beyond symbols of education or wealth, to include broader social integration and inclusion (Bautsch et. al. 2001; Geser 2004; Gergen 2002). Amparo Lasen (2002: 27) refers to mobile phones as "symbolic bodyguards" to describe the manner in which individuals protect their private space. In "On the mobile: the effects of mobile telephones on social and individual life", Sadie Plant (2002) provides a rich account of the gendered nature of mobile phone users in Tokyo, Beijing, Hong Kong, Bangkok, Peshawar, Dubai, London, Birmingham and Chicago. In this work, the third chapter titled "Men, Women, and Mobile Displays" specifically examines gender differences in mobile telephone access and use. Plant's research indicates cultural differences in the perception of mobiles, their display in public spaces, and their use among men and women. For example, female business women in Chicago claimed their male peers are generally more inclined to show off their mobiles as a symbol of status and virility (2002: 40); men in London confessed to displaying their mobiles when they are considered state-of-the art, but cease to do so when their specific model fell behind the 'cutting edge' (ibid. 43); teenage girls in Hong Kong were found to "have their mobiles festooned with stickers, trinkets, straps and toys" (ibid. 46); and young men in Peshawar were observed to fabricate mobile calls in public on fake mobile handsets (ibid. 49). These examples are among many that unpack the symbolic nature of

\footnotetext{
${ }^{30}$ J.P. Roos carried out his study in Finland. Amparo Lasen studied mobile telephones in the U.K. and found a shift in users from business professionals to 'gossiping' among rural women and adolescents exchanging text and audio messages with one another (Lasen 2002: 24).
} 
mobile phones among men and women occupying a variety of different classes, cultures, ethnicities, and generations.

Symbolic elements relating to mobile telephony in different societies can be examined via the vocabulary and language that are used in its daily operations. According to Geser (2004: 13), there are considerable cleavages between age groups, whereby adults concentrate relatively more on voice calls and young people generally leverage text messages, which are characterized by specific linguistic codes and conduct. In addition to the use of different vocabulary, the asynchronous mode of communication that is enabled via text message exchanges provides an opportunity to strategically postpone responding to more appropriate time (Ling \& Yttri 2002: 265), and/or enable candid and informal exchanges that are often difficult to achieve in face-to-face or verbal exchanges (Plant 2002: 56). Plant (2002: 82) discusses "textperantos", which she defines as localized, hybrid languages used for text messages. Although English is the accepted lingua franca by many, the use of shorthands based on English (such as "cul8r" and "IDK") 31 are being joined by shorthand originating from other languages. These include Mandarin shorthands using numbers to convey messages - such as 521 meaning 'I love you' and 531 meaning 'I miss you' (ibid: 82).

Wajcman (2004) and Cockburn (1985) discuss the coterminous relationship between the culture of masculinity and the culture of technology. Wajcman (2004: 15) posits "to enter [the technology] world, to learn its language, women have first to forsake their femininity", and Cockburn (1985: 12) states "femininity is incompatible with technological competence; to feel technically competent is to feel manly". However, masculine and feminine behaviours and attitudes are not universal across cultures or

\footnotetext{
31 'cul8r' is shorthand for the phrase "see you later", while 'IDK' is shorthand for "I don't know".
} 
technologies. The examples discussed in this section (QWERTY keyboard, microwave, computers and mobile phones) span a wide array of feminine and masculine symbols, which respond to material conditions and different societal contexts.

\subsubsection{ICTs as part of Social and Technological Continua}

The focus of this literature review thus far has been placed on some technologies that fall outside the direct scope of this study. The remainder of the review focuses on ICTs - first examining how different ICTs relate to each other in a historical, economic and social sense, and then in relation to gender in the Third World and in Bhutan. Heeks (2002: 3) contends "current ICTs are seen merely as a present stage in digital evolution that has been going on for more than 50 years ... [and] promotes the idea that we can learn from the long-standing literature on IT and development, rather than ignoring it". Heeks (2002: 9) also discusses the "design-reality" gap of ICT solutions, which he defines as "the gap between a system's design conceptions and the realities into which it is introduced". These gaps can arise from explicit discrepancies in technological infrastructure or implicit via Northern assumptions inscribed into ICTs, which are often at odds with Southern cultural realities (ibid.).

The term 'leapfrogging' appears frequently when examining the literature on ICTs. Defined as "bypassing stages in capability building or investment through which countries were previously required to pass during the process of economic development" (Steinmueller 2001: 194), many argue that leapfrogging implies skipping over 'critical junctures' such as literacy, infrastructure, institutions, and social structures - often taken for granted in many Western contexts (Raiti 2007; Heeks 2002; Warschauer 2003). In a thoughtful paper, Merridy Wilson (2003) makes the overarching argument that 
leapfrogging is imbued with assumptions of a linear development path, and insinuates a deficit model and relatively fixed, defined stages of development. Wilson (2003: 6) points to a situation whereby this understanding is widely criticized in general development discourse, yet continues to be actively pursued in the ICT for development discourse. The article considers empirical examples of leapfrogging in Africa, such as the proliferation of mobile telephones and satellite technology. Instead of interpreting these findings as leapfrogging over stages in a linear process, Wilson (2003) presents the possibility of multiple adoption paths for ICTs.

Since the 1980 "Many Voices, One World" multi-stakeholder report (a.k.a. the MacBride Report) highlighted imbalances in telecommunication and media between developed and developing countries, there has been a mounting recognition of this disparity - since referred to by many as an example of the 'digital divide'. The origins of the term 'digital divide' can be traced back to the U.S. in the mid-1990s. In response to the growing popularity of the Internet and its varying penetration rate among the U.S. citizenry, the National Telecommunications and Information Administration (NTIA) released a report in 1995 titled "Falling Through the Net: a Survey of the 'Have Nots' in Rural and Urban America". ${ }^{32}$ Although the report did not explicitly use the term "digital divide', it provided much of the foundation for how the term is generally interpreted and commonly used today. Building on the NTIA report findings, Allen Hammond and Larry Irving officially coined the term 'digital divide' in 1996 to convey the binary divide between those in the U.S. that have computers and Internet access and those that do not. Today, the digital divide is used to describe discrepancies in access and the ability to use ICTs within and among different parts of the world and among different societal groups.

\footnotetext{
${ }^{32}$ The report can be accessed here: http://www.ntia.doc.gov/ntiahome/fallingthru.html
} 
However, the origin of the term is situated within a continuum of ICTs in the US context, where many individuals had prior knowledge of and/or exposure to computers and the Internet at the time of the NTIA study.

Although the concept of a digital divide is effective in its simplicity, some find the notion to be simplistic and overly focused on technology (Heeks 2002; Cisler 2000; Warschauer 2003). Failure to recognize the existing technological and social circumstances governing the lives of individuals can lead to a parochial understanding of the mutual shaping of ICTs and social relations. In his book Technology and Social Inclusion: Rethinking the Digital Divide (2003), Mark Warschauer argues that the construction of the digital divide implies that technological and social contexts are separate from one another. Stressing co-dependence of technological and social systems in defining technology's influence in society, Warschauer (2003: 8) challenges the notion that ICT is an external variable that is injected from the outside to engender certain results, and argues it is "woven in a complex manner into social systems and processes".

Knud Sørensen (2002) presents findings about gender and ICTs from a compilation of reports written about five European countries. ${ }^{33}$ The study finds that the existing literature included marginal reflection on cultural variations and tends to provide a relatively universal depiction of gender and ICTs across industrialized countries. Sørensen (2002: 15) maintains ICTs should not be made into "some kind of fetish" because knowing and using ICT "do not necessarily contribute to the reduction of social inequalities in general". Situating computers and the Internet on a continuum, the paper cites " $[\mathrm{t}]$ he heart of the problem lies in broader patterns of social stratification that shape

\footnotetext{
${ }^{33}$ The study titled "Love, Duty and the S-Curve: An overview of some current literature of gender and ICT" examines the issue in Ireland, Italy, the Netherlands, Norway and the U.K.
} 
not just access to the virtual world, but also full participation in other common forms of information and communication technologies" (Norris 2001: 91-92 cited in Sørensen 2002: 16).

Related to the notion of technological and social continua is the limitation of examining only the extremes of binary constructions such as users versus non-users, and information haves versus information have-nots. These are arguably simplistic and misrepresentative of different situations; Warschauer (2003: 7) finds "the notion of a binary divide between haves and have-nots [as] ... inaccurate and can even be patronizing because it fails to value the social resources that diverse groups bring to the table." Steve Cisler's paper "Subtract the Digital Divide" (2000) discusses the valueladen binary constructions of user and non-user, which implies being a 'user' is categorically more desirable than being a 'non-user'.

When $21^{\text {st }}$-century digital evangelists express their fervor by casting the world as online (good) and offline (doomed), it reminds me of the $19^{\text {th }}$-century European and American missionaries who looked at all the unconverted lost souls in Africa, Asia, the Pacific and South America. Their efforts were well-meaning but had many unintended consequences.

Although a binary or dualism represents the two extremes of a continuum, much of the literature about the digital divide (including the gender digital divide) fails to discuss the nuanced positions between the extremes. Cisler suggests a "spectrum of connectivity" to more accurately capture different shades of use and non-use that exist in a given community context. Similarly, Warschauer (2003) puts forth the notion of a scale of users and non-users to respond to differences within the two extreme positions of use and nonuse. 


\subsection{Gender and ICTs in the Third World}

Failure to consider gender issues in the early stages of technology diffusion may unwittingly generate negative effects on women. Even seemingly gender-neutral decisions about infrastructure can impact women's opportunities to use new technologies. (Hafkin \& Taggart 2001:4)

Many argue that the Western ethnocentric manner in which empowerment through ICTs is interpreted fails to consider the historical and social contexts within which ICTs are accessed and used (Parpart, Rai \& Staudt, 2002; Huyer and Siskoka 2003). The effect of ICTs on different individuals and groups are influenced by myriad different value systems, including those related to gender. Huyer and Siskoka (2003: 11) describe the embedded nature of different technologies within the lives of women in the Third World, stating " a technology project should be seen as a component of the social context in which it is placed, and not the other way around". The social context of which they write relates to both the motivations and realities that govern the lives and livelihoods of Third World women and men. According to Nancy Hafkin and Nancy Taggart (2001: 9), women in developing countries find themselves in the deepest part of the digital divide, further removed from the Information Society than men whose poverty they share.

In their authoritative contribution Gender, Information Technology and Developing Countries: An Analytic Study (2001), Hafkin and Taggart claim gendered factors such as income, time constraints, language, education and cultural contexts affect women's access to facilities, training and employment using ICTs. In a similar vein, Huyer and Mitter (2003) indicate women's lower ICT access rates are a result of several economic, as well as a range of socio-cultural factors such as literacy and language skills, 
training and domestic responsibilities. Anita Gurumurthy (2003: 12) claims women's limited access to ICTs in the South Asian region is a result of "barriers of illiteracy, preoccupation with survival and constraints of time, inegalitarian and oppressive sociocultural norms and practices, high costs and predominantly urban character of facilities, and bandwidth limitations". Women's time is a critical resource in short supply; therefore any ICT aimed at improving their lives and increasing empowerment must be perceived by women to save time or increase their efficiency rather than add to their list of responsibilities in a given day (Huyer 1997). In addition to limited leisure time away from reproductive and productive tasks, women often do not have the necessary mobility to visit public access Internet or telephone kiosks. This may be due to cultural restrictions, safety precautions or a range of other socio-economic factors (Hafkin \& Taggart 2001: 29).

Before the advent of mobile telephony services in the Third World, the majority of the literature examining the digital divide (including the gender digital divide) in the developing world was limited to computer and Internet use. As such, the prerequisite criteria for bridging the digital divide included a necessary level of formal education and literacy in languages available on the Internet. According to Hafkin \& Taggart (2001: 27), basic literacy and numeracy is required to read and compose simple messages, navigate the Internet, and execute commands in most software applications. In many Third World societies, the ability to read and write in English is not a readily available skill for many, including a significant number of girls and women (Hafkin \& Taggart 2001: 27). The dominance of English and, to a lesser extent, other major international languages on the Internet, excludes access to the majority of the world's population who 
utilize (speak, read and/or write) other languages - a syndrome that is especially pronounced in Asia (Hussain et al. 2005). Hafkin and Taggart (2001: 28) find that even users with basic proficiency in English experience relative discomfort, which discourages use when web pages are not available in their native language. ${ }^{34}$

In "Blinded by Text: Revaluing the Oral Imperative in Communication", Collette Snowden (2000) argues that initiatives to 'bridge the digital divide' have been blinded by the primacy of text-based tools, as greater value is generally associated with text in the intellectual and economic domains. She contends that text-based ICTs are often difficult to access and use in developing countries due to limited literacy, disabilities, or preferences for non-text based technologies; and thus proposes placing greater emphasis on oral/aural technology as a means to providing access to ICTs in both developed and developing countries (Snowden 2000: 2-3).

Cisler (2000) and Warschauer (2003) insist that framing the digital divide in the Third World around computer accessibility and Internet connectivity is simplistic and insulting. Similarly, Hans Geser (2004: 4) argues an overemphasis on text-intensive ICTs such as computers and Internet technologies ignores the fact that voice-intensive ICTs such as mobile phones are used by broader strata of the population around the world, have a stronger impacts on their lives, and that most are ready to spend greater sums of money on monthly phone bills than on Internet or computer use. A recent groundswell in mobile telephony access and use in developing countries has broadened the scope of the digital divide to include ICTs that are voice-intensive, in addition to those that are text-

\footnotetext{
${ }^{34}$ According to the study by Hafkin and Taggart, in a research study on an Internet training program conducted in Mexico, users with a low level of proficiency in English were reluctant to access the program's online help center because it was in English (2001: 28).
} 
intensive (Castells et al. 2006; Waverman et al. 2005). ${ }^{35}$ In early 2002, access to mobile phones in Asia surpassed fixed line phones (ITU 2004) ${ }^{36}$. Mobile phones have ushered in two distinct changes - the first relates to examining text-intensive versus voice-intensive ICTs, ${ }^{37}$ and the second relates to examining wireless solutions. These shifts carry implications beyond mobile phones to include researching other voice-intensive ICTs (such as fixed telephones and radio) and other wireless technologies (such as personal digital assistants). However, since the scope of this study is restricted to the Internet, fixed telephony and mobile telephony, the remainder of this chapter is limited to exploring these three specific ICTs in the context of gender relations in Bhutan.

\subsubsection{Gender and ICTs in Bhutan}

In a country where monastic education was the sole mode of formal education until 1965, social science and the idea of foreigners carrying out research in Bhutan was met with caution and mistrust up until the 1980s (Pommaret 2004). Since then, Bhutanese scholars and a handful of foreign academics have produced a steadily growing body of social science research. ${ }^{38}$ Bhutan is relatively young in the field of ICTs, which renders a

\footnotetext{
${ }^{35}$ The Grameen Bank model of Bangladesh is perhaps the most widely discussed and documented case study linking women's empowerment and mobile telephony (Yunus 1998; Bayes et al., 1999). Designed by Muhummad Yunus and others at the Grameen Bank, the model involves a microentrepreneur approximately $97 \%$ of all recipients are women (according to Yunus's Nobel Lecture given on December 10, 2006 in Oslo ) - who borrow money to acquire a mobile phone. These "phone ladies" then purchase pre-paid minutes in bulk and subsequently resell the minutes to clients in their respective villages (According to calculations from Grameen Bank, each phone can make a profit of US \$2 a day, which is significantly higher than the country's average per capita income of US $\$ 0.60$ a day (Dholakia \& Kshetri 2002)). Muhammad Yunus and the Grameen Bank of Bangladesh were jointly awarded the Nobel Peace Prize in 2006, which recognized the scalable, sustainable and transformative impact of the initiative. The model has since been replicated in Uganda, Rwanda, and other parts of the Third World.

${ }^{36}$ Mobile telephone uptake in the Philippines has been especially significant. According to the International Telecommunications Union (ITU), there were less than half a million mobile subscribers in the Philippines in 1996, which grew sharply to six million in 2000, and again to nearly 33 million in 2004.

${ }^{37}$ Recognizing that mobile phones can also be used for text transmissions, much of the use in developing countries (especially among the illiterate) is limited to voice transmissions.

${ }^{38}$ Foreign researchers can rarely conduct research in Bhutan without official permission from a recognized Bhutanese or international body. Many are affiliated with the Centre for Bhutan Studies (an arm's-length
} 
study on gender in ICTs as a new and challenging endeavour (Wangmo 2004: 18). This final section of the literature review, examines the limited body of literature on the overlap between gender relations and ICTs. Separate investigations into ICTs and into gender relations in Bhutan can be found in Chapter Four of this thesis.

The first national ICT policy and strategy paper titled the "Bhutan Information and Communications Policy and Strategies" (BIPS) was released in July $2004 .^{39}$ The document (RGoB 2004) was designed to contain the "whole-of-government response to the need for shared national ICT policies and strategies" (Wangmo 2004: 27). Examining ICTs in Bhutan in relation to five areas: policy, infrastructure, human capacity, content and applications, and enterprise, BIPS explores several challenges including those related to ICT infrastructure roll-out (geographic challenges), limited qualified personnel trained in ICT-related areas (education challenges), and the country's small size and considerable discrepancies between rural and urban ICT penetration (natural geographic challenges). ${ }^{40}$ However, despite the broad scope and intent of BIPS, discussions about gender, gender relations and gender disparities are entirely absent.

A report commission by the ITU titled "Trend and Status of Gender Perspectives in ICT Sector" includes a case study on Bhutan (Wangmo 2004). This work is the most complete and recent document examining the issue of gender relations and ICTs in Bhutan. The overall objective of the definitive case study is to investigate the state and trends related to gender and ICTs in Bhutan with regards to employment, programs, and

think tank inaugurated in 1999) or the Royal University of Bhutan, which includes the Institute for Language and Cultural Studies (ILCS), and Sherubtse College.

${ }^{39}$ More information about BIPS can be found here: http://www.moic.gov.bt/bips.php

${ }^{40}$ The report states: "Teledensity is currently estimated at $4.3 \%$ nationally, with a large disparity between urban (15\%) and rural areas (1\%). Urban teledensity has been boosted by the enthusiastic take-up of cellular mobile phones since the network was launched in some urban areas in November 2003." (RGoB 2004: 13) 
policies. The findings indicate limited awareness of the government's commitments to gender equality; and despite relatively equal legal opportunities and entitlements, gender inequalities are apparent in areas of education, employment, and governance (ibid: 27). The study draws a link between a drop in female students enrolled in higher education and their limited visibility in higher positions of the civil service. ${ }^{41}$ It presents two case studies (both located in urban parts of Thimphu) - the first is of Yeshey Tshogay, an employee at Bhutan's mobile telephone service provider B-Mobile, and the second is of Tshering Wangmo, a housewife and mother. ${ }^{42}$

Tshogay is an engineer by training and currently a manager at B-mobile, where her colleagues include 5 other women and 40 men (Wangmo 2004: 56). She cites the reasons for gender discrepancies in the workplace to include the following: "education, traditional roles of women in the society and preference of other professions like medicines [sic.] or academics" (ibid.). Tshering Wangmo is married to a civil servant and has two children (10 and 12 years old). Married at 18 years of age, she dropped out of school after completing class ten and has been a housewife and mother ever since. In discussing different factors affecting the career paths of women, Wangmo points to marriage and family as a key factor. Many female respondents in the study indicated household responsibilities and childcare as a predominantly female domain, regardless of their income, education or employment status - "this places a great burden on women and restricts women's choices in terms of better job opportunities" (Wangmo 2004: 61). Although this study provides a sound overview of gender relations and ICTs in Bhutan, I

\footnotetext{
${ }^{41}$ The proportion of female to male students enrolled in the formal education sector in 2003 represented a gradual decline from $48 \%$ in primary school, $46 \%$ in middle secondary school, to $30 \%$ at the tertiary level (Wangmo 2004: 43).

${ }^{42}$ It should be noted that both subjects are Drukpas.
} 
found its investigation of ICTs as embedded artifacts in existing Bhutanese social and gendered fabrics to be lacking. The use of case studies added a marginal degree of context, however they failed to uncover the underlying perceptions and motivations behind different levels of ICT access and use, thus resulting in a relatively impoverished look at the issue.

\subsection{Conclusion}

There is a relative dearth of research examining gender relations and ICTs in Bhutan. This, combined with the country's recent introduction to several ICTs (some of which are designed and produced in the First World) ${ }^{43}$, signals the need to develop a conceptual framework that can adequately capture and convey the diverse range of gendered experiences with the Internet, fixed telephones and mobile telephones in Thimphu and Tangmachu. Certain issues have been flagged throughout the literature review as areas requiring special attention in the conceptual framework design. These include acknowledging the reciprocal relationship between gender and ICTs (both materially and symbolically); responding to demands for different types of ICTs that are situated along the social and technological continua (depending on their text/voiceintensity, requisite mobility, necessary income etc.); examining a spectrum of use that considers positions between the two extremes of 'user' and 'non-user'; and refraining from attaching value propositions to the different positions on this spectrum. The conceptual framework will build from existing works on gender and technology in the First and Third World, and also draw on relevant feminist theories to plug conceptual

\footnotetext{
${ }^{43}$ Although the majority of new ICT innovations originate in the First World, there are a handful that are developed in the Third World such as the Simputer (http://www.simputer.org/), which was designed and produced by organizations based in Bangalore, India.
} 
cavities or inconsistencies. In doing so, the study will approach the research topic in a historically, socially and culturally informed manner. 


\section{CHAPTER 3: RESEARCH METHODOLOGY}

Unfolding in a conceptually chronological fashion, this chapter captures my intellectual and physical journey throughout the research process. Based on the context, literature review and conceptual framework outlined thus far, the following pages describe the research methodology, instruments and processes that were implemented before, during and after my primary fieldwork in Bhutan. The first section examines several delimiting factors of my field visit and explores a range of suitable social science research methods. The second section describes how the actual research process unfolded, and the final section reflects on the different lessons, opportunities and challenges that arose over the course of the study.

\subsection{Defining the Boundaries and Scope}

Considering the range of conditions, obligations and limitations of the proposed field visit facilitated the process of narrowing options for appropriate research methodologies. In addition to limited time and resources, other factors such as developing linkages with key institutions and individuals in Bhutan, obtaining an extended visa, and acclimatizing to linguistic and cultural barriers were among the issues that were taken into account when designing the overall methodology and specific research instruments.

Over the course of my graduate studies, I was concurrently a part-time student at Carleton University and a full-time employee at the International Development Research Centre (IDRC) based in Ottawa, Canada. As a Research Officer at IDRC's Pan Asia Networking (PAN) program ${ }^{44}$ I was exposed to a range of research findings and contacts pertaining to ICTs in Bhutan, and found myself drawn to the convergence of ICTs,

\footnotetext{
${ }^{44}$ Pan Asia Networking (PAN) is IDRC's regional ICT4D program working in Asia.
} 
carefully preserved traditions and relatively progressive legal gender norms. A colleague at IDRC brokered my relationship with individuals at the Department of Information Technology (DIT) in Bhutan. Located in the capital city of Thimphu, DIT agreed to sponsor my visa and acted as my host institution during my stay. As a reciprocal gesture of gratitude, I volunteered some time to assist DIT staff with specific activities. Given my affiliation with IDRC (a donor institution), ${ }^{45} \mathrm{I}$ was acutely aware of quelling any questions pertaining to conflict of interest and/or unethical conduct. As such, I attempted to clarify the purpose of my field visit - clearly distinguishing my role as an independent researcher (representing Carleton University) from that of an employee from a donor institution.

I was granted an eight and a half week study leave from IDRC - from October 5 to December 6, 2006. The resulting timeframe became a key delimiting factor in my research design and data collection methods. Although obtaining a visa extension was theoretically feasible, the combination of thick bureaucratic processes in Bhutan and my responsibilities at IDRC contributed toward a relatively inflexible window. Consequently, I familiarized myself with different social science research methods and their applicability to this study prior to arriving in Bhutan. Although I tried to prepare in many ways, my intention was to approach the research process in an inductive manner, whereby the findings would materialize over the course of various iterative and responsive exercises. I landed in Bhutan with a range of research instruments approved

\footnotetext{
${ }^{45}$ PAN has been active in Bhutan for nearly a decade. It co-funded the country's first Internet Service Provider (Druknet) in 1999, and subsequently supported projects in distance education, wireless technology solutions, and font localization. In PAN's 2006-2011 programming prospectus, Bhutan is identified as one of five "focus countries" where PAN will develop coherent countrywide ICT4D programming activities.
} 
by the Ethics Board at Carleton University. These were meant to act as a solid foundation for further refinement as required.

\subsubsection{Searching for a Suitable Methodology}

Based on the proposed conceptual framework, I sought a methodology that could capture myriad experiences in Thimphu and Tangmachu, and draw out both material and symbolic interpretations of gender and ICTs in the daily lives of different women and men. The diversity of languages, cultures, norms and institutions extant among individuals at Thimphu and Tangmachu necessitated a methodology that could respond to specific aspects of livelihood opportunities and struggles. Gupta \& Ferguson (1997: 2) challenge the perception that the 'field' is a space "where an 'other' culture or society lies waiting to be observed or written"; similarly, I recognized the critical need to examine different social actors in the research process (including myself), as they relate to one another and to the overarching research environment. Thus, a certain degree of malleability and responsiveness was built in to the general methodology as well as the specific research instruments.

Long and Long (1992) provide a compilation of works arguing for an actororiented approach to social research in development. An actor-oriented approach is grounded in the everyday life experiences and perceptions of women and men, regardless of their actual or perceived position in the community. According to Norman Long (1992: 6), "the research encounter is one in which actors with varying positionalities interact and create spaces for negotiation, accommodation, exchange, and transformation". Thus, it is through the 'elucidation of actors' (Long \& Long 1992: 5) in these situations that knowledge and truths gain context and grounding. As the research 
topic on gender and ICTs in Bhutan represents an area that is both geographically and topically under-researched, I felt the adoption of an actor-oriented method could help respond to participant needs as well as my own learning curve. Moreover, an actororiented approach seemed germane to this research study, as it privileges the experiences of the research participants in Thimphu and Tangmachu, while remaining cognizant of the multiple identities, struggles and negotiations that define their actions as well as my own.

Thimphu and Tangmachu are home to a diverse range of people, cultures, languages and livelihoods. As such, I expected to encounter a corresponding range of information and communication needs, as well as ICT exposure, access and use. Recognizing the delimiting factors of my field study, I felt the need to transcend ephemeral realities and avoid universal claims about gender relations and ICTs. Instead, I set out to collect data that would allow for some degree of cross-comparison, yet emphasize individual qualitative analysis. Such an approach led me to Third World feminism and its critique of 'othering' in the research process. In Chandra Mohanty's (1991) extensive analysis of Western feminist texts she charges many researchers with preconceived notions about a singular 'third world woman' prior to engaging in the research process. Mohanty (1991: 72) argues:

... Western feminist discourse, by assuming women as a coherent, already constituted group which is placed in kinship, legal, and other structures, defines third world women as subjects outside social relations, instead of looking at the way women are constituted through these structures (emphasis in original).

Mohanty's argument indicates the historically, culturally and structurally embedded nature of gender relations in struggles over resources - be they land, water, income or 
ICTs. Similarly, Lila Abu-Lughod (1993: 8) states, if “people's everyday lives are stripped of their rich detail, diversity, and complexity" the resulting research findings can produce a "homogenized, coherent, self-contained, and different 'other"'. Drawing on literature examining actor-oriented and Third World feminist research methodologies, I adopted a responsive, actor-oriented and predominantly qualitative research methodology to address the thesis topic and modified conceptual framework.

Third World feminists generally criticize First World feminists on account of their biased perception of Third World women. However the source of this criticism is not based on the geographic positioning of different scholars, but rather on the epistemological assumptions that drive their respective feminist inquiry. According to Mohanty (2003: 502), First World and Third World feminists "are not embodied, geographically or spatially defined categories. Rather, they refer to political and analytic sites and methodologies used". In a similar vein, Sandra Harding rejects the notion of limiting social science research to 'like study like', which implies that "whites cannot create anti-racist knowledge, men cannot create anti-sexist knowledge etc. - in short no one can learn anything from anyone else's, experience" (emphasis in original) (Harding 1992: 78). My geographic affiliation with the First World - as someone born and raised in Canada - played a role in the research process. However it was mediated by continual reflection and emphases on the aforementioned methodological approaches and practices.

\subsection{Actual Research Process}

I arrived in Bhutan on October 5, 2006. I had originally intended to conduct a case study on a single urban community with a suitable range of interactive ICTs. For several reasons I was inclined to study a community located near the DIT office in 
Thimphu, which is also the most populous city and the capital of Bhutan. Home to all government headquarters, Thimphu also boasts a critical mass of Internet, fixed telephone and mobile telephone users. ${ }^{46}$ Upon considering these statistics, logistics, and other intelligence gathered from DIT staff, I tentatively decided to collect primary data from the urban neighbourhood of Babesa (located a 15-minute drive from the DIT office). Under this presumption, I had planned to compare these primary data with secondary sources on gender and ICTs in other urban and rural communities (see Wangmo 2004; RGoB et al. 2001). However, shortly after arriving in Thimphu, my research design changed to incorporate a site visit to the rural community of Tangmachu, located in Lhuntse district in eastern Bhutan.

Including Tangmachu in the research design allowed for gathering primary data from a rural community (with access to fixed telephones and Internet-enabled computers) for comparative purposes. Equipped with a wireless antenna that provides Internet and fixed telephone services (fixed telephones operating on a wireless loop), the Tangmachu community information centre (CIC) was opened in May 2006 and was officially launched in September 2006. ${ }^{47}$ The trip from Thimphu to Tangmachu takes approximately two days by car in a single direction. In a broader sense, visiting Tangmachu would provide an occasion to conduct a first-hand study of the differences in geography, demography and livelihoods that exist between eastern Bhutan (Tangmachu) and western Bhutan (Thimphu). Upon considering the repercussions of adding

\footnotetext{
${ }^{46}$ The 2005 national census indicates $90 \%$ of Internet subscribers are in urban areas (of which $68 \%$ reside in Thimphu); $71 \%$ of landline telephone subscribers are in urban areas (of which 53\% reside in Thimphu); and $79 \%$ of cellular telephone subscribers are in urban areas (of which $66 \%$ reside in Thimphu).

${ }^{47}$ A Community Information Centre (CIC) can be defined as a public place where people can use ICTs to access, create or share information and knowledge. CICs are also commonly referred to as telecentres, information kiosks, virtual knowledge centres, virtual information centres, community technology centers, community multimedia centers, or a variety of other names. During the CIC launch, the Minister of Information and Communications inaugurated the centre.
} 
Tangmachu as an additional data collection site, I decided it would be beneficial to adapt my research design and instruments. Despite the work this entailed, much of the formal and informal intelligence I had gathered about conducting field research prior to my arrival led me to (paradoxically) anticipate these unanticipated changes.

\subsubsection{Site Selection}

The two sites selected for this study generally juxtapose nicely against one another. Thimphu, the capital city located in western Bhutan, is a relatively densely populated urban centre, which boasts a high concentration of tourism, government offices, private enterprises and individuals belonging to the English-speaking educated elite. In contrast, Tangmachu ${ }^{48}$ is a sparsely populated, mountainside community in eastern Bhutan. The majority of households do not have running water (although there is electricity in many households due to a power substation located at the base of the mountain) and are primarily involved in subsistence farming activities. Moreover, most residents have little or no command of English or Dzongkha; they speak Kurtoep or Chocangacakha (neither of which have a written script associated with them).

The timing and length of my trip to Tangmachu was contingent on several factors, such as avoiding the harvesting season (early September to late October), coinciding the trip with a baseline study to be administered by DIT staff, ${ }^{49}$ and having adequate time to finalize the slightly modified semi-structured interview questions. For these and other reasons, I travelled to Tangmachu in late October. Recognizing that my time would be

\footnotetext{
${ }^{48}$ It should be noted that although 'Tangmachu' is the name most people use to refer to the area near the community information centre (CIC), it is in fact one of many scattered villages that comprise Membi gewog (block). A district (dzongkhag) is comprised of multiple gewogs.

${ }_{49}$ Among the activities I assisted DIT with during my stay was developing a baseline survey for the CIC project in Tangmachu. My trip to Tangmachu was timed in a way to coincide with the administering of these surveys.
} 
relatively limited (eight days) in Tangmachu, I secured an interpreter prior to arriving. During my visit, I stayed in a small room inside the CIC (there are no hotels or guest houses in Tangmachu).

The CIC is located on a slight incline above the gup's (equivalent to a mayor) office. It utilizes a wireless signal emitted from an antenna located on the roof of the gup's office to provide Internet access using Wireless Fidelity (WiFi) technology. In addition to providing Internet connectivity to the four computers inside the CIC, the wireless signal is also received by 78 households, which fall within "line of sight" are equipped with WiFi-enabled fixed telephones. These telephones reach approximately 400 users who live in or around the 78 households. All calls dialed and received among these telephones within the 78-member wireless loop bears no charge to either party; however calls made outside this loop are charged according to Bhutan Telecom rates (payable directly to the CIC). Prior to the establishment of this wireless antenna and wireless telephone loop, people in Tangmachu were forced to walk for numerous hours or days (in a single direction) to access a telephone in Lhuntse town, which is located over an hour's drive away.

In Thimphu, fixed telephone lines were introduced in the 1960s, followed by Internet services in 1999 and mobile telephone services in 2003. Despite the availability of these ICTs, the parity in access and usage patterns differ considerably across diverse individuals and groups. User profiles depend on, among other indicators, age, sex, education, income, and mobility. Consequently, although the Internet and mobile telephones are officially the only ICTs introduced in Thimphu within the past decade,

\footnotetext{
50 'Line of sight' can be defined as an unobstructed view from transmitter to receiver.
} 
fixed telephones (as a complement or substitute for mobile telephones) were also included within the study's ambit.

\subsubsection{Situating Myself in the Research Process}

As the chief interpreter of experiences and data, my role as the primary researcher was important to reflect on periodically over the course of the study. As many researchers "seem to stand apart from and outside of what they are describing" (Abu-Loghud 1993: 8), I was conscious of how my involvement in various aspects of this study could be perceived by different actors in the process. As a 27-year old middle class Canadian woman of West Bengali descent (the Indian state of West Bengal borders Bhutan to the south) I experienced coexisting feelings of being an 'insider' and an 'outsider'. Although I speak fluent Bangla (the principal language in West Bengal and spoken by a handful of Bhutanese and some Indian expatriates), my command of spoken Hindi, which is far more pervasive in India and Bhutan, is limited. As a result, I had the outward appearance of an Indian, yet spoke and dressed like a Westerner.

Bhutan's relatively small population and tightly knit social networks left little room for ambiguity with regards to a visit from a foreigner who is not a tourist. Most people living for a relatively extended period of time in Bhutan (locals and expatriates alike) make it their business to know about all non-tourist foreigners in their community. My situation in the research process as an independent researcher from Carleton University and as an IDRC employee added an extra layer of complexity. Despite repeated and concerted efforts to disambiguate these roles and avoid confusion about the purpose of my visit, there were several instances when the lines between them blurred. 
Eventually, people began to identify me as "the IDRC employee collecting data to complete her Masters thesis".

\subsubsection{Research Methods and Instruments}

The research methods and instruments chosen for this study were designed to capture gendered perceptions, roles and identities vis-à-vis the Internet, fixed telephones and mobile telephones. After making the necessary amendments to my original research design $^{51}$ to include Tangmachu as a data collection site, I arrived at a new research design and corresponding instruments. In order to gather the necessary data and knowledge within the same eight and a half week window, I modified the initial proposed methodology to limit the scope of research methods and the number of research instruments. The final research design consisted of a tripartite approach of semistructured interviews, participant observation and key informant interviews. Offered an opportunity to revise my methods, I made an effort to avoid excessively time-intensive research instruments that could create considerable inconvenience or disruptions for the respondents and their immediate surroundings. By doing so, I reduced the amount of time spent with each interviewee and relied on other research instruments for the purposes of triangulation. Copies of the household survey, and interview question plans for Thimphu and for Tangmachu are found in Appendix A, Appendix B, and Appendix C respectively. In addition, a list of key informant interviewees can be found in Appendix D.

The semi-structured interviews were each designed to take between 60 and 75 minutes to complete. Several colleagues at DIT pre-tested the interviews planned for

\footnotetext{
${ }^{51}$ The initial proposed methodology included the following research instruments (in chronological order): an initial structured interview to take between $45-60$ minutes, a semi-structured interview also taking between 45-60 minutes, maintenance of an ICT usage $\log$ for 2 weeks, and a small number of 1-day focus group discussions for selected individuals.
} 
Thimphu as well as the ones for Tangmachu. They provided input and advice on adding, removing, rephrasing, or reordering questions to better suit the different data collection sites. This exercise was extremely valuable in helping to customize the interviews for each community. During the vetting process, I was often surprised at the questions that were perceived as sensitive and those that were not. ${ }^{52}$ In the event of such mismatches in cultural perceptions and sensitivity, I was reminded of how unintentional researcher bias could limit and/or influence data collection, analysis and eventual findings. I realized early on that it would be impossible to avoid all types of researcher bias; however I tried my best to minimize them by systematically capturing my reflections about the process.

\subsubsection{Selecting Interpreters and Participants}

Selecting interpreters and participants for the semi-structured and key informant interview processes was highly contingent on social networking. I secured the services of two different interpreters because of the diversity in language, culture and community awareness in Thimphu and Tangmachu. The interpreters at both sites played a key role in securing participants (all of whom were above 18 years of age at the time of the interview). When searching for the interpreters I used some objective criteria, which included finding someone who would be able to understand the basics of my research project, approached gender issues in a sensitive manner, illustrated awareness of the local context, and would be trusted by the respondents. ${ }^{53}$ I had no strong preference for a male

\footnotetext{
${ }^{52}$ For example, I assumed direct questions about income earned would be a sensitive issue, only to learn it was quite harmless. Overall, I felt my perception of sensitivity was often overzealous.

${ }^{53}$ Although English is widely spoken in Thimphu, I wanted to create a selection of participants that covered individuals that preferred to express themselves in other languages (e.g. Dzongkha, Nepali, Sharchopkha, Bumthangkha etc.). In Tangmachu, English-speakers represent a minority group. Making the respondents feel at ease during my interactions with them was a central objective during the data collection phase. At both sites, I wanted respondents to speak in a language in which they had a strong command of essential grammar and vocabulary and one with which they could freely express themselves in.
} 
or female interpreter; however I was clear that the individual required some sort of understanding and empathy toward the gender issues I wished to explore. As my understanding of the different cultures and peoples living in Thimphu and Tangmachu was narrow, I asked the interpreters to play a dual role as my linguistic and cultural guide throughout the process.

In Thimphu I hired Dolkar Lham, a bright, (formally) educated and articulate young lady in her mid-twenties. I met her through contacts at DIT and immediately felt she was the right person for the job. Her fluency in English, Dzongkha, Nepali, Sharchop, Hindi and a range of other dialects, was complemented by her sincerity, dedication, open attitude, and interest in the research topic and proposed methodology. We discussed the purpose of my thesis, reviewed the different questions in the interview plan, and outlined our specific roles in the interview process. Based on a series of discussions, we decided the best way to proceed in administering the interview and recording data would be to follow an immediate direct translation style. This process would allow me to observe the respondent, take notes in the margin and also interject with probing questions if and when necessary.

Given the criteria I had set out, my choices for interpreters in Tangmachu were more limited in comparison to Thimphu. Fortunately, due primarily to my association with IDRC and DIT, I soon found a prime candidate for the job. I hired Pema Lhazin, a 19-year old woman who manages the day-to-day operations of the CIC in Tangmachu. Initially, I had to work very closely with Pema to help her feel comfortable with me and her role in the research process. Concerned that her shy demeanour may become a liability during the interview process, I was pleasantly surprised and relieved as I 
observed her gradually emerge from a shy shell and exhibit her confidence and genial manner during the interviews. In discussing how to proceed with the interviews in Tangmachu, we decided to follow the same technique (immediate direct translation) as I used with Dolkar in Thimphu.

Looking back on my experience with Pema and the time it took for her (someone who works directly with ICTs and has a relatively sound command of the English language) to feel comfortable with me, I understood the plethora of problems a foreign researcher who parachutes into a particular environment can face with regards to building trust and confidence with her/his respondents. This trust is sometimes on temporary loan from the interpreter or other local connections, and may slowly become a permanent feature of direct interactions between the researcher and his/her research subjects.

\subsubsection{Semi-Structured Interviews}

Semi-structured interviews represent the cornerstone of the three data collection instruments used in this study. I conducted 15 semi-structured interviews in Thimphu and another 15 in Tangmachu. ${ }^{54}$ Each of the interviews began with an initial household data collection procedure (sample found in Annex D), which includes general demographic data such as names, linguistic proficiency, gender, age, occupation, marital status, number of children and migrant status. This information was valuable to situate the respondents within his/her respective household, extended family, and community. Questions for the interviews conducted in Thimphu and Tangmachu followed the same general pattern, with minor changes to incorporate local specificities and priorities (see Annex A and B). Both interviews used a mix of open and closed questions, which

\footnotetext{
${ }^{54}$ I also informally interviewed some colleagues at DIT; these findings are captured among the participant observation data collection method.
} 
investigated direct and some epiphenomenal factors influencing gendered access and use of the Internet and telephony (fixed and mobile).

I began every semi-structured interview with some polite informal banter to communicate (either directly or via an interpreter) the purpose of my visit, the value of the respondent's contribution and my desire to learn more about the community. This exchange helped put the respondent at ease, made me feel like less of an 'outsider', and added to my bank of participant observation of the community and its people. Although met with frequent well-mannered giggles, I often attempted to show my negligible command of Dzongkha, Sharchop, Nepali, Kurtoep and Chocangacakha ${ }^{55}-$ depending on $^{5}$ the native language of the respondent. With the immediate translation method I had devised with both interpreters, I had ample opportunity to probe responses when I felt I could gain deeper knowledge about or explanatory value with regards to an issue. In the event I was aware of some level of misunderstanding of terminology or phraseology, I learned to rephrase or unpack questions in several different ways to facilitate comprehension.

Each interview was divided into predefined sections. After beginning the interview with the household data gathering exercise, the first section contained a series of closed questions about income, education and migration. These were meant to make the respondents feel at ease and confident about their ability to participate in the study. The second section probed the respondent's awareness of different ICTs, followed by a

\footnotetext{
${ }^{55}$ Prior to leaving for Bhutan, I spent 3 weeks teaching myself Dzongkha phrases. In the case of Nepali, my limited knowledge of Hindi was an asset. Kurtoep, Sharchop and Chocangacakha were all foreign to me upon arriving to Bhutan. I stole some time with each of the interpreters to learn some key phrases prior to the interviews.
} 
series of pertinent usage/non-usage questions. ${ }^{56}$ Finally, the last section dealt with intrahousehold responsibilities and perceived power relations.

\subsubsection{Key Informant Interviews (KIIs)}

After having conducted a significant amount of secondary source research and several semi-structured interviews, I began to notice some trends and to identify several deficiencies or disconnects among the data. To address these, I developed a list of key issues and questions, and a corresponding list of potential key informants who could speak to them. By this point, I had managed to steadily grow my social network and found strategic ways to contact relevant subject matter experts. Depending on the availability of the KIIs and the nature of the questions, I opted for either a face-to-face interview or a written questionnaire sent via email. It was rare to find individuals specializing in gender and ICTs; however several individuals were well acquainted with either issues relating to gender analysis or issues relating to ICTs. Moreover, the key informant interviewees were often able to provide valuable insights on the convergence of these and other interrelated issues. The interview plans for the face-to-face KIIs generally comprised open-ended questions. I developed a list of questions beforehand and vetted their phrasing and sequence with DIT staff. These questions were intended to be indicative, rather than definitive in nature. The emailed questionnaires required considerably more form and closed ended questions. I tended to focus on key issues and limited the use of open-ended questions.

I interviewed senior staff from a number of NGOs with a mandate to examine women's equity and empowerment issues in Bhutanese society. These include the

\footnotetext{
${ }^{56}$ If a respondent indicated (s)he was unaware of an ICT (something that occurred frequently), I refrained from asking about usage or non-usage.
} 
National Women's Association of Bhutan (NWAB), Respect, Education, Nurture and Empower Women (RENEW) and the National Commission on Women and Children (NCWC). I also interviewed a handful of Bhutanese and expatriate academics and authors, who each possess a considerable knowledge base on a wide spectrum of socioeconomic issues. With regards to ICTs, I conducted interviews with senior staff at DIT, the Department of Information and Media, and the Ministry of Labour and Human Relations. In addition, I distributed questionnaires to representatives at Druknet, Bhutan Telecom and B-Mobile. Several responses from these interviews and questionnaires, which were all conducted in English, were valuable when analyzing data and formulating findings.

\subsubsection{Participant Observation}

The glue that binds many of my arguments in this study was derived from notes I took while observing individuals and groups in Thimphu and Tangmachu. Although the method of gathering responses from semi-structured or key informant interviews are generally more systematic or rigorous when compared to participant observation, they often lack explanatory or contextual value to connect disparate data or findings. Careful and consistent participant observation played an irreplaceable role in my research design. These observations were collected as they wove in and out of my formal and informal activities - such as conducting interviews, buying vegetables in the open market, attending social gatherings, or interacting with the Bhutanese men and women I met throughout my stay. Participant observation can 'fill in the spaces' between responses, provide insights for probes during interviews, and impart general explanatory influence within the study. 


\subsubsection{Recording Data}

Before arriving in Bhutan, I had intended to audio record all my interviews and perhaps video record some focus group discussions. Armed with two handheld tape recorders and a camcorder upon arrival, I soon realized their restricted application within my revised research design. Forced to consider the advantages of recording interviews such as data integrity and archiving, versus the potential drawbacks, such as limiting honest and open communication, I opted against audio or video recording the semistructured interviews. I recognized that the nature of my questions and my desire to maintain an open and non-threatening environment superseded the advantages of recording the sessions. Indirectly, I believe this decision sharpened my observation and recording skills during the process.

The audio recorders were used during several of the key informant interviews, which were generally less structured. Although they followed a predefined question plan, most of the questions were open-ended and often included nested and improvised probes. Audio recording these sessions permitted my focus to remain on the responses being given and on formulating additional questions or clarifications if required. Most of the key informant interviewees were subject matter experts and were often accustomed to public speaking and/or giving interviews. I communicated the purpose of my study, their role within it and the confidential nature of their responses. Some of the interviewees waived the confidentiality clause of the interview, while others chose not to. In accordance to my ethical obligations, I assured the key informant interviewees that I would refrain from directly associating their names with specific quotes and/or comments without acquiring their explicit consent. 
A logbook, which captured my copious field notes, was by far the most valuable data-recording tool during my field visit. It acted as a scratch pad for the myriad facts and observations I encountered on a daily basis, and also as my 'paper conscience' to reflect the different emotions and reactions I experienced along the journey. My initial entries tended to be more functional in nature, mirroring a list of activities with a smattering of superficial observations. However, within days the entries grew in length and took on a life of their own - filled with rich observations, reflections and follow-up questions. I frequently referred to my notes throughout my time in Bhutan, and continued to do so while analyzing data and pulling together my findings. As a general rule, I made a habit of writing down my thoughts and impressions as soon as I could, which required restraining any urges to discuss them with others. This was done to avoid inadvertently diluting or contaminating my initial perceptions and reactions. The logbook was undoubtedly my chief tool to capture reflections throughout the research process.

\subsection{Reflecting on the Research Process}

The actual research process encompassed a range of unique, rich and unpredictable experiences. Geraldine Pratt describes the research process as one that does not unfold on a gentle even terrain, but instead is a lively, halting and political encounter (Pratt 2000: 639). These words resonated with me as I reflected on the process, its opportunities, and its challenges. My choice of methodology allowed for a certain level of agility, flexibility and responsiveness throughout the research process. Among my many reflections on the process, there are three that stand out as particularly noteworthy: i) recognizing the importance of social networks and social networking ii) responding and 
adapting to faulty assumptions and ii) balancing flexibility and integrity within my research design.

\subsubsection{Paramount Importance of Social Networks}

In a country that has a relatively small and dispersed population (with respect to landmass), I was struck by the paramount importance and strength of social networks and social networking practices in Bhutan. Although this phenomenon is not anomalous relative to other societies, the ubiquitous nature and strength of these social networks struck me as particularly significant. These networks often span multiple communities, districts, or beyond the country's borders to Bhutanese diaspora. According to Pain and Pema (2000: 214), social networks:

... permeate and fuse both the formal and informal institutions. They allow for constant transactions and maneuver, which are often openended; they are a key part of Bhutan's culture, of internal power relations and ultimately of economic activity as well.

I quickly learned the value of informal networking - often more so than the formal type as a prerequisite to acquiring information, securing volunteers, or communicating with influential individuals who possessed pertinent knowledge related to my thesis. My dual affiliation with IDRC and DIT served as the nucleus of my own social network. ${ }^{57}$ Since the number of foreign social scientists conducting research in Bhutan is limited, it was imperative for me to have strong linkages with recognized and respected individuals and institutions. As I spent more time in Bhutan, my social network began to snowball through serendipitous encounters, from contacts in my own burgeoning social network, and from contacts generated through secondary and tertiary networking activities

\footnotetext{
${ }^{57}$ Canada's official representative body in Bhutan is the Canadian Cooperation Office (CCO) located in Thimphu. I communicated with the Field Coordinator of my impending visit to Bhutan and was hoping to schedule periodic meetings with her during my stay; however, due primarily to conflicting travel schedules, we were unable to coordinate a substantial meeting until shortly before my departure from Bhutan.
} 
(leveraging the respective networks of those I knew). Social networks and social networking were key factors in securing interpreters, selecting participants, speaking to key informants, and collecting general ethnographic data.

Many Bhutanese offered me a warm welcome and acquainted me with local perceptions, culture, cuisine, music and etiquette. Such gestures provided me not only with a rich range of participant observation and experiential learning, but also helped me feel less like an 'outsider'. Over time, I was able to broaden and deepen my social network; and by the end of my stay, it was not uncommon to meet a stranger in Thimphu and trace our respective social networks back to one or more common individual(s). Therefore, although my affiliations with DIT and links with IDRC garnered some looks of recognition, it was only after people learned of my position in the broader social network, that they began displaying more sustained and sincere interest in my research study.

\subsubsection{Overcoming Faulty Assumptions}

The notes captured in my logbook afforded several insights with regards to faulty assumptions that surfaced over the course of the research process. Among them, two key assumptions emerged: i) the complexities around collecting intrahousehold data; and ii) overestimating the time and availability of participants. My intention to uncover intrahousehold power dynamics and resource allocation was based on the assumption that it would be relatively easy to consistently separate interviewees within the same household. Nested within this faulty assumption were others involving i) the availability and willingness of multiple household members to participate in the study, ii) ample time to draw out complexities of intrahousehold power dynamics and resource allocation, and iii) 
a basic threshold of comfort and trust to divulge such matters to a foreigner in a relatively short time frame.

Although I had some initial success using this interviewing technique with individuals in Thimphu (all of whom had a strong command of the English language and some of whom demonstrated knowledge of social science research methods), I soon realized that most respondents - in both Thimphu and Tangmachu - were hesitant when asked to respond to my questions in isolation from other members of the household. Many perceived the research topic as inherently technical, which exacerbated existing feelings of unease at being interviewed alone. In the end, despite my efforts to allay the respondents' apprehension or perceived inability to respond to the questions when left alone, I decided to alter the question plan to compensate for this faulty assumptions.

Another faulty assumption on my part was overestimating the availability and willingness of respondents to participate in repeated data collection exercises. My original research design comprised an array of research instruments including a structured interview, a semi-structured interview, a usage log and focus group discussions. It became apparent that the sheer number of research instruments, and the amount of time and commitment they required from the participants (who were all volunteers), were not realistic. Even if I had limited data collection to a single site, I still believe my eight and a half week stay in Bhutan would not have been sufficient to systematically collect data using my initial research design and instruments. As a result, I decided it would be best to select the important elements of the different instruments and merge them into a single comprehensive semi-structured interview, which was subsequently triangulated with key informant interviews and participant observation. 


\subsubsection{Balancing Flexibility and Integrity within the Research Design}

During the early parts of my stay I learned the value of striking a balance between a flexible research design and one that adheres to my academic and ethical obligations. Although my original research proposal clearly expressed its focus on a single urban community, I was urged to consider expanding my focus to include Tangmachu. Initially I was hesitant to add another data collection site due primarily to concerns around compromising the focus of my study. Moreover, as an IDRC employee visiting the site of a funded project, my presence could be construed as a conflict of interest. However, since my role was not to monitor the project or to evaluate it in any way, I was able to avoid such a situation.Upon further consideration and reflection I realized that my association with IDRC would not inherently compromise my ethical obligations. As indicated in my reflections on social networks and social networking, my association with IDRC and DIT fostered feelings of trust with the interpreters, respondents and key informant interviews.

After deciding to add Tangmachu as a data collection site, I crafted a two-pronged arrangement that involved i) assisting DIT staff to design a baseline survey for the IDRCsupported project before arriving in Tangmachu and ii) collecting data for my own thesis upon arrival. The latter portion of this arrangement required a dedicated interpreter and a range of respondents who were distinct from those approached for the DIT baseline survey. The exercise of negotiating this arrangement with DIT helped me uncover a lesson around the difficulties in clearly demarcating between my roles as an independent researcher and that of an IDRC employee. This lesson led me to realize two errors in assumption - the first involves my naïveté in assuming it would be simple to distinguish 
these roles; and the second involves my misconception that sharing both these identities would inevitably compromise my research in some way.

Reflecting on various aspects of the research process helped strengthen my cognitive map of how the overarching methodology actually unfolded. Gupta and Ferguson (1997) describe the physical and emotional detachment a researcher may feel upon returning home from a field visit - including the perception of 'the field' as a discrete and bounded sphere, which is disjointed from the academic realties that await one at home. There is no doubt I felt a distinct physical and emotional separation between my time in Bhutan and my time back in Ottawa. However, having a rich collection of notes and taking the time to reflect on the process helped me bridge this chasm.

\subsection{Conclusion}

This chapter presented my search for a research methodology that would adjust to several delimiting factors, place the different social actors involved in the research process at the core of its design and implementation, and honour my formal and ethical obligations (to Carleton University and my host institution DIT). Elements from actororiented social science research methods were combined with feminist inquiry to develop a research design that was fluid and responsive to political, social and cultural contexts. A responsive and actor-oriented methodology was designed to address the overarching impetus and conceptual framework of this thesis. The flexible nature of each of the three research instruments and recording mechanisms facilitated an inductive process, whereby different findings gradually emerged over the course of the entire research process. 


\section{CHAPTER 4: GENDER IN BHUTAN: THIMPHU AND TANGMACHU}

Strategically placed between initial chapters of this thesis, which contain the context, conceptual framework, and research methodology used in the study; and the latter chapters, which present corresponding data analysis, findings, and recommendations, this chapter introduces and discusses material relevant to gender relations and ICTs in Thimphu and Tangmachu. The first section discusses the gendered division of labour, rural-urban migration, inheritance and residence laws, formal and nonformal education, and interactive ICTs in Bhutan as they pertain to rural and urban populace in general. The following section examines the same issues in light of specific information collected during my field research in Thimphu and in Tangmachu. The resulting background and site-specific profiles are referred to throughout the analysis that is conducted in Chapter Five and Chapter Six.

\subsection{Rural and Urban Communities in Bhutan}

Several distinctions exist between typical rural and urban communities in Bhutan. Many of these are accentuated due to differences in physical geography, livelihood opportunities, and relative accessibility via motorable roads and communications infrastructure. Although Kunzang Choden (1997: 253) indicates the emergence of cities in Bhutan as a new experience of no more than 30 years, the latest national census (RGoB 2005a) indicates a declining majority of $69 \%$ of the population lives in rural areas. The Gender Pilot Study in Bhutan (RGoB et al. 2001$)^{58}$ is a comparative study, which is based on data collected from 200 urban households and 602 rural households

\footnotetext{
58 The study was a joint initiative between the Planning Commission and Central Statistical Office of RGoB, and several UN Agencies - UNDP, UNICEF and WFP, Bhutan Country Office; with technical support provided by UNIFEM.
} 
(1135 adult respondents - 640 women and $495 \mathrm{men}),{ }^{59}$ examines gender and gender relations vis-à-vis livelihood activities, property ownership and inheritance, decisionmaking patterns, education, migration patterns, and governance. These findings, in conjunction with other literature examining gender relations and ICTs in rural and urban communities of Bhutan contribute to the conceptual basis for the subsequent gender analysis. Although focused predominantly on Bhutan, references from other Third World countries are periodically drawn on throughout this section for explanatory or contextual purposes.

\subsubsection{Gendered Division of Labour}

Several documents indicate the identity of women in Bhutan to be related predominantly as housewives, mothers, and/or wives (Kinga 1999; Wangmo 2004: 43; RGoB et al. 2001). Gender identity, relations and power structures within private and public spheres are influenced by everyday roles and responsibilities assumed by men and women (Huber 1991; Lorber 1994). Whereas the biological sexual division of labour pertains to a limited subset of reproductive labour, including pregnancy and childbirth; the gendered division of labour is a result of socially constructed and assigned gender roles and responsibilities. Research findings consistently show that women undertake a larger proportion of unpaid labour within the household.

Maria Mies (1982) examines the "housewifization" to Western capitalist labour models. She presents a case study on the lacemaking industry

\footnotetext{
${ }^{59}$ Respondents in the study were selected from six districts (two geogs in each district) - notably Thimphu, Ha, Bumthang, Trongsa, Mongar, and Trashigang. The two urban areas for the study were Thimphu City and Phuntsholing City (RGoB et al. 2001: 1).

${ }^{60}$ Mies defines housewifization as the "process by which women are socially defined as housewives, dependent for their sustenance on the income of a husband, irrespective of whether they are de facto housewives or not" (Mies 1982: 180).
} 
located in Narsapur, India, which was introduced by colonizers and eventually displaced women's 'productive' role in the community and assigned them as 'non-productive' lacemaking housewives. This type of gendered division of labour can result in the isolation, devaluation and exploitation of women's productive work within the private sphere (Rogers 1980; Mies 1982). The division between labour in the private and public spheres plays a role in determining paid versus unpaid labour and is related to decision making patterns in Bhutan. Bhutanese "housewives" reportedly possess a relatively strong degree of power and decision-making authority (Schicklgruber 1998; Brauen 1998; RGoB et al. 2001). The Gender Pilot Study (RGoB et al. 2001: 21) mentions a "public-private difference in governance", whereby men dominate decision-making in the public domain and women dominate decision-making in the private domain.

The Food and Agriculture Organization (FAO) reports male subsistence farmers in developing countries are generally responsible for ploughing fields and driving draught animals, while women handle most of the sowing, weeding, harvesting and threshing. ${ }^{61}$ In instances of cash cropping practices, men are found to work most of the large-scale cash cropping activities, particularly when they are highly mechanized; whereas women often handle the majority of household food production and several small-scale cash crop cultivation activities (Benería \& Sen 1986; Crehan 1982; Boserup 1970). In Bhutan, much of the literature about the division of labour indicates a limited amount of rigid sexdisaggregation among women and men in rural subsistence livelihoods - save for some division of labour based on 'physical strength' (Wangmo 2004: 43; CEDAW 2003: 5; RGoB et al. 2001: 10). ${ }^{62}$ Traditionally women's key roles in Bhutanese subsistence

\footnotetext{
${ }^{61}$ http://www. fao.org/Gender/en/lab-e.htm

62 These findings apply predominantly to traditional rural subsistence communities.
} 
farming households include weeding, digging, harvesting, transplanting, threshing, and winnowing; while men are generally responsible for ploughing, preparing the land, collecting firewood, and woodworking (RGoB et al. 2001: 10; Brauen 1997: 86).

The Gender Pilot Study (RGoB et al. 2001: 11) reports more than two-thirds of women are engaged in primary reproductive tasks in both rural and urban households. Specifically, women are responsible for the majority of cooking, laundry, house cleaning, kitchen gardening, and food preservation in $80 \%$ of the rural households; and two-thirds of these women are responsible for rearing children, fetching water, collecting manure, attending to domestic livestock, and distilling alcohol. The study found women in rural areas "were involved in the productive as well as the household tasks -multiple responsibilities, multiple tasks" (RGoB et al. 2001: 11). In addition, the study reported nearly $80 \%$ of all women and men in rural areas engage in subsistence farming activities $^{63}$ and that both men and women are generally involved in taking care of the domestic livestock - though the number of women was slightly higher than that of men (ibid: 10). Rural women participate in main economic activities as well as supplementary activities, such as kitchen gardening, handicrafts, selling Ara (rice wine) and other types of small businesses (RGoB et al. 2001: 11). Weaving generally serves as a complementary income generating activity for many women, often done during lulls in the farming season.

\footnotetext{
${ }^{63}$ This figure does not distinguish between subsistence farming and cash cropping. Chief cash crops include potatoes, apples, cardamom, oranges and chilies. Valley cultivation is reserved for crops such as paddy rice in the summer and wheat in the winter, in addition to some buckwheat, mustard, maize, and potatoes. Terraced cultivation produces maize as the prime crop in the summertime, as well as wheat, maize, barley, mustard, buckwheat and potatoes; and shifting cultivation (tsheri) is dominated by maize. Kitchen gardens are prevalent in the majority of rural and urban households. While chillis are by far the principal vegetable grown in these kitchen gardens, other vegetables include onions, tomatoes, and a variety of leafy greens.
} 
In urban households, the Gender Pilot Study revealed women cook, wash clothes, and clean the house in $90 \%$ of households; and rear children and preserve food in $60-80 \%$ of the households. When examining the gendered division of household work, there seemed to be more sharing among men and women in rural areas than in urban areas. The aforementioned tasks performed by women in rural and urban areas are predominantly done in and around the household, and thus contribute to women's limited mobility relative to men (ibid: 19,23 ).

The majority of urban male respondents (47\%) in the Gender Pilot Study (RGoB et al. 2001: 10) worked in the government service - compared to $18 \%$ of female respondents; while the majority of urban female respondents (60\%) described themselves as housewives. Women in rural and urban communities are predominantly responsible for weaving thagla bela (work related to wool and weaving) and specifically kishuthara (an intricate hand woven textile for which Lhuntse dzongkhag is well-known) (Choden 1997; Terada 2005). In urban areas men are reportedly the primary income earner in a household, whereas women's incomes are mostly supplementary in nature (RGoB et al. 2001).

\subsubsection{Rural-Urban Migration}

Migration can be seasonal, sequential, long-term and/or permanent in nature, and can bring about possibilities for empowerment as well as exploitation (Wright 1995). On the positive side, rural-urban migration can help to reduce pressure on agricultural land and food supplies, provide new opportunities for unemployed and underemployed individuals, and potentially raise living standards and livelihood prospects across rural and urban communities (FAO 1996). On the other hand, rural-urban migration could 
result in high unemployment, social unrest and city slums in urban areas, and declining agricultural output, growing pauperization (markedly among women), and a disruption of traditional family and social structures in rural areas (Roca 1991). The propensity toward rural-urban migration results from a combination of 'push factors' and 'pull factors'; whereby the former involves limited opportunities (perceived or actual) in rural areas, and the latter speaks to the allure of a 'better life' in the comforts of the city. Cultural traditions and societal expectations can also influence an individual's decision to migrate. ${ }^{64}$

Rural-urban migration patterns in South Asia have been found by many to be chiefly male-dominated (Chant 1998). According to a study titled "Rural-Urban Migration in Bhutan: Walking the Extra Mile" (RGoB 2006), the profile of most ruralurban migrants ${ }^{65}$ is male between the ages of 16 and 30 . The same study indicates $72 \%$ of the urban population is comprised of migrants, and $47 \%$ of all rural households have at least one member who has out-migrated - common destinations include predominantly urban areas of Thimphu, Paro and Phuntsholing located in western Bhutan. This disproportionate out-migration of men from rural communities has direct and indirect consequences on gendered division of labour and livelihood options, especially in households engaged primarily in farming activities. This is often referred to as the feminization of agriculture (Croll \& Huang 1997; Buvinic et al. 1996; FAO 2003; Simmons 2002). According to Hugo (1993: 63):

\footnotetext{
${ }^{64}$ Examples of such restrictions can include purdah, which limits women's mobility outside of the private sphere.

65 The definition of migrants used in this study stipulates that individuals must have stayed outside their home geog (block or commune) for five or more years. (RGoB 2006: 11 ).
} 
In the case of male rural-to-urban migration [in developing countries], young men seek employment in the cities, leaving behind female relatives to manage on their own and to provide for both the elderly and the young. This results not only in changes in family structure, but usually leads to adjustments in family roles, and more importantly, in the division of labour as well as in the way labour is utilised in the community of origin and destination.

Similarly, the Gender Pilot Study (RGoB et al. 2001: 4) indicates, although both women and men migrate, it is only when "... men have migrated, women and children had to cope with a heavier workload". In addition to changing the gendered division of labour and overall distribution of workload, rural-urban migration results in altering family structures in both rural and urban households.

In "Women in the City" (1997), Kunzang Choden discusses changes in family structure due to shifts from extended family structures to nuclear family structures. Specifically she mentions the "... social reality of living in nuclear family settings, without the ever-present grandmothers, aunts elder sisters and other relatives of the traditional extended families" (Choden 1998: 258). Changes in livelihoods and family structure have implications on household decision-making and general power relations. For example, the Gender Pilot Study findings indicate women's declining decisionmaking power as households moved away from subsistence agrarian activities. (RGoB et al. 2001: 23). Therefore, rural-urban migration and the corresponding range of changes in livelihood options are shown to influence, and be influenced by, existing and emerging gender relations.

\subsubsection{Legal and Customary Norms: Inheritance and Residence}

In her work "Religion and Gender Values in a Changing World" (2004), Reiki Crins examines gender and gender relations in Bhutan. She describes how women and 
men generally choose their own partners, live with one another without performing a ritual, and equally are free to initiate divorce proceedings (Crins 2004: 581). Bhutan's Drukpa people have a long history of matrilocal residence, matrilineal inheritance and control of land by women (Pain \& Pema 2004: 421; CEDAW 2003: 16; RGoB 2001: 3, 11). Matrilineal inheritance and matrilocal residence are not unique to Bhutan and should not be conflated with matriarchy (Bartle 1978). ${ }^{66}$ Schneider \& Gough (1961) and Goode (1963) posit the institution of marriage in matrilineal societies generally tends to be weaker than those in patrilineal societies. The marriage system in Bhutan is referred to by many as flexible and fluid (Pommaret 1997; Crins 2004). As such, there is generally little stigma attached to the dissolution of marital relationships, and single parents seldom fear social stigma (CEDAW 2003). According to Pommaret (1998) and Crins (2004), Bhutan's traditional fluid marriage system is increasingly influenced by cultural norms and values that originate in India and parts of the First World. Crins (2004: 582) states the "[marriage] system is becoming somewhat more rigid than before, and traditional arrangements are giving way to a kind of standardization”. Francoise Pommaret (1997: 18-19) posits a link between Bhutan's fluid marriage system and the dominant practice of Kagyupa Mahayana Buddhism and traditional matrilineal inheritance practices.

Adam Pain and Deki Pema's study titled "The matrilineal inheritance of land in Bhutan" (2004: 425) indicate that both village norms and household-specific circumstances influence patterns of land inheritance. They contend that the inheritance and control of land are generally accompanied by the additional responsibility of maintaining the household and familial duties. Furthermore, the authors argue "the

\footnotetext{
${ }^{66}$ Other matrilineal customs can be found among a variety of other communities in the Third World, including the Kaonde people of Zambia (Crehan 1983), the Zomba people of Malawi (Dickerman \& Bloch 1991) and the Minangkabau people in Indonesia (Blackwood 1997; Chadwick 1991).
} 
inheritance and control of land by women does not necessarily lead to transformatory effects" and claim ownership of land in remote parts of Bhutan "may do little to enhance the position of women, given their limited visibility in public arenas and the need to maintain the subsistence dimensions of their livelihood" (ibid. at 421, 422).

According to traditional Drukpa norms, land and property are inherited by the eldest daughter, who is expected to take care of her parents and is generally denied an education (RGoB et al. 2001). The Gender Pilot Study indicates a 60:40 female/male ownership ratio in rural areas - most of which is received through inheritance - and a 36:55 in urban areas ${ }^{67}$ - where most property is purchased rather than inherited (ibid: 11). Pain and Pema (2004) refer to traditional matrilineal inheritance norms as a double-edged sword because although eldest daughters generally inherit property, they are expected to stay with their parents and forego opportunities that may be afforded to them via formal education.

\subsubsection{Formal and Non-Formal Education}

The 2005 Bhutan Human Development Report (RGoB 2005b) describes the education landscape in Bhutan as one that has marked differences across gender, districts, and rural/urban areas. Literacy levels are at $80 \%$ in urban areas and only $33 \%$ in rural areas. There is a further disparity between women and men. According to Wangmo (2004: 43), education disparities between men and women represent the biggest constraint to full gender equality in Bhutan. Monastic education, which was the only type of formal education available in Bhutan before the 1950s, has given men a significant advantage over women over the years in religious, political, social and economic contexts.

\footnotetext{
${ }^{67}$ It should be noted that the ratio for female/male ownership in urban areas indicates 91 instead of 100 .
} 
As in all traditional agrarian societies, Bhutanese women's significant economic roles as viable producers must be recognized. While the men entered the monasteries for religious education and practice ... the women continued to work the crop fields, weave fabrics, keep family hearths ablaze, and feed and nourish the children. (Choden 1997: 254)

With the provision of universal education in Bhutan, more and more women are getting the opportunity to get educated. However, studies have indicated that while there are relatively similar numbers of boys and girls enrolled in primary school, the dropout rate among girls increases as the education level increases, which is sometimes attributed to family responsibilities such as marriage, rearing children or a range of other household chores (Wangmo 2004: 63). In the past, families preferred sending boys to school because of the long distances, lack of accommodations and hostels and other general hardships involved and because of the traditional view that daughters were more vulnerable (Wangmo 2004: 44).

In 1992, the Royal Government of Bhutan (RGoB) began offering non-formal education (NFE) programs as an alternative education system covering basic literacy (in Dzongkha) and a range of relevant knowledge and skills in areas such as agriculture, health \& hygiene, income generation, and social issues. NFE classes are generally held in the evenings to allow students with productive and reproductive jobs during the day to attend; the majority of students are women. ${ }^{68}$ Girls tend to lag behind boys in the formal education system after Class VIII; moreover, women generally indicated their desire to attend NFE courses but were unable to because of time and/or mobility constraints (RGoB et al. 2001: 24).

\footnotetext{
${ }^{68}$ In $2003,68 \%$ of the 12,838 students were women (RGoB - MoE 2003 cited in Wangmo 2004: 44).
} 


\subsubsection{ICT: Introduction, Access and Usage}

The gendered effects and outcomes resulting from ICT diffusion in developing countries are both direct and indirect. Many perceive such interventions as strictly positive, and thus neglect to consider the societal context within which different ICTs are introduced. The role of ICTs in the overall development efforts in rural and urban Bhutan has been actively recognized and promoted. According to the Prime Minister, Lyonpo Jigme Thinley, "ICT impacts on every aspect of our society today ... [it] can increase the incomes of our farmers ... [it] can take phone lines and data into remote valleys ... [and] can be a means to express our unique national identity and culture through local media" (RGoB 2004:3). Analog radio was first broadcast on November 11, 1973 and is the ICT with the largest audience in Bhutan - estimated by Bhutan Broadcasting Service (BBS) at approximately $60 \%$ of the population (quoted from the 2003 Bhutan Media Study in Wangmo 2004: 31). BBS radio broadcasts in Dzongkha, English, Nepali and Sharchopkha. BBS television was launched in 1999 and offers programming in Dzongkha and English. Other cable television channels also provide programming in other languages, such as Hindi. Most television sets are found in Thimphu and Phuntsholing (Wangmo 2004: 33).

Fixed telephone infrastructure in Bhutan was introduced in 1963. The Royal Government of Bhutan's Ninth Five-Year Plan aims to provide at least 10 telephones in each geog (block) in Bhutan by 2007 (Wangmo 2004: 35). According to a study supported by the International Telecommunications Union (ITU) in 2004, 76 of the 201 geogs in the country (approximately 37\%) had access to at least four telephone lines (Wangmo 2004: 35). The majority (65\%) of fixed telephone users are concentrated in 
three major towns of western Bhutan - Thimphu, Phuntsholing and Paro (ibid. 32). Bhutan's mobile telephone service was launched in November 2003. Since then, mobile telephone uptake has increased at rates that were not foreseen at the time of its introduction (personal communication with B-Mobile employee). B-Mobile is to increase telephone coverage to all 20 dzongkhags and more geogs in the coming years. First brought into Bhutan in 1984, computer uptake and use was relatively limited due to a lack of stable power supplies at the time (Wangmo 2004: 38). ${ }^{69}$ Initially computers were used without Internet connectivity, which was introduced to Bhutan in June 1999. Internet use today is concentrated in urban areas, mostly at government offices, several private businesses, Internet cafés and some private homes.

\subsection{Thimphu \& Tangmachu: Demographic and Contextual Information}

This section of the chapter presents a demographic overview of respondents in Thimphu and Tangmachu, and provides additional contextual information about gender relations and ICTs at the two sites. The respondents represent a selection rather than a sample at each of the two communities. A general breakdown of selected demographic characteristics provides some broad community-level context for subsequent analysis in Chapter Five and Chapter Six. Names of individuals are not used unless explicit permission was garnered; thus, in the event a reference to a specific individual, a pseudonym (initials sex: age) is used as a method of identification. Figure 1 provides a graphical representation of the sex and age composition of the interviewees in Thimphu and those in Tangmachu.

\footnotetext{
${ }^{69}$ The completion of the Chhukha power plant in the late 1980s provided more reliable power to many parts of the country.
} 
Figure 1: Sex and Age Composition of Interviewees in Thimphu \& Tangmachu

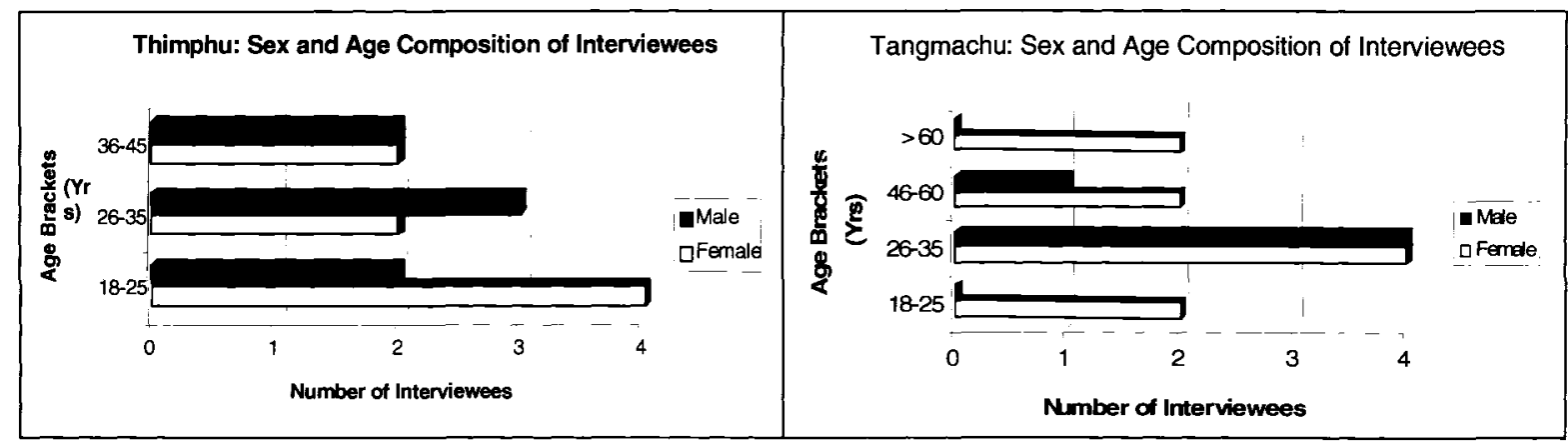

In general, the age range of selected respondents in Tangmachu is larger than that found in Thimphu. In addition, more women were interviewed in the former (ten) than in the latter (eight). According to a needs assessment study conducted by DIT in early 2006, the female to male ratio in Tangmachu is $2: 1$; whereas the national female-to-male ratio is approximately $1: 1$. The ratio in Tangmachu is indicative of male dominated rural-urban migration. Over the course of my stay, I noted young adult men (between 18 and 45 years) in Tangmachu were conspicuous by their absence. Several respondents in Tangmachu commented on similar observations:

There are not many young men in the village, which is a problem for girls who would like to get married ... many have to look for husbands in other villages or cities (TC Female: 50 ).

Several households I encountered in Tangmachu contained only female members between the ages of 18 and 45 . At the time of the interviews, many of these women were unmarried, divorced, widowed, or were married to men who migrate back and forth from an urban area (often away for over six months at a stretch). Among the 15 respondents in Tangmachu, ten were married (of which six had remarried at some point), one was 
widowed, and four were divorced. ${ }^{70}$ Despite the relatively high divorce rate, I encountered little stigma attached to a divorced man, woman, or children born out of wedlock.

When asked about preference for boys or girls in Tangmachu, seven respondents indicated equal preference, one indicated a preference for boys and the remaining seven indicated a strong preference for girls. The primary reason cited for preferring girls to boys in Tangmachu was linked to the fact that girls generally stay at home to provide long-term support and care to their households and families, while boys tend to outmigrate and have less of a commitment to sustained and long-term household responsibilities. All 15 of the respondents in Tangmachu were Drukpa.

In Thimphu, seven interviewees were married, seven were single, and one was divorced. Overall, men and women in Thimphu indicated they were getting married at an older age compared to their parents, and perceived that many individuals in rural communities continue to get married at a relatively younger age. The respondents in Thimphu that were single at the time of the interview included three women (ages 22, 23 and 25) and four men (ages 23, 23, 28 and 28). When asked about their perceptions of marriage, most indicated they felt it was generally fluid yet preferred to wait a few years before marrying - to avoid a divorce. Upon further probing, I learned that influences from other countries (especially India, and other countries in Europe and North America) are influencing the growing tide of negative perceptions attached to broken marriages, single parents and children born out of wedlock. ${ }^{71}$ All 15 respondents in Thimphu

\footnotetext{
${ }^{70} \mathrm{I}$ did not encounter any divorced males. Among the households and individuals interviewed in rural areas, I encountered four interviewees who were divorced and another four interviewees who lived with female divorcees. Their ages ranged from 19 to 64 .

${ }^{71}$ Foreign influences are also pointed to as a cause of increased violence and crime.
} 
revealed an equal preference for boys and girls. Thirteen of the fifteen respondents in Thimphu are Drukpa and the other two are of Nepali descent (Lhotshampa).

\subsubsection{Respondent Profiles: Education}

There are clear differences between formal and non-formal education attainment among men and women in Thimphu and Tangmachu, as well as across the two sites. Although NFE programs are offered in both rural and urban areas, none of the respondents interviewed in Thimphu had been enrolled in NFE, while four interviewed in Tangmachu (all women) had. Figure 2 provides a graphical representation of formal and NFE programs attended by men (M) and women (F) at the two data collection sites.

Figure 2: Organized Education in Thimphu and Tangmachu

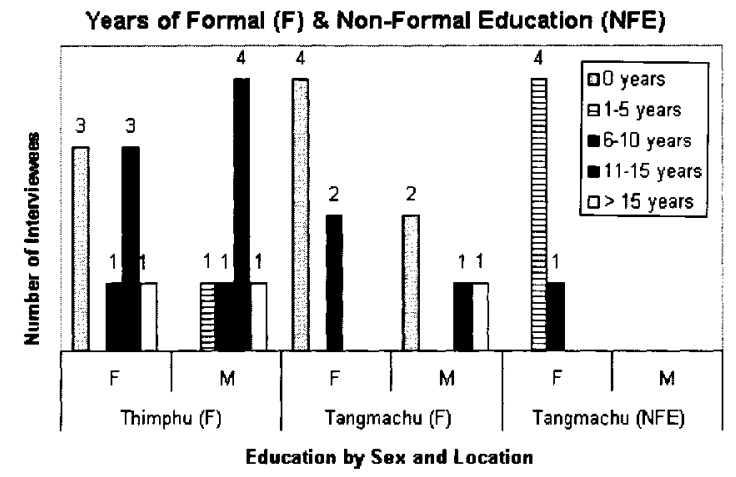

According to Figure 2, there are more individuals without any type of organized education in Tangmachu (six) compared to Thimphu (three). In Tangmachu, only two individuals (both men) received over 10 years of formal education - one is a primary school teacher who migrated from Paro (an urban area in western Bhutan) and the other is a former monk who had received over 20 years of monastic education. ${ }^{72}$ Among the women who enrolled in formal education programs, three of the six in Tangmachu indicated the reason for dropping out of school was because they either got married or pregnant. Other women and men in Tangmachu commented on the dearth of local jobs that require more than a basic level of education. Many asserted this applied more to women relative to men, since men could migrate to

\footnotetext{
${ }^{72}$ Monastic education is the oldest form education in Bhutan. Before the beginnings of formal school-based education, it was the only form of education available (only to boys and men).
} 
and work in other parts of Bhutan and generally acquire more formal education. Paraphrasing the comments of a female farmer:

I need to look after the house and farm. My husband migrates to Dagana [a district in western Bhutan] and returns every 6 months with the income he has earned ... there is no need for me to get a [formal] education for what I do ... (CW Female: 30 )

$\mathrm{CW}$ was not alone in her assessment of formal education with regards to women planning to stay in Tangmachu. Many jobs that require formal education (e.g. school teachers) are filled by women and men from other parts of Bhutan or from India. Several female shopkeepers stressed the need for basic education (basic mathematics and perhaps the ability to read/write a few key phrases); however they felt that extended literacy in English or Dzongkha or other academic pursuits represented a waste of scarce time and energy for most individuals (men and women) who remained in rural communities. However, when asked about the situation today, all respondents indicated that girls and boys currently acquire a relatively equal formal education - until girls get married or pregnant (or both).

The balance in formal education attainment between male and female respondents in Thimphu was relatively more equitable - however, still favouring men. Three of eight women interviewed had no form of organized (formal or non-formal) education, whereas all of the seven men had a minimum of three years of formal education. At the other end of the spectrum, four of eight women, compared to five of seven men, had over 10 years of education at the time of the interview. Nearly everyone I interviewed in Thimphu acknowledged the virtue of formal knowledge and literacy. Although this sentiment came across more strongly from members of the educated elite, those who had not received a formal education in their own youth were clear about emphasizing the value of education to their own children and youth in general. Overall, the respondents in Thimphu 
displayed limited sex-based discrimination when it came to sending girls and boys to school.

\subsubsection{Livelihoods in Tangmachu}

Of the 15 interviewees in Tangmachu, seven were farmers ${ }^{73}$ - of which four were women. Two of the female respondents were shopkeepers (which is among the most lucrative livelihoods in Tangmachu). ${ }^{74}$ Other livelihoods among the semi-structured interviewees included three female house ministers ${ }^{75}$, one male primary school teacher, one male civil servant, and one female privately employed individual. Overall, subsistence farming was found to be the dominant livelihood for men and women in Tangmachu.

\subsubsection{Subsistence Farmers}

My trip to Tangmachu was scheduled at a time to avoid the harvesting season; however a heavy bout of rainfall during the latter parts of October pushed some of the harvesting to late October and early November. This unexpected turn of events allowed me to observe the tail end of some harvesting activities on different farms. The female farmers I interviewed and/or observed generally had children very near by (mostly their own and sometimes a child or two from neighbouring households) and seemed to be dividing their time and concentration between minding the children and doing their farming activities. Upon observing several male farmers, most of who were 40 years or

\footnotetext{
${ }^{73}$ Most of these respondents were subsistence farmers, however some sold surplus yield via the local Tangmachu shops and to nearby Lhuntse.

${ }^{74}$ There are four shops in all of Tangmachu that serve as a combination general store, pharmacy, restaurant, bar and the shopkeeper's abode. All of the shopkeepers in Tangmachu are female, many of whom run the establishment single-handedly, while looking after their children, cooking and cleaning.

${ }^{75}$ Bhutanese women who stay home and do much of the reproductive work in a household are sometimes called "house ministers" - to reflect their decision-making authority - rather than the oft-used term housewives.
} 
older, I noticed they were generally able to commit the majority of their attention to the farming activity they were involved in.

All of the subsistence farmers I interviewed and observed either had fixed telephones at their home or had access to a telephone within a 10-minute walk. Three of the six semi-structured interview respondents had not received any type of organized education and had others dial telephone calls for them. In general, the respondents felt as though the fixed telephone was beneficial for them to stay in touch with others in Tangmachu and with many family members that have since migrated on a seasonal, temporary or permanent basis. When asked about mobile telephones, several respondents expressed the value it could hold for them - especially when they are herding cattle or working in fields late at night or far away from their home.

None of the seven farmers I interviewed had ever heard of computers or the Internet. Although some periodically visit the CIC to pay long distance phone bills or after shopping at the stores located nearby, there was a general absence of awareness and interest related to computers and Internet connectivity. Some expressed curiosity and could recall the publicized visit from the Minister of Information and Communications, however they all confessed never to have visited the CIC for Internet use (or to use any of the other services). The overarching sentiment was that farmers in Tangmachu did not have time to visit the CIC unless they needed to see the gup or conduct other official business. 


\subsubsection{School Teachers}

An examination of the Internet usage $\log$ at the CIC for the month of September 2006 revealed that all users were male. ${ }^{76}$ Among the 64 recorded male users, most were concentrated among six or seven individuals, including teachers, B.H.U. (Basic Health Unit) employees, and the local ranger. Approximately $85 \%$ of the use was by primary school or middle school teachers. These individuals are all formally educated and originally from urban parts of Bhutan or from India. One middle school teacher (SM Male: 31) indicated the high value of the Internet for him in developing lesson plans, typing and printing tests and exams, and staying in touch with his family in South India. He found the cost of making and receiving international calls over Internet telephony to be much cheaper than calling from the fixed telephone system. SM pays $30 \mathrm{Nu}(\sim 0.70$ USD) per hour to call his family in Kerala; this is a considerably lower price than calling over fixed telephone lines. When I asked about his students, SM assessed a healthy amount of curiosity in learning about and using the Internet, however he found that most girls and boys are generally responsible for household chores and thus lack the necessary time and mobility to visit the CIC. SM has a fixed telephone at home but claims that he does not use it very frequently - mostly to contact other teachers, friends, or parents of students. Most of his phone calls are made to friends and family using Internet telephony. Although SM owned a mobile telephone when he lived in India, he does not own one at

\footnotetext{
${ }^{76}$ Although there were no female users noted in the log, the CIC administrator is female and often uses the Internet. Moreover, I witnessed several occasions when Pema's friends would visit her on their way home from school and use the computers and the Internet if they were idle. This indicates a number of 'unaccounted' Internet users in Tangmachu. Pema does not charge her friends the $30 \mathrm{Nu}$. ( 0.70 USD)/hour fee. Most of these individuals use the Internet in a group, huddling around a single machine and chatting or surfing (mostly the former) as a group.
} 
the moment because Tangmachu did not have any mobile telephone service at the time of the interview.

\subsubsection{Livelihoods in Thimphu}

According to the Gender Pilot Study (RGoB et al. 2001) government service was the livelihood for $47 \%$ of male respondents and $18 \%$ of female respondents among the respondents in urban households. The same study found that $60 \%$ of women in urban households described themselves as 'housewives'. Six of the 15 interviewees in Thimphu work in the government service, which include four men and two women. Other livelihoods of interviewees include one elementary school principal, three private business owners, three private business employees, one unemployed post-secondary school graduate, and one housewife (often called 'house minister'). Among the respondents in Thimphu, most indicated their respective workplace as the most common location they use the Internet. Personal computers and Internet access are generally still too expensive for most people in Bhutan to have in their homes. Even among the educated elite, only a limited percentage of individuals own a computer - and a smaller proportion with Internet connectivity. ${ }^{77}$ Fixed telephone access and mobile telephone access are generally more widely available and affordable.

\subsubsection{Government Service}

Most government servants I spoke to in Thimphu, including the six formally interviewed, felt that their jobs afforded them the necessary mobility, time and purpose to use computers and the Internet. They indicated their comfort level with computers and the Internet grew because of their exposure and necessity to use them at work. This

\footnotetext{
${ }^{77}$ Only two of the individuals I interviewed had a computer and Internet access at home. They used a dialup connection, which they claim is very slow. Both individuals have faster connections at their workplace.
} 
eventually led to additional use that was not directly work related, such as social emailing, instant messaging, photo sharing and other online social networking activities. As several government servants are educated abroad, many have social networks that extend beyond Bhutan. For such cases, email and instant messaging are of great value.

Fixed telephones were available at all of the government offices I visited. Many of the civil servants I interviewed had fixed telephones at their homes, yet indicated most of their use was concentrated at their workplace. During work hours, these respondents often receive calls on their mobile phones and return them on the fixed phones. Most of the respondents indicated they use their mobile phones most during the evenings and the weekend. However, mobile phones have become so popular in Thimphu that the cellular networks are regularly clogged between 5 PM and 9 PM on weeknights and periodically throughout the weekends. ${ }^{78}$ As such, many of the government employees I interviewed indicated that their fixed telephone use outside of their workplace was limited to acting as a backup method for their dominant mobile telephone use. Moreover, most indicated that mobile phones are increasingly becoming a sign of status among the government services. DP (Male: 28) discussed how he and many of his colleagues ogle the new mobile handsets and features over lunch. All but one civil servant interviewed owned a mobile phone. KO (Female: 40) used to own a mobile phone when she studied in Australia but has chosen not to use one in Thimphu because she likes to be 'unreachable' at times. $^{79}$

\footnotetext{
${ }^{78}$ According to a B-Mobile general manager, cellular network clogging during peak hours in Thimphu is about 50 percent - meaning the probability to get a connection was one in every two calls (Kuensel, November 2, 2006).

${ }^{79}$ KO's husband and two daughters both own mobile phones. She feels as though many people use their mobiles irresponsibly (driving in their car) and waste their time with frivolous texting and playing games.
} 


\subsubsection{2 'House Minister' or Housewife}

I formally and informally spoke with several housewives (I did not meet a househusband) over the course of my stay in Thimphu. KC (Female: 31) was the sole housewife formally interviewed in the semi-structured interview process. KC watches after her four children under the age of 10 , cooks, cleans and sells momos ${ }^{80}$ three times a week to government employees to earn supplementary income. KC's husband is a security guard and is the primary income earner in the household. She has never heard of computers or of the Internet, has limited access to disposable income and rarely has time to leave her home - unless it is to sell momos. Other house ministers I spoke to had relatively more access to disposable household income; many were responsible for paying bills and making purchases of varying magnitudes. According to one such individual (TW, Female: 44), "there are so many things to learn about in Thimphu these days - learning about computers and the Internet does not interest me at this point".

$\mathrm{KC}$ had access to a fixed telephone in her home, but no mobile phone. Her use of the fixed telephone is restricted to answering calls because she does not know how to dial. KC's husband generally makes all outgoing calls. Many other housewives I spoke to made reasonable use of their fixed telephone lines at home and more so of their mobile phones. They discussed the value of having mobile phones when you wish to have instantaneous contact with loved ones. For example, parents often give their children mobile phones. When the credit on these telephones expires, children send their parents a 'missed call' (which is free of cost), to which the parents respond with a voice call. Comparing mobile phones to the Internet, TW indicates the appeal of mobile phones

\footnotetext{
${ }^{80}$ Momos are dumplings that are popular in Bhutan and other countries in the Himalayan region.
} 
because of its portability and limited influence on changing your lifestyle (i.e. she can still do the groceries and have her mobile phone with her, whereas she needs to stay at home to use the computer and the Internet).

\subsection{Conclusion}

The purpose of this chapter was to bridge the literature and conceptual framework of the study with the data analysis, findings and recommendations. Beginning with an overview of gender relations and ICTs in typical rural and urban communities of Bhutan, the latter part of the chapter focused more specifically on these issues in Tangmachu and in Thimphu. The resulting range of contextual information is drawn on in the following chapter, which examines perceptions and actual usage patterns of the Internet, mobile telephones and fixed telephones at the two data collection sites. 


\section{CHAPTER 5: GENDERED PERCEPTIONS AND USE OF ICTS IN TANGMACHU AND THIMPHU}

This chapter analyzes data and presents findings on how the Internet, fixed telephones and mobile telephones are perceived and used in Thimphu and in Tangmachu. Building on the discussions presented in Chapter Four about gender relations and ICTs in rural and urban communities of Bhutan, as well as specific demographic and contextual information pertaining to the two data collection sites, this chapter analyzes gendered perceptions and use of ICTs and relates them to the three assertions derived from the literature review: i) gender relations and ICTs are socially constructed and mutually shaped; ii) interactions between ICTs and gender relations are both material and symbolic in nature; and iii) ICTs are complex, dynamic and flexible, situated within broader social and technological continua. The resulting analysis will contribute toward the summary of findings presented in the following chapter.

Analysis in this chapter is based on a selection of individuals in Thimphu and in Tangmachu, and therefore should not be interpreted to represent a wider sample of the two respective communities. Drawing on primary data collected during the research process, the range of responses and observations presented in this chapter are intended to reveal perceptions and usage patterns of men and women from different communities, ethnicities, age groups and classes. The chapter is structured to present general observations relating to respondents from each of the sites, followed by specific examples for illustrative purposes. In order to maintain the anonymity of the respondents, most data are represented according to the pseudonym structure described in Chapter Four. 
However, specific names are used in cases where individuals have provided their consent. $^{81}$

\subsection{Gendered Perceptions of ICTs in Tangmachu and Thimphu}

Early in my field visit I realized the importance of examining different perceptions of ICTs and how they relate to gender identity and gender relations. Given the relatively recent introduction of different interactive ICTs in Tangmachu and in Thimphu, and the potentially limited number of corresponding users, it became apparent that perceptions of the Internet, fixed telephones and mobile telephones would be at least as important to investigate as actual usage patterns. ${ }^{82}$

\subsubsection{Perceptions of the Internet}

The Internet is examined in this study as it is accessed via computers. As such, several questions posed with regards to how one perceives the Internet were complemented by similar questions relating specifically to perceptions of computers. Before considering different responses from Thimphu and Tangmachu, it is important to note the considerable variation that exists with regards to history, availability, and potential exposure to Internet-enabled computers at each of the sites. For example, in Thimphu Internet access has been available in the majority of government office buildings, at numerous Internet cafés, within several schools, and inside a limited number of private homes for several years; whereas in Tangmachu, Internet access is limited to four computers inside the Community Information Centre (CIC), which opened in May

\footnotetext{
${ }^{81}$ For the cases when an interpreter was used in the interview, I chose to paraphrase direct opinions and thoughts rather than directly quoting them. The latter approach was used only for respondents who chose to communicate in English.

${ }^{82}$ Despite the fact that Tangmachu did not have mobile telephony service at the time of data collection, all 15 semi-structured interview respondents and most others I spoke to were aware of mobile telephones and able to articulate corresponding perceptions.
} 
2006. The following discussion about diverse perceptions of the Internet at the two sites should not be conflated with actual use - the latter is discussed in the second section of the chapter.

\subsubsection{Perceptions of the Internet in Thimphu}

Of the 15 interviewees in Thimphu, 12 were aware of the Internet and thus able to articulate their perceptions. Among the remaining three, two were completely unaware of the Internet, and one had heard of the term but was unclear with regards to its purpose and how it is used. In general, the findings indicate considerable stratification of Internet perceptions across class and age groups, whereby clear perceptions were concentrated among the group of relatively young (i.e. under 50), upper class and formally educated women and men. Some individuals, like LD (Female: 24) expressed limited awareness and interest in the Internet and its use; while others such as CT (Male: 42) and KO (Female: 40), who each have many years of formal education and work with the Internet on a regular basis, shared relatively sophisticated and nuanced perceptions.

LD had heard of the Internet but was unclear about its precise definition, form and purpose. A 24-year old female who spent her first 15 years living in a rural subsistence farming community (in Samdrup Jongkhar district), LD migrated to Thimphu nine years ago when she got married, and currently lives with her husband and their five-year old son. LD has not received any type of formal or non-formal education and is unable to read or write Dzongkha or English. ${ }^{83}$ Working as a cleaner in a government building from 8:00 AM until 6:00 PM (Monday to Friday), a significant fraction of LD's tasks are demand-driven. As such, she often has pockets of free time, during which she knits while

\footnotetext{
${ }^{83}$ In order to cater to LD's language of preference and comfort, the interview was conducted in Sharchopkha, which is a dominant language spoken in eastern Bhutan.
} 
seated in front of an idle Internet-enabled computer. Indicating the term 'Internet' as familiar to her, LD confesses she is unaware of what it is or how to use it. When asked to explain her perception of it, she described the Internet as a concrete, tangible commodity such as milk or eggs that could be purchased at a store and then inserted into the computer. Relating the concept of the Internet to mobile phones, LD conveyed her perception of the Internet as a type of pre-paid voucher for computers.

LD's perception of Internet users consisted of civil servants, students in higher levels of study, expatriates, and tourists. When asked to provide a more detailed description of what characteristics she would perceive these users to have, LD indicated a relatively broad description for foreigners including women and men from a variety of age groups. With regards to Bhutanese users, she generalized most to be similar to the people working at her place of employment, primarily educated men between the age of 20 and 45. LD mentioned some women (also educated and in a similar age group) also use the Internet, but much less compared to men. In addition to these differences in gender and class, LD mentioned differences in users with regards to age. She seldom saw older Bhutanese men or women near computers. However, after explaining her perception of Internet users, LD pointed to her limited ability to answer the question because she could not know what happens inside buildings she has not entered. Paraphrasing:

It is hard to know who uses the Internet because computers are inside. They are not like mobile phones that people use outside and others can see (LD).

I asked LD if she would like to learn how to use computers or the Internet, especially since she had physical access to an Internet-enabled computer for several hours 
during her workday. Originally framing her lack of interest around shyness and illiteracy, LD later broadened the scope of her response to include an overall apathy toward these ICTs because she perceives them to be irrelevant and too 'serious'. Her sentiments are paraphrased below:

Most people in the office are men that look very serious when they use the computer ... I am afraid to use it because I cannot read or write, and do not know how to purchase more Internet if I run out ... I have no need to use the computer or the Internet and prefer not to because I would rather not be so serious (L Female: 24 ).

According to LD, nobody in her immediate social network uses computers or the Internet; therefore instead of feeling marginalized or excluded, she feels liberated by her ability to forego using the Internet - a technology that she cannot relate to and has virtually no incentive to use. Other respondents in Thimphu, several of whom use the Internet frequently, conveyed significantly different perceptions of the Internet.

CT (Male: 42) and his wife KO (Female: 40) live in Thimphu with their three daughters. CT works at the Kuensel (Bhutan's first newspaper) and KO works as a civil servant. They both use the Internet at their respective workplaces and at home. CT is originally from Paro and $\mathrm{KO}$ is from Thimphu. They each have 15 years of formal education - some of which they acquired abroad ${ }^{84}$ - and are literate in English, Dzongkha and Hindi. They also speak Sharchopkha and Nepali. Although KO and CT were interviewed separately, their individual responses about how they perceive the Internet were similar in nature.

CT was first exposed to the Internet while studying journalism in Singapore in 1999. Proclaiming to be among the more enthusiastic Internet users in Bhutan, CT is a self-proclaimed early adopter - using the Internet both as a tool for academic research

\footnotetext{
${ }^{84} \mathrm{CT}$ studied in Singapore and KO studied in Japan.
} 
and personal communication. He recalls using the Internet and computers to conduct research and to stay in touch with friends long before Internet use became a staple at his workplace a few years ago. CT perceives the Internet primarily as a tool for empowerment and democratization. As a journalist in Bhutan, he explains how the Internet allows individuals to research, communicate, and disseminate relatively independently from the Indian press and other foreign press bodies. More specifically, CT perceives the Internet as a means to inform the Bhutanese citizenry, among others, about relevant local, national and international news stories in a timely manner. He indicates:

We no longer have to wait for our colleagues in India or elsewhere to send us news to report, like we did in the past. The Internet allows us to communicate with individuals in an efficient way and avoid receiving news stories that are irrelevant to the readership in Bhutan or out of date by the time it is printed and distributed (CT Male: 42).

In response to a question about any negative perceptions he may have about the Internet, CT indicated that excessive Internet use could lead to health problems such as stress to the wrist, eyes and back, as well as potentially limiting one's attention span.

When asked to describe his perception of typical Internet users, CT indicated that users span different sections of Bhutanese society, including government employees, academics, private business owners, expatriates, tourists, etc. Specifically looking at Bhutanese users, CT conveyed his perception of individuals - both women and men who are formally educated and generally those who work or study in an environment that requires regular Internet use. He discussed characteristics that he perceived to separate those who use the Internet from others who do not, which included formal education (specifically the ability to read and write in English), age (he mentioned that most elderly 
Bhutanese had limited capacity and incentive to learn how to use the Internet), and income (Internet access is not yet widely affordable to many).

Responses provided by KO (Female: 40) indicated she perceived the Internet, when used responsibly, as a useful tool for a wide range of purposes. In addition to her positive perceptions of the Internet as a tool to learn, communicate and share, KO more readily alluded to some of her negative perceptions. She mentioned how her daughters "waste time chatting online" rather than doing their homework, reading books, helping with chores around the house, or getting physical exercise. KO indicated that chatting (an activity she associates most with younger Bhutanese between 12-25) and playing games on computers (an activity she perceives to be more common among boys and young men)

are becoming too common an activity for those who have the means to indulge. As a result, she is concerned that Internet addiction or simply irresponsible and/or unsupervised use - especially for youth - can lead to declining levels of physical health and weakening social ties within families and the community.

\subsubsection{Perceptions of the Internet in Tangmachu}

Computers and the Internet were introduced to Tangmachu approximately six months prior to my visit. Given the primacy of the CIC and the considerable distance many have to travel to physically access it, I ensured all interview respondents lived within a 30-minute walk of the CIC. Nine respondents recalled hearing about computers, while five among these had heard of the term 'Internet'. Among the respondents who had heard of the computer or the Internet, their respective perceptions varied between those that regularly used the Internet at the CIC and others who had difficulty recognizing it as 
an ICT distinct from the fixed telephone system that was simultaneously introduced in Tangmachu.

Pema Lhazin (Female: 19), the CIC administrator, ${ }^{85}$ is among the avid Internet users in Tangmachu. Having received nine years of formal education, Pema is able to speak, read and write English at an intermediate level. Her preferred languages for communication (in descending order of preference) include Kuertop, Chocangacakha, Sharchopkha, English and Dzongkha. Pema was married when she was 16 years old, at which point she immediately dropped out of school. She divorced her husband two years after they married - they did not have any children. At the time of my visit, Pema lived with her parents and relatives in a house located a 20-minute walk away from the CIC.

As my interpreter and cultural guide in Tangmachu, Pema and I discussed her perceptions of the Internet on several different occasions. She indicated that her perception of the Internet changed significantly after she accepted the job as CIC administrator. Before this point, Pema did not have a clear conception of what the Internet was or how it was used to communicate with other people. She has since gained considerable experience using the Internet, stating:

The Internet is like a window to help me stay in touch with the outside world - mostly with my boyfriend who is currently studying in India. I chat with him almost everyday ... and I email with DIT staff in Thimphu about the CIC project (Pema Female: 19).

Pema's initial perception of computers and the Internet was of technologies to be used only for serious official business or emergency situations. However, over time she was able to observe how several CIC visitors used the Internet for different purposes,

\footnotetext{
${ }^{85}$ Pema's role as CIC administrator includes opening and closing the CIC, operating the computers, printer, photocopier and fax machines, maintaining a usage log for the different ICTs, and collecting and recording payment for service. In general, Pema has unlimited cost-free access to the Internet.
} 
including sending personal emails, engaging in online chats and even talking to their families (using Internet telephony) who lived many miles away.

Pema perceives most Internet users in Tangmachu as formally educated professionals such as teachers, health workers and the local ranger. According to the CIC Internet users log for the month of September, all recorded users were male. However, I personally witnessed several girls (between 12-16 years of age) using the Internet at the CIC during my visit. These users tended to visit the CIC on their way home from school and often huddled around the machines to collectively search for information, photos, music, videos, or to engage in online chatting. Upon asking Pema why she did not record this type of usage or include them in her perceptions of Internet users, she sheepishly responded that these were her friends who are just 'playing around'. Pema explained how she occasionally allowed her friends to use the Internet free of charge to have some fun after school. ${ }^{86}$

Other individuals in Tangmachu who had heard of computers were somewhat perplexed when asked about the Internet. Despite having visited the CIC and having seen the computers, these individuals exhibited confusion with regards to what the Internet is and how it can be used with computers. One specific individual explained his perception of the Internet as follows (paraphrased):

I see some men working on the computers to fix the Internet, which then allows us to use the telephones in our houses (KD Male: 52).

KD's perception of the Internet is understandable given the simultaneous introduction of Internet and fixed telephone services in Tangmachu. His explicit mention of male users indicates a consistent imbalance of male versus female Internet users at the CIC. Several

\footnotetext{
${ }^{86}$ Pema only let people use the CIC free of charge when at least two of the computers lay idle. They stopped using when a paying client wished to use the computer.
} 
others in Tangmachu recalled the high profile visit of the Minister of Information and Communications to Tangmachu in September 2006 to inaugurate the CIC. They remembered the physical unveiling of computers but could not recall a similar unveiling of the Internet. Upon probing further, I realized many individuals equated technology with something tangible and thus had a difficult time conceptualizing the intangible nature of the Internet.

\subsubsection{Perception of Fixed Telephones}

All 30 respondents across both sites indicated they were aware of fixed telephones ${ }^{87}$ for several years. Despite widespread recognition of fixed telephones in both Thimphu and Tangmachu, it is interesting to note how this particular ICT is situated within individual and community-specific social and technological continua. Fixed telephones have been physically available in homes, at work places, and at public access booths in Thimphu for many years, whereas their physical presence in Tangmachu is relatively new. However, despite the recent physical introduction of fixed phones in Tangmachu, many people had used them in Lhuntse or other parts of the country before the CIC opened. ${ }^{88}$ In addition to different timelines for fixed telephone introduction at the two sites, Thimphu has been introduced to an additional ICT that can also send and receive voice calls - notably the mobile telephone. Given this functional overlap, perceptions of fixed telephones in Thimphu are discussed in relation to mobile phones.

\footnotetext{
${ }^{87}$ The category of fixed telephones includes conventional landline phones as well as cordless phones. However, cordless phones are not commonly found in many homes or offices in Thimphu (all telephones in Tangmachu are fixed). During my entire stay in Thimphu, I only came across three or four cordless phones, which were all located within private homes.

${ }^{88}$ Prior to the establishment of the CIC in May 2006, individuals in Tangmachu had to travel for days (on foot) or several hours (by car) to make telephone calls in neighbouring Lhuntse.
} 


\subsubsection{Perceptions of Fixed Telephones in Thimphu}

Awareness of fixed telephones seemed to be universal among individuals in Thimphu; however the associated perceptions differed among class, generation, ethnicity and gender. Many expressed perceptions about fixed telephones that pointed to its limited mobility, privacy, perceived status and overall empowering influences in relation to mobile phones. Portending the strong link between perceptions of fixed phones and those of mobile phones, many alluded to a significant dip in perceived value of fixed phones since the introduction and widespread adoption of mobile phones.

LD (Female: 24) does not have access to a fixed phone at her home, but has her own mobile phone. She perceives the fixed telephone as an inferior option relative to her mobile phone. However, she finds the fixed phone in her workplace to be useful as she is able to make local calls free of charge. Although LD uses fixed telephones at her workplace and occasionally at public access booths, her perception of fixed phones is that of a technology that is relatively difficult to use (compared to mobile phones) - especially for her as a woman - because of limited privacy and the need to remain stationary for extended periods of time. In general LD exhibited lukewarm feelings toward fixed telephones. She tends to use it as a backup to her mobile phone as a means to save money on her pre-paid mobile voucher.

\subsubsection{Perceptions of Fixed Telephones in Tangmachu}

Fixed telephones and the Internet were introduced simultaneously when the CIC was established in Tangmachu. However, despite this temporal convergence, fixed telephones are more clearly understood by the general populace. ND is a 57-year old subsistence farmer living with his wife and two teenage sons (ages 15 and 17 - both 
students). Never receiving any type of organized education, he is unfamiliar with both Dzongkha and English, and speaks Kurtoep and Chocangacakha. ND's house falls within the wireless antenna's "line-of-sight" and is therefore equipped with a fixed telephone handset. He is very enthusiastic about the types of opportunities the fixed telephone in his house has provided him and his family. He perceives calls within Tangmachu, which are free of cost, as a means to reduce the time and energy required to communicate for the purposes of emergency, information inquiry, knowledge exchange, business transactions, and social affairs. The last call ND received prior to the interview was from his brotherin-law living in Thimphu. ${ }^{89}$ They spoke for approximately 10 -minutes in Kurtoep.

In addition to calling family members living outside of Tangmachu, ND also makes periodic calls to Thimphu to place orders for his wife's medication. When asked about how he felt about the cost of calling outside the local wireless loop ${ }^{90}$, ND replied (paraphrasing):

Making a call to Thimphu once in a while from our home is far less expensive than traveling there ourselves, and much more reliable than if we sent someone to place the order for us. This way, we can continue working on the farm and be sure that the proper order has been placed in Thimphu ... and ... fixed phones help us stay in touch with our family members outside Tangmachu.

According to ND, the perceived value of the fixed telephone, as a vital connection to his kin and others living in Tangmachu and across Bhutan, supersedes the associated monetary cost. Moreover, he perceives the telephone as a tool to save time, energy and money, which subsequently increases farming efficiency, productivity, crop yield, and general well being of household members. One of ND's comments about the fixed

\footnotetext{
${ }^{89}$ It should be noted that ND cannot read numbers and thus cannot dial numbers. He asks his children to dial on his behalf when he makes a phone call.

${ }^{90}$ Calling among the 78 telephones connected via the local wireless loop is free (no monetary cost); however when calling outside this loop, individuals are charged according to Bhutan Telecom rates.
} 
telephone effectively summarizes his perceptions; he indicated it was difficult to imagine his life before there was a fixed telephone in his home (even though it was only 6 months prior to my visit).

Other respondents in Tangmachu mentioned a myriad purposes and benefits fixed telephones brought to them. One woman commented on the transformatory effect the telephone has had on her life. She states (paraphrasing):

My home and farm are far away from other houses ... my husband works in Memji [a neighbouring geog] and only comes home every second weekend ... The telephone in my house helps me stay in touch with my friends and learn about news in Tangmachu ... it is free so I can use it as much as I like (RD Female: 55).

RD's case is not uncommon in Tangmachu, where previously large extended families are gradually becoming smaller due primarily to increases in rural-urban migration. Thus, perceptions of fixed telephone use in Tangmachu covered several purposes, including emergency situations, information gathering and exchange, and as a general interlocutor among people who may otherwise not have been able to communicate on a regular basis. In general, perceptions were overwhelmingly positive in nature. The only negative comment I received was when someone described the potential problems he would face if and when the telephone malfunctioned or needed repair.

\subsubsection{Perception of Mobile Telephones}

Examining the material and symbolic aspects of mobile phones provided a rich array of perceptions in Thimphu and in Tangmachu. Although there was no mobile telephony service in Tangmachu at the time of my visit, virtually everyone I came across was aware of mobile phones and expressed their keen interest to use them once B-Mobile provides service to their community. In addition to making and receiving voice calls, 
many respondents discussed their perceptions of mobile phones vis-à-vis a range of other functionalities such as text messages, 'missed calls", address books, ring tones and games.

\subsubsection{Perceptions of Mobile Phones in Thimphu}

I found it difficult to walk through the streets of Thimphu without encountering people with mobile phones pressed against their ears or furiously tapping out text messages with their thumbs. Encompassing a wide cross-section of society, these individuals included taxi drivers, private business owners, civil servants, expatriates, tour operators, housewives, and school children. The high level of mobile telephone usage is apparent as most stores in Thimphu advertise the sale of B-Mobile pre-paid vouchers, which are used to add credit on mobile telephones.

In earlier discussions about different ICTs in Thimphu, LD (Female: 24) commented on the heightened visibility of mobile phones and mobile phone use in relation to the Internet and fixed telephones. LD's perception of mobile phones was overwhelmingly positive. She commented on its ability to make her feel flexible, free, and confident - as a woman, wife, daughter, mother and friend. She conveyed her perception of mobile phones as a form of empowerment, as it allowed her to overcome several challenges and inconveniences. These include: leveraging limited leisure time and disposable income to communicate with her kin and friends in different parts of the country; providing the flexibility to send and receive voice calls and missed calls in a

\footnotetext{
91 "Missed calls" (also knows as "beeping" or "flashing") occurs when a caller dials but hangs up before the call is connected. This type of communication does not incur cost to either calling or receiving party. In addition to cost savings, missed calls allow for discreet exchanges and could sometimes be used as a code language between the sender and recipient. A system can be devised to use sequential or sporadic beeping to communicate simple messages.
} 
private or public setting; having the choice to accept and return calls selectively; and providing a sense of safety in times of emergency or loneliness.

According to LD, her ability to use mobile phones gives her confidence because she is able to use the same technological tools that are used by other men and women with more formal education and/or income. She said (paraphrased):

I think mobile phones can be used by anyone in Bhutan. ... You don't need to have a lot of money and you don't need to know English. ... If I run out of credit on my phone, I use 'missed calls', which don't cost anything at all (LD Female: 24).

LD's comments imply mobile telephone users cut across individuals belonging to various societal groups. However, she mentioned the relative lack of elderly women or men using mobiles, which points to age as a limiting factor in mobile phone use - more so than education, income or sex.

G (Male: 28) is a salesman at a convenience store in Thimphu. He migrated from the eastern district of Trashi Yangste when he was 14 years old. He has three years of formal education, and is able to speak Dzongkha and write and read at a basic level. G's preferred spoken language is Sharchopkha, followed by Dzongkha, Hindi and Nepali. He lives in a rented room above the store he works at and has cost-free access to a fixed telephone inside the store. Despite this, G makes limited use of the phone because he does not want to be perceived as abusing this privilege, and more importantly, feels he has limited privacy when making or receiving phone calls at the store. Therefore, $\mathrm{G}$ uses his mobile phone to send and receive voice calls and missed calls within Thimphu and to his family members and friends living in Trashi Yangste.

$\mathrm{G}$ discussed his perception of the mobile phone as an extension of himself. Despite having to replace his mobile phone three times in the past two years (losing one 
and having two others stolen $)^{92}$, he continues to seek out the most recent models. He explains this desire to own state-of-the-art mobile handsets in Thimphu because people tend to associate mobile phones with the individuals who use them. As such, he feels it is important for him to keep up with the latest trends and thus uphold a certain perceived social status. During the interview, G spent several minutes proudly demonstrating the features of his mobile phone to me. He strongly associates his personal identity with his mobile phone, stating (paraphrasing):

My mobile phone has all my personal phone numbers and my favourite songs and photos. My phone is like a part of me ... it can show people what type of person I am (G).

When asked about his perception of mobile telephone users, G, like LD, alluded to limited differences between different users. He did, however, indicate that text messaging - which is cheaper than voice calls - is limited to those who are able to write and read in English. However, G quickly pointed out that 'missed calls' which have a limited literacy requirement (mostly recognition of some letters and numbers) is accessible by everyone and is even more economical when compared to text messages.

Both $\mathrm{LD}$ and $\mathrm{G}$ perceive mobile phones as transformative tools that are predominantly positive in their effects on individuals and society. However, everyone I spoke to did not share this perception. KO (Female: 40) shared her perception of the mobile phone as one that is comprised of both positive and negative elements. As someone with physical and social access to several ICTs for many years, KO used fixed telephones, computers, the Internet, television and mobile phones on a regular basis. She had been using mobile telephones during her studies in Japan (in 2001), which preceded

\footnotetext{
${ }^{92}$ Mobile phone theft is increasingly common in Thimphu. I saw a number of news stories on television and articles in the newspaper discussing this growing trend.
} 
the official introduction of mobile telephones in Bhutan. KO commented on a range of advantages associated with mobile telephone use - such as strengthening social networks, increasing incomes, enabling communications in times of emergency, etc. However, she also pointed to a number of perceived drawbacks such as safety hazards and diminishing social interaction. With the steady increase in cars on Bhutanese roads and the absence of traffic lights throughout the country, KO discussed the increase in traffic accidents due to irresponsible use of mobile telephones while driving. She expressed her concern about the safety of pedestrians and of other drivers. Moreover, she discussed her perception that mobile phones can lead to diminished social interaction, as more and more people are talking on their mobile phone, sending or receiving text messages, playing games, looking at photos, or using a range of other features commonly found on different mobile phones across Thimphu, to the detriment of traditional face-to-face social interaction.

In general, people in Thimphu seem to perceive mobile telephones as accessible to different classes, ethnicities, genders and generation in society. Differences in perceived usage among age groups surfaced as the most common distinction between users and non-users of mobile phones. Some indicated elderly men and women living in the cities tend to live a relatively sedentary life and thus do not need to use mobile phones very much in relation to younger Bhutanese who tend to be more mobile.

\subsubsection{Perceptions of Mobile Phones in Tangmachu}

Examining perceptions of mobile telephones in Tangmachu was interesting as it was an ICT that was not yet operational in the community. While some, like ND (Male: 57) had never used a mobile phone but heard of them through family members in Thimphu, others like W (Male: 32), a former a taxi driver in Thimphu, and KY (Female: 
26), whose husband migrates back and forth every six months from Dagana equipped with his own mobile phone, have varying degrees of direct or indirect exposure to mobile telephones. In addition, the high visibility of mobile telephones in Tangmachu (regardless of the ability to use them) seemed to raise awareness levels and curiosity. My colleagues from DIT and I each had our own mobile phone with us during our visit to Tangmachu. Several individuals asked to see my mobile phone. Initially I thought they wished to see it because mobile phones were not commonly seen in Tangmachu; however, I eventually realized they were mentally comparing my phone to other phones they had seen before. Thus the perceptions associated with mobile telephones seem to have preceded the provision of service; moreover the appearance and functionality of mobile phones seem to attract considerable and sustained attention.

ND (Male: 57) is a farmer who has not left Tangmachu in nearly 10 years. When asked about the Internet, he was completely unaware of its existence. This is despite living within a 30-minute walk from the CIC and periodically visiting it to pay his phone bills. However, when asked about mobile phones, ND conveyed his awareness and keen interest to use it. He learned about mobile telephones through word-of-mouth in Tangmachu, and more specifically through his brother-in-law in Thimphu. This contributes to a counter-intuitive situation, whereby ND is aware and interested in mobile phones, which are currently unavailable in Tangmachu, yet unaware of the Internet and computers, which are available at the CIC that he periodically visits.

A number of other respondents in Tangmachu indicated their perception of mobile phones as a new and innovative tool that could lead to a range of benefits. One farmer (TD Female: 27) discussed her desire to use mobile phones because she worries 
her elderly mother will not be able to contact her while she is working in the fields. TD thinks a mobile phone would be very useful for farmers who work in the field all day, often far away from any fixed telephone. She specifically mentioned the term 'missed call' - something she learned about from her brother who lives in Thimphu (paraphrasing):

I don't know how much mobile phones will cost, but my mother and children can always send me a 'missed call' to let me know they are alright.

Several other individuals mentioned speaking with family members or friends who use mobile phones and indicated their excitement to use mobile phones when B-Mobile offers services to Tangmachu.

\subsection{Gendered Use of ICTs in Tangmachu and Thimphu}

Building on the discussion about ICT perceptions at the two data collection sites, this section presents findings that relate to actual usage of each of the ICTs occurring within a three-month span prior to the interview. The following pages discuss actual usage patterns, desired levels of use, purpose(s) of use, frequency of use, and perceived or actual challenges for use. The focus is not meant to swing back to examining overarching perceptions, but rather to unpack some of the usage statistics and contextualize them within the rationale for use/non-use, as well as the range of other issues that accompany different types of access physical access (time, proximity, mobility, income) and social access (incentive, linguistic diversity, and cultural and gender norms). Given the high degree of complementary use between mobile phones and fixed phones in Thimphu, this section is divided into two rather than three broad sections: the first examines Internet use at the two sites, and the second examines telephony use - fixed and mobile in Thimphu and only fixed in Tangmachu. 


\subsubsection{Use of the Internet}

According to Hafkin and Taggart (2001: 27), basic literacy and numeracy is required to read and compose simple messages, navigate the Internet, and execute commands in most software applications. Bhutan is home to a plethora of languages; however only English and Dzongkha have written scripts associated with them. After spending time in Thimphu and Tangmachu, I recognized the relative geographic centralization of both English and Dzongkha in western Bhutan. ${ }^{93}$ Most individuals I encountered at both sites spoke multiple languages - among which English and/or Dzongkha were often absent. Although a process to localize computer fonts in Dzongkha is gradually developing the capacity to generate online content, it was still in its early stages at the time of this study. ${ }^{94}$ Moreover, there is considerable confusion among native Dzongkha speakers with regards to how it is written and read (Gyatsho 2004: 274). The close relationship between literacy and Internet content influenced my joint analysis of linguistic capacity and overall Internet usage levels.

In Tangmachu, eight of the fifteen respondents spoke only Kurtoep and Chocangacakha; five spoke Dzongkha, among which three could read and write at a comfortable level; and three could read, write and speak English. There was a relatively wider linguistic array in Thimphu. With the exception of one respondent who spoke only Nepali, all other respondents spoke a minimum of three languages - Sharcopkha, Nepali, Dzongkha, English, Kurteop, Bumthapkha and/or Hindi. Nine of the fifteen respondents

\footnotetext{
${ }^{93}$ Dzongkha is native to eight out of twenty districts in the country (all located in western Bhutan). However, there are some exceptions when it comes to Dzongkha and English speakers in eastern Bhutan. Sherubtse College is located in the small town of Kanglung in Trashigang dzonghag in eastern Bhutan. As an intellectual hub, Dzongkha and English are spoken widely in and around the college campus.

${ }^{94}$ It should be noted that web pages were available in Dzongkha prior to the launch of PAN localization in 2003 (PAN Localization is a multi-country project that supports localization of Asian language fonts). However, the pages were comprised of scanned images that would take a relatively long time to load and were not possible to edit or search on.
} 
in Thimphu were fluent in English (reading, writing and speaking) and 14 were proficient in Dzongkha. When asked about the language of preference to use the Internet, all individuals I spoke to preferred English to Dzongkha (even those who spoke Dzongkha as a mother tongue $)^{95}$

\subsubsection{Internet Use in Thimphu}

Internet usage in Thimphu was found to be relatively stratified and limited to the educated, English-speaking elite. Respondents who had liberal access to the Internet at work indicated they were generally satisfied with their usage levels and thus did not feel a strong urge to use the Internet outside of work hours. Several comments were made about the exorbitant expenses that can accrue upon frequent and/or lengthy visits to an Internet café; however, most found cost to be a secondary or tertiary deterrent to Internet use.

DL (Female: 23) is a recent graduate of business administration looking for employment. The closest Internet access point from her home is approximately a 15minute drive away. At the time of the interview, she used the Internet (in English) 1-5 times a month. Although DL does not enjoy sustained cost-free Internet access, she occasionally visits a friend with Internet access at her home or uses the Internet connection at her sister's government office building. However, the majority of her Internet use takes place at Internet cafés located in downtown Thimphu. The main purposes of DL's use of the Internet include reading and responding to emails, engaging in chat sessions with friends and family (her mother lives in Australia), reading about

\footnotetext{
${ }^{95}$ This is consistent with findings from Gyatsho (2004). Approximately $28 \%$ of Bhutanese are native Dzongkha speakers, $60 \%$ can read and speak basic Dzongkha, $20 \%$ can read, write and speak it fluently, and 5\% can do so at a professional level. (Gyatsho 2004: 274).
} 
national and international news, and keeping up with other things such as Bhutan's cultural scene, horoscopes, photos and gossip. According to DL, most of her friends (some male, but mostly female) visit Kuzoo.net ${ }^{96}$ to keep up with stories about Bhutan's royal family, upcoming festivals, popular photos and other social activities. She feels that this web site and others like it will gradually draw in more and more Internet users concentrated among the educated youth. Although cost is a slight deterrent for DL's Internet use (she currently spends less than $3 \%$ of the household income on Internet access), physical proximity to Internet access points is the chief limiting factor.

SW (Male: 23) is a shop owner - originally from Trashi Yangste - who moved to Thimphu over 10 years ago. He has 12 years of formal education and is able to read, write and speak English and Dzongkha fluently. Accessing the Internet 1-5 times per month at an Internet café within a 10-minute walk of his store, SW spends approximately $3 \%$ of his monthly income on Internet services. For him, it is not the cost of access that is a chief deterrent, but more so setting aside the necessary time away from his shop, his family, and other responsibilities to travel to and from the Internet café, wait for a computer to become free, and then use it. He indicated that his usage would increase substantially (under the same costing system) if he had access closer to his home and did not need to wait in a queue to use it. Both DL and SW have the necessary elements of social access to use the Internet, but seem to lack adequate physical access - notably time, proximity and mobility.

\footnotetext{
${ }^{96}$ Kuzoo.net (http://www.kuzoo.net/) is a popular social networking web site that many Bhutanese (especially youth) frequent. 'Kuzoo' is a clever take on kuzu zangpo, which means 'hello' in Dzongkha. The site is currently only offered in English.
} 


\subsubsection{Internet Use in Tangmachu}

An examination of the Internet usage $\log$ at the CIC for the month of September 2006 revealed that all users were male. ${ }^{97}$ Among the 64 recorded male users, most were concentrated among six or seven individuals, including teachers, BHU (Basic Health Unit) employees, and the local ranger. These individuals are all formally educated and most are originally from urban parts of Bhutan or from India. SM (Male: 31 ) is a middle school teacher who often uses the Internet at the CIC to develop lesson plans, type and print tests and exams, and stay in touch with his family in Kerala, South India. When I asked SM to explain the most valuable use of the Internet, he indicated it was Internet telephony to call his family and friends living predominantly in southern India, stating:

The cost of making and receiving international calls over Internet telephony is much cheaper than calling from the fixed telephone system. I pay the cost of Internet access and the sound quality is very clear.

When I asked about his students, SM expressed his assessment of a healthy amount of curiosity in learning about using the Internet; however he found that most of them (especially girls) are generally responsible for household chores and thus lack the necessary time and mobility to visit the CIC.

There is a nominal cost of 30 Ngultrum $(\sim 0.70 \text { USD })^{98}$ per hour to use the Internet at the CIC in Tangmachu. Intended as a source of financial sustainability, I personally found 30 $\mathrm{Nu}$ per hour to be rather high - especially in a community where many individuals earn less

\footnotetext{
${ }^{97}$ Although there were no female users noted in the log, the CIC administrator is female and often uses the Internet. Moreover, I witnessed several occasions when Pema's friends would visit her on their way home from school and use the computers and the Internet if they were idle. This indicates a number of 'unaccounted' Internet users in Tangmachu. Pema does not charge her friends the $30 \mathrm{Nu}$. ( 0.70 USD)/hour fee. Most of these individuals use the Internet in a group, huddling around a single machine and chatting or surfing (mostly the former) as a group.

${ }_{98}$ The Bhutanese Ngultrum is pegged to the Indian Rupee, which is currently valued at approximately 44 INR for 1 USD.
} 
than 500 Ngultrum a month (less than 15 USD). Such a pricing structure may exacerbate existing feelings that Internet access and use is limited to the educated elite in Tangmachu. However, as mentioned earlier in this chapter, there are instances when individuals use the Internet at the CIC free of cost. Moreover, there seemed to be some general confusion about the Internet costing scheme among different people I spoke to in Tangmachu. Many thought Internet use at the CIC was free of cost. This conflation of business models arose due to the cost-free nature of telephone calls within Tangmachu, which was part of the same CIC project. This misplaced assumption clearly indicates the limited influence of cost in relation to actual Internet use. It reveals elements of physical access to influence usage patterns only if adequate social access exists.

\subsubsection{Fixed Telephone \& Mobile Telephone Use}

Although fixed telephones and mobile telephones have several differences in the way they are used, they share some key overlapping functionality - notably sending and receiving voice calls. At the time of this study, many people in Thimphu were using both fixed telephones and mobile telephones, sometimes as complements and other times as substitutes for one another. Given the strong relationship between these two ICTs and their different positions on social and technological continua in Thimphu, they are discussed in conjunction with one another. In Tangmachu, although many know of mobile phones, the absence of mobile service provision at the time of the study precludes its discussion in this section. As such, the portion of text examining telephony usage in Tangmachu focuses strictly on fixed telephones. 


\subsubsection{Fixed \& Mobile Telephone Usage in Thimphu}

Bhutan Telecom has divided the 20 dzongkhags (districts) in the country into eight calling areas. ${ }^{99}$ The costing structure for calls on fixed telephones depends on when a call is placed, ${ }^{100}$ if the call is being made to a fixed telephone or a mobile telephone, and the location of sender and receiver (e.g. if they are both within the same dzongkhag, within the same area, or between different areas). For example, local calls or intra-area calls are cheaper than inter-area calls; calls made during off-peak hours are cheaper than those made during peak hours; and calls made to mobile phones are cheaper than those made to other fixed phones. In comparison, the pricing structure for mobile phones in Bhutan is very simple: a fixed charge of $5 \mathrm{Nu}$ /minute applies when placing a call to any mobile phone in Bhutan.

Twelve of fifteen respondents in Thimphu had physical access to fixed telephones within their respective households at the time of the interview, and the remaining three respondents had access to one within 10 minutes of their home. In the case of mobile phones, 13 of 15 respondents owned a mobile phone, while the remaining two had access to a shared mobile phone. Many people I talked to about mobile phone usage and fixed phone usage pointed to the advantages mobile phones have in terms of mobility, affordability and convenience. Given Bhutan's growing rural-urban migration trends, many people make frequent calls to kin and friends located in other parts of the country.

\footnotetext{
99 Area 1: Thimphu; Area 2: Trongsa, Bumthang, Zhemgang; Area 3: Lhuntse, Trashi Yangste, Mongar, Trashigang; Area 4; Pema Gatshel, Samdrup Jongkhar; Area 5: Dagana, Tsirang, Sarpang; Area 6: Samtse; Area 7: Haa, Paro, Chhukha; Area 8: Gasa, Punakha, Wangdue Phodrang.

${ }^{100}$ The entire country falls under a single time zone. Peak hours are between 9:00-18:00 and off-peak are between 18:00-9:00. Bhutan operates under a CPP (Calling Party Pays) system.
} 
LD (Female: 24) uses her mobile phone to send and receive voice calls and missed calls on a regular basis. In a typical month, she recalls receiving $26-50$ voice calls and over 50 missed calls. In the same time period, she sends approximately $16-25$ voice calls and over 50 missed calls. ${ }^{101}$ She never sends text messages and rarely receives them. If she does receive text messages, $\mathrm{LD}$ generally asks literate individuals at her workplace to read the message to her - most are unsolicited advertisements. ${ }^{102}$ Many of the calls LD makes on fixed telephones at her workplace consists of calls being returned after initially receiving them on her mobile phone. She, like nearly all mobile phone users I encountered in Bhutan, uses pre-paid vouchers. This type of credit system does not discriminate against individuals based on their credit history. She contends her use of mobile phones has in many ways displaced fixed phones. Prior to owning her mobile phone, LD remembers visiting a public telephone booth to make phone calls in the evenings or on the weekend. However, the booth was over an hour's walk away from her home, and as a result was inconvenient to use. In general LD feels the cost of mobile phones is well worth the flexibility, convenience and freedom they bring, stating (paraphrasing):

I cannot take a fixed line with me everywhere I go - back and forth from work, while doing my chores or going out in the evening - but I can have my mobile with me. ... My mobile is useful to me even without credit ... I can use missed calls and use other things on it too, such as games and music.

\footnotetext{
${ }^{101}$ A range of responses accompanied all questions pertaining to monthly usage of ICTs. These include: i) None; 1-5 times a month; 6-15 times a month; 16-25 times a month; 26-50 times a month; and More than 50 times a month.

${ }^{102}$ The issue of unsolicited advertisements (a.k.a. SPAM) was discussed a great deal during my stay in Bhutan. An article in the Bhutan Times titled "SMS advertisements to be stopped" (October 1, 2006) discussed the policy to stop unsolicited mobile advertisements as of December 31, 2006 because they intrude on people's privacy and exacerbate issues of mobile network congestion.
} 
LD does not generally share her handset or credit with others. She indicated most of her friends had their own mobile phone; however, in times of emergency it was not uncommon for individuals to share their handsets or credit with one another. Most mobile telephone users I spoke to indicated limited sharing of handsets and credit among users.

Many in Thimphu described their decision to substitute mobile telephones for fixed telephones because of the higher return on investment. They felt as though the overhead costs and static state of fixed line phones did not compare favourably against the pre-paid, flexible and portable nature of mobile phones. When examined in conjunction with the cost-free 'missed calls' phenomenon and the single calling zone, the perceived value of mobile phones was generally found to exceed their monetary cost of use. ${ }^{103}$ Missed calls were found to be extremely popular and cost-effective ways to use mobile phones. Many parents equip their children with mobile phones and have them send missed calls to notify them through a predefined sequence or code. For example, a single missed call could imply a child is leaving home and a double missed call could imply the child has reached home safely. By utilizing such means, individuals are able to communicate with one another in real-time without paying a single Ngultrum.

Fixed telephone and mobile telephone use in Thimphu were found to be prevalent among users from different income brackets and educational backgrounds; however, most lower-income and less-formally educated respondents seemed to substitute a mobile phone for fixed line phones, while other users with more disposable income seem to use both mobile phones and fixed phones. Mobile phones have become so popular that the

\footnotetext{
${ }^{103}$ The cost of sending a text message within Bhutan is Nu $2 /$ message, a voice call costs between 4-5 $\mathrm{Nu} /$ minute, and a missed call is free of charge.
} 
cellular network in Thimphu and other large cities in Bhutan are regularly clogged between 5 PM and 9 PM on weeknights and periodically throughout the weekends. ${ }^{104}$

\subsubsection{Fixed Telephone Usage in Tangmachu}

Before the CIC was established and operationalized, individuals living in Tangmachu were forced to walk for several hours or days (one way) to use a telephone in neighbouring Lhuntse town. Such a journey was generally reserved for able-bodied men who could afford to take a leave from intra- and extra-household responsibilities for a sufficiently lengthy stretch of time. The majority of people I spoke to in Tangmachu both women and men - confirmed the distance between their homes and Lhuntse limited telephone use for most women. Since the CIC formally began offering fixed telephone service, virtually all of the respondents and other individuals I spoke to during my stay in Tangmachu either had fixed telephones installed in their home (i.e. their homes are among the 78 households that fall within 'line of sight' of the WiFi antenna) or had access to a fixed telephone within a 15-minute walk.

All calls made within the wireless loop are free of cost to both calling party and receiving party. The call log for the month of September indicates a steady flow of calls made outside of Tangmachu. These calls, made mostly to family members living in other parts of Bhutan (with average call times of about 10 minutes), ${ }^{105}$ are charged according to Bhutan Telecom rates. When I asked about the high cost associated with making such long distance phone calls, most respondents - like ND - argued that such a question does not factor in the immense savings gained by avoiding time-, labour- and cost-intensive

\footnotetext{
${ }^{104}$ According to a B-Mobile general manager, cellular network clogging during peak hours in Thimphu is about 50 percent - meaning the probability to get a connection was one in every two calls (Kuensel, November 2, 2006).

${ }^{105}$ This calculation was done using precise figures from the CIC call log.
} 
trips. Moreover, the emotional benefit of being able to speak to family and friends held far more value than the monetary sacrifices.

TD is a 27-year old woman who is the primary income earner for her household. Divorced from her husband 11 years ago, TD lives with her 70-year old mother and two children. She received one year of non-formal education and is able to read some Dzongkha and recognize numbers. TD has two brothers who have migrated to urban centres - one to Thimphu and the other to Trashi Yangste. When her mother needs to make a phone call, TD dials the number on her behalf. The telephone in her house is used to contact others in Tangmachu, but mostly to receive telephone calls from her brothers living in other parts of Bhutan. Therefore, TD's social network was found to play an influential role in dictating the nature and frequency of fixed telephone use.

\subsection{Conclusion}

Data analysis presented in this chapter examined diverse perceptions and usage patterns related to the Internet, fixed telephones and mobile telephones among selected women and men in Thimphu and Tangmachu. Expanding the scope of analysis to include perceptions of ICTs - regardless of prior exposure or use - provided an opportunity to examine elements of social access as well as physical access. In addition to examining this analysis in relation to the thesis assertions, the following chapter identifies and discusses any additional noteworthy observations or findings that surfaced over the course of the study. 


\section{CHAPTER 6: SUMMARY AND CONCLUSIONS}

Examining the perceptions and use of fixed telephones, mobile telephones and the Internet in Thimphu and Tangmachu reveals several interesting findings about gender relations and ICTs. This concluding chapter synthesizes the analysis conducted thus far and identifies additional areas for further investigation. The first section revisits the scope, objective, and limitations of the study; the second and third sections present findings related to perceptions and use of ICTs respectively; the fourth section situates these findings vis-à-vis the stated assertions; and the final section expands the areas flagged for further investigation and provides recommendations on how these can be addressed in future research on gender and ICTs.

\subsection{Revisiting the Scope, Objectives and Limitations}

Bhutan's gradual and measured exposure to external influences includes its introduction to information and communications technologies (ICTs). With the official introduction of national television and Internet services in 1999, and mobile telephony services in 2003, familiarization of and access to particular ICTs have occurred in a relatively incremental and controlled manner. A review of literature about ICTs and gender relations revealed a dearth of critical research interrogating the impacts of newly introduced ICTs on existing gender relations in urban or rural communities. The objective of this thesis, which is inductive in its approach, is to investigate the range of gendered perceptions and usage patterns associated with regards to interactive ICTs notably fixed telephones, the Internet and mobile telephones - and to explore if and how these interactive ICTs reinforce or challenge existing gender relations in the two selected communities. 
A comparative case study was used to analyze data collected from respondents in the rural community of Tangmachu and in the urban community of Thimphu. These individuals represent a selection rather than a sample of the respective populations in each of the communities. The research process across these two communities afforded an assortment of situations and experiences influenced by variances in natural geography, ethnic composition, language, literacy, and livelihoods. Complementing library research and previous experience working in the area of gender and ICTs in the Third World, primary data was collected over an eight-and-a-half week period using semi-structured interviews, participant observation and key informant interviews. Recognizing the assumptions and limitations of the research process, which are described in Chapter Three, subsequent analysis revealed several findings related to the perceptions and use of each ICT, as well as to the assertions articulated earlier.

\subsection{Perceptions of ICTs in Thimphu and Tangmachu: Findings}

Despite the differences (historical, geographical, political and social) that exist between the two data collection sites, in general, I found several similarities in ICT perceptions across different user groups in Thimphu and in Tangmachu. For instance, a number of respondents at both sites conveyed difficulties conceptualizing the intangible nature of the Internet and its relationship with computers. LD (Female: 24) in Thimphu provided her description of the Internet as a product that can be bought in a store (such as milk or eggs) and subsequently inserted into the computer to begin using the Internet. In Tangmachu, KD (Male: 52) communicated his perception of the Internet as an intermediate step to provide fixed telephone service to households in Tangmachu. These examples reveal how ICTs are inevitably placed within individual and community- 
specific social and technological continua. In the case of LD, who is an avid mobile telephone user, the Internet and computers are situated on a technological continuum alongside the mobile telephone - drawing an analogy between the Internet and mobile telephone vouchers, and another between computers and mobile telephones. KD's interpretation of the Internet in Tangmachu seems to be symptomatic of how fixed telephones and the Internet were simultaneously introduced in Tangmachu. Although two distinct ICTs were introduced in Tangmachu, only fixed telephones were germane to KD's social needs. As such he conceptually merged the Internet and fixed telephones into a single technological process that he positioned in relation to the context and needs extant on his own social continuum.

Others in Tangmachu expressed their confusion around the term 'Internet' because they had not seen it physically unveiled at the CIC inauguration ceremony, or any time since then. Not surprisingly, they associated a technology with something concrete and tangible. Upon reflecting on these responses, I suddenly realized the naiveté of my assumption that individuals without prior exposure to abstract networking concepts or physical hardware (such as computers) would be ready and willing to understand or use the Internet. As a middle-class Canadian researcher with over a decade of experience using Internet-enabled computers, I found myself stepping back to interpret how the Internet could be conceptually positioned in social and technological continua for different men and women in Tangmachu and Thimphu. Upon doing so, the link between new ICTs and existing technologies, as well as social contexts became extremely clear.

Individuals in Thimphu and Tangmachu who had a clearer grasp of the Internet shared considerably different perceptions. Many among this group, including CT and KO 
in Thimphu and SM in Tangmachu, have each received at least 15 years of formal education -rendering them fully literate in English. Moreover, they have regular access to affordable Internet access points, and are part of social networks that extend to other Internet users. Perceptions of the Internet among these individuals include: a tool for democratization, a means to strengthen ties in social networks, and a repository of information and knowledge. These perceptions indicate the Internet as a technology, which acts both as a source and a consequence of gender relations (Wajcman 2004: 107). SM, CT and KO's early Internet adopter status was made possible by their existing gender identity, as relatively young, literate and privileged members of their respective communities. This indicates that the resulting confident and skilful use of the Internet is due in part to their gender relations prior to using a particular ICT. Continued use of the Internet has subsequently moulded their respective gender relations and allowed them to retain a privileged position in a society where Internet use is not yet commonplace. When juxtaposing the perceptions provided by $\mathrm{KO}, \mathrm{SM}$ and $\mathrm{CT}$ with those provided by LD and $\mathrm{KD}$, it becomes apparent that Internet technologies are stratified among the formally educated, English-speaking elite in both Thimphu and Tangmachu.

Internet user profiles were generally perceived to comprise young individuals who are formally educated, working in an area that requires Internet use, and predominantly male. The CIC administrator, Pema, provided an interesting response when asked about her perception of typical Internet users in Tangmachu. Conveying a user profile that matched the official CIC Internet user log (e.g. male teachers and health workers), Pema's perception omitted other users such as her friends who visited the CIC to use the Internet on their way home from school. She indicated her perception of Internet use to 
entail some sort of official business and thus dismissed other use as 'playing around'. Interestingly, Pema's definition of a bona fide Internet user also excludes much of her own Internet use; she only accounts for the time she spends on official CIC business matters. It is difficult to ascertain whether this perception is a result of paid versus unpaid use, male versus female use, older versus younger users, or a combination of the above. Regardless, it is apparent that there are different kinds of users and non-users (Warschauer 2004; Cisler 2000) and that Pema's perception is stratified along several predefined characteristics. This portends some incongruence with regards to the material and symbolic elements of bona fide Internet use - as material use is not always deemed as symbolically significant.

Awareness of mobile phones in Tangmachu seemed to be prevalent across men and women of diverse gender identities. Relative to the Internet, which was referred to by some as a 'serious' and 'official' tool, the mobile telephone was perceived as a technology that is relatively accessible, affordable and relevant across different societal groups. Several individuals remarked about the privacy, freedom and flexibility they felt mobile phones provided. Moreover, several indicated a minimal degree of difference in use among women and men from diverse educational, ethnic, cultural and economic backgrounds. However, some pointed to a dip in perceived usage levels among elderly individuals in Thimphu.

Discussions about mobile telephone uncovered a wealth of different material and symbolic aspects of its relationship with gender. Unlike other developing countries where sharing mobile telephones is a relatively common practice (Lopez 2000; Konkka 2003), individuals in Thimphu from various economic and social groups indicated limited 
sharing of mobile handsets or credit. Differences in material and symbolic use of the different interactive ICTs were discussed by LD (Female: 24). She pointed to the visibility of mobile phones as a key difference setting it apart from the other two ICTs examined in this study. This visibility seems to hold both material benefits, as some people discuss their preference for new mobile phone models (including colours, shape, and size of screen etc), ${ }^{106}$ as well as symbolic benefits (including perceived status, safety, and confidence). In general perceptions of mobile telephones seem to point to its role as a democratizing and transformative tool, which is transcending different social hierarchies. Such perceptions are closely tied with physical and social accessibility and usage patterns in a given community.

\subsection{Use of ICTs in Thimphu and Tangmachu: Findings}

Analysis of ICT usage patterns across individuals in Thimphu and Tangmachu revealed the combined role of physical access and social access in determining use. As such, this section considers factors that span across both - including cost of access, proximity, literacy, incentive, and relevant content. Literacy was repeatedly discussed as a challenge for individuals to access certain ICTs - particularly knowledge of English to use the Internet. The Internet is used predominantly as a text-intensive technology, fixed telephones as voice-intensive, and mobile telephones as voice-intensive, text-intensive, or a combination of the two modes. ${ }^{107}$

Fixed telephone usage generally requires limited literacy, as it focuses primarily on recognizing numbers from 0 to 9 . On the other hand, using mobile telephones and the

\footnotetext{
${ }^{106}$ A study by Sadie Plant (2000) discusses, among other things, gendered aspects of displaying mobile telephones in public.

${ }^{107}$ Missed calls generally include some kind of aural indication and the name or phone number of the sender. Most of these calls are returned via voice calls, while some are returned via text message.
} 
Internet can require varying levels of literacy. However, where literacy seemed to be an insurmountable obstacle for Internet use, many respondents explained how they managed to use fixed telephones and mobile telephones despite their inability to read or write. In Tangmachu, ND (Male: 57) and S (Female: 70) are illiterate, but are able to use fixed telephones because they ask their respective children to dial the numbers on their behalf. Similarly, when LD (Female: 24) receives text messages on her mobile phone in Thimphu, she asks others to read them out to her. These findings point to innovative means to bypass literacy constraints through existing social networks and social networking, and also indicate a need to examine the issue of text- versus voice-intensive ICTs within the context of different economic, cultural and social incentives or disincentives.

Proximity to different ICTs was another issue that seemed to emerge as usage data was analyzed across the two data collection sites. For example, ND (Male: 57) has made numerous visits to the CIC in Tangmachu yet is unaware of computers and the Internet. Although he has probably seen computers and people using the Internet inside the CIC, the irrelevance of such technologies to his social needs and interests (as a subsistence farmer) seem to negate their proximity and physical accessibility. However, in other cases, such as SW (Male: 23) and DL (Female: 23) in Thimphu - both are literate English speakers - proximity plays a significant role in influencing use. These cases allude to the varying degree of influence and incentive physical and social access can have on a specific individual's ICT use. In examining the two types of access, ND had relatively limited social access, whereas SW and DL had sufficient social access, yet lacked adequate physical access. 
Monetary requirements to use the Internet, fixed telephones and mobile telephones were generally found to play a minimal role in determining use. In the case of some individuals, usage fees were found to play no role at all. For example, a number of respondents in Tangmachu were under the impression that Internet use at the CIC to be free of charge. I later realized this misunderstanding was a result of the cost-free pricing scheme that was used for telephone calls within Tangmachu. As is obvious from the confusion about usage fees, many of the people I spoke to in Tangmachu had never actually used the Internet services at the CIC because they lacked social access including other users within their respective social networks. However, despite scant and concentrated usage of the Internet in Tangmachu, the CIC call logs paint an entirely different picture for telephone usage. In addition to copious calling amongst telephones within the local wireless loop, I was surprised to see the significant number of calls placed to telephones outside of Tangmachu. These calls are charged according to Bhutan Telecom rates and are not subsidized in any way by the CIC. However, the issue of cost seemed to be secondary or tertiary considerations for most individuals in Tangmachu, as many of them had kin living temporarily or permanently away from home. For example, according to ND, the cost of calls made outside the Tangmachu local wireless loop pay great dividends in relation to their cost - they allow his household to retain contact with those who have migrated from Tangmachu, to respond to household medical needs, and as a result, to increase productivity levels at the farm.

\subsection{Thesis Assertions: Findings}

A review of works discussing gender and technology raised a number of assertions that were subsequently used to shape the study's conceptual design. These 
include the mutual shaping of gender relations and ICTs; the existence of material and symbolic features of gender and ICTs; and the situation of different ICTs within individual and community-specific social and technological continua. Although the study is inductive in nature, these assertions helped narrow the scope of the research and framework for analysis. The purpose of this section is not to provide in-depth analysis, reflection and discussion of data, but rather to concisely consolidate key findings as they relate to each of the three assertions.

\subsubsection{Mutual Shaping of Gender and ICTs}

Characterizing the mutual shaping of gender and technology as their co-influence, co-production and co-dependence, Wajcman (2004: 107) argues technology is "both a source and a consequence of gender relations". Findings from this comparative case study indicate the variable role existing gender relations can play in defining perceptions and use of ICTs - depending on the nature of the ICT, its dominant uses, as well as the nature of use. For example, the mutual shaping of gender and the Internet was generally found to reinforce existing gender relations, whereas fixed telephones in Tangmachu and mobile telephones in Thimphu were both found to challenge some of these gender constructions and norms.

The dominant group of Internet users across the two sites comprised Englishspeaking individuals with several years of formal education, the economic means to access the Internet, and engaged in livelihoods that afforded regular opportunities to use the Internet. Moreover, these individuals were generally part of the limited cadre of people in their respective communities who were able to conceptualize the nature of the Internet, as well as its purpose and functionality. As a result, the capacity to use the 
Internet seemed to be influenced by existing gender relations, which in turn shaped gender relations on an ongoing basis by situating these individuals in a privileged socioeconomic position. For instance, many of the respondents expressed their perception that most Internet users are predominantly members of the English-speaking, educated elite classes (particularly men) who work either as civil servants, teachers, or other jobs that require interaction with computers and the Internet.

Considering the mutual shaping of relationships between gender and technology with respect to mobile and fixed telephones demonstrated incidents where existing gender constructs and relationships were challenged in some way. While gender relations existing prior to the introduction of the Internet were found to play a prevailing role in determining its perception and use, this was less so the case for the recently introduced fixed telephone in Tangmachu and the mobile telephone in Thimphu. Prior to the opening of the Community Information Centre (CIC) in May 2006, people in Tangmachu needed to travel for hours or days - one way - to access telephones in neighbouring city of Lhuntse. These trips were predominantly made by able-bodied men who could afford being away from their households for long stretches of time. As a result, women in Tangmachu seldom had direct exposure to telephones and were generally dependent on their male kin to make and receive telephone calls. This gender disparity in fixed telephone use has decreased considerably since the installation of 78 fixed telephones within households and businesses in Tangmachu in May 2006. Some previously isolated individuals - mostly women of all ages and elderly men - conveyed the role of fixed telephones in heightening their sense of empowerment and security (emotional, physical and financial). 
In Thimphu, many women and men indicated the mobile telephone as an ICT that is affordable, accessible and relevant to a wide range of men and women across class, ethnicity, and education. However, differences were found among different age groups, with older women and men using mobile phones relatively less frequently. Use of mobile telephones in Thimphu was found to shape, and often challenge, the perceived and actual social status of women and men, as well as their sense of empowerment, strength of social networks, and ability to improve livelihoods. Some respondents conveyed their heightened sense of security and independence, while others pointed to the prestige and identity they attach to their own mobile handset. The appearance and functionality of a mobile phone in private - and especially public - settings were found to play a significant role in influencing how individuals relate to others from their respective class, ethnicity and generation - as well as across these societal axes.

\subsubsection{Gender and ICTs: Material and Symbolic Significance}

Technology as a material and symbolic artefact pertaining to gender relations has been evidenced by, among other studies, Cynthia Cockburn and Susan Ormrod's (1993) account of the microwave, Sherry Turkle's (1988) assessment of female and male computer programmers, and Hans Geser (2004) and Sadie Plant's (2002) examination of the role of mobile phones in different societal contexts. As discussed in Chapter Two, findings from these studies point to the influence of technology extending beyond its material and functional purposes, to include symbolic perceptions and values. The technologies themselves can act as a conduit for social, cultural and gender norms in a given society - be it through production, marketing strategies, or through the language used to describe it or to communicate with it. In the case of this thesis, the ICTs 
examined were found to carry both material and symbolic significance for different individuals.

A number of Internet users and non-users alike described their perception of the Internet as a tool used for material purposes that are serious and related to some form of official business. Such a perception bleeds into the symbolic significance of Internet use. For example, when Internet use was limited to non-official or non-business related activities for several young female users in Tangmachu, the CIC administrator categorized this use as 'playing around' and did not consider this type of use to fit her symbolic definition of Internet user. Instead, her understanding of bona fide Internet use involves structured and official types of use by teachers, health workers etc. This finding was among several that revealed variances between different ICT users and non-users, and led to the identification of this issue for further study.

Although fixed telephones were used at both sites, their use in Tangmachu was a relatively recent occurrence; whereas in Thimphu their use often occurred in conjunction with mobile telephones. As such, many respondents in Thimphu indicated the role of fixed telephones in their lives as materially functional and relatively inconvenient when compared to mobile telephones. Moreover, symbolic aspects of fixed telephone usage seemed to be mitigated by the fact that most usage occurred indoors. The majority of fixed telephone users in Thimphu claimed to use fixed telephones predominantly at their workplace. In Tangmachu, fixed telephones are used indoors - within private homes, businesses, schools or in the CIC. As a result, material and symbolic aspects of usage was found to be contingent on the location of the telephone relative to different households, and on the mobility of different male and female household members. The ability to 
directly use fixed telephones was found to have undeniable symbolic impacts on empowerment and agency for men, and especially for women, who did not previously have the opportunity to communicate directly with others outside their immediate vicinity.

Examining mobile telephones provided an example in which the material and symbolic significance of an ICT were found to hold considerable influence on individual perceptions and behaviour. A number of mobile phone users in Thimphu insisted on having the latest models of mobile telephones, despite the increasing rate of mobile telephone theft. They explained the need to possess newer and more innovative mobile telephone handsets as tantamount to augmenting their social status. The single calling zone used for mobile phone calls, in conjunction with the spread of social networks across different districts, makes using a mobile phone for many individuals in Thimphu an economically feasible option that satisfies their material communication needs. Moreover, relative to the Internet, which is referred to symbolically by some as a 'serious' or an 'official' tool, the mobile telephone is perceived by many as a technology that is relatively accessible, affordable and relevant across different societal groups. Several individuals remarked about the privacy, freedom and flexibility they felt mobile phones provided - this was emphasized among many of the female respondents with multiple responsibilities to juggle.

\subsubsection{Social and Technological Continua}

Challenging the notion of leapfrogging over social and technological changes, the third assertion in the thesis examines how the three different interactive ICTs are situated within individual and community-specific social and technological continua. Many argue 
that leapfrogging implies bypassing 'critical junctures' such as literacy, infrastructure, institutions, and social structures, which are taken for granted in many Western contexts (Raiti 2007; Heeks 2002; Warschauer 2003; Wilson 2003). The findings from this study confirm this line of argumentation, as despite the introduction of certain interactive ICTs without prior exposure to similar technologies, individuals tend to associate them with other social and technological phenomena in their daily lives.

Some men and women in Thimphu and Tangmachu, who either had prior exposure to the Internet or computers and/or were in situations that required frequent use of the Internet, were able to situate the Internet within their social and technological continua and thus generally had more success appropriating and using it. However many others, who are among those expected to 'leapfrog', found it more challenging to conceptualize and appropriate the Internet into their respective technological and social continua. For example, when asked about the perception of the Internet, one individual in Thimphu associated it with the mobile telephone model. In this particular case, the novelty of the Internet did not lead to a leapfrogging scenario, but rather one that has fallen outside the social and technological realms of certain user groups. Similarly, in Tangmachu, where the Internet and fixed telephones were introduced simultaneously with the establishment of the CIC, there was a degree of conflation between the purpose and function of the two distinct ICTs.

Although individuals in Thimphu and Tangmachu were familiar with mobile telephones, only those in Thimphu had access to these services at the time of this study. As a result, individuals in Tangmachu placed fixed telephones in a position of relative primacy on their technological continuum, while those in Thimphu tended to situate fixed 
telephones in relation to mobile telephones. In Tangmachu fixed telephones fulfilled a social need to exchange information and knowledge that was previously left unsatisfied for many. Whereas in Thimphu, where most individuals have direct or indirect access to mobile telephony, the fixed telephone was generally found to be an inflexible and inconvenient alternative to mobile phones. Mobile telephone users in Thimphu felt as though the fixed telephone could satisfy a subset of needs on their respective social continuum, but was deficient in relation to mobile phones. These examples refute the leapfrogging hypothesis and reveal how ICTs are inevitably placed within individual and community-specific social and technological continua.

\subsection{Summary and Areas Flagged for Future Research}

The assertions derived from existing gender and technology literature provided the scaffolding for this exploratory study. A double-pronged approach examining the perceptions and use of ICTs was used to interrogate these statements and capture additional noteworthy findings. In doing so, this method was able to address an individual's perceived and actual incentive to become an ICT user and to move away from the rigid assumption that ICT use is necessarily desirable to all. In addition to the findings that confirmed the assertions, a handful of other significant findings emerged through the data analysis process.

In general, access was illustrated as both a physical and social phenomenon. More specifically, the social aspects of access (incentive, visibility, and social networks) seemed to occupy the basis of an access hierarchy; whereby without adequate social access, the influence of physical access (time, income, and proximity) was found to be negligible. For example, incentive to maintain contact with members in one's social 
network, or increase the visibility of ICT use leading to elevated social status were generally evidenced to play a greater role when compared to issues of pricing and proximity. Two particularly relevant findings were flagged for examination in future research endeavours: the mode of communication via voice- versus text-intensive ICTs, and a need to expand the two-dimensional ICT user/non-user dichotomy to more accurately portray the textured realities of users and non-users. Although both of these areas were mentioned in the literature review, they were not included among the guiding assertions. The remainder of this section elaborates on these issues and provides general suggestions on how they can be addressed in future social science research studies.

\subsubsection{Text- versus Voice-Intensity of ICTs}

The strength of social networks and social networking in Bhutan (Pain \& Pema 2000: 214) and growing rural-urban migration trends ( $R G o B$ 2006; $R G o B$ et al. 2001) contribute to the critical role of interactive ICTs in the daily lives of people living in Thimphu and in Tangmachu. The Internet is a predominantly text-intensive ICT, whereas fixed telephones are voice intensive, and mobile telephones are a combination of both voice- and text-intensive. The capacity and frequency of text-intensive or voice-intensive ICT utilization were found to depend on relevant content, accessibility, affordability and the existence of other users in one's social network. Furthermore, text-intensive ICT use required a certain level of formal education and literacy.

Respondents in Thimphu and Tangmachu possessed a diverse range of linguistic proficiency and literacy levels. Although Dzongkha is Bhutan's national language, it is not widely spoken outside of western Bhutan; moreover, it is considered to be a difficult language to read and write - even for native Dzongkha speakers (Gyatsho 2004). In 
Tangmachu, where the majority of people speak Kuertop and Chocangacakha, English and Dzongkha are rarely spoken, read or written. As such, where most Internet content and mobile text messages (i.e. text-intensive formats) are created and exchanged in English, voice-intensive ICTs such as fixed telephones and mobile voice calls are able to transcend linguistic barriers and allow individuals to use them in their language of choice - regardless of literacy levels.

In general, there seemed to be limited disparity in mobile telephone ownership between women and men from different classes or ethnicity; however the patterns and mode (voice, text or missed calls) seemed to vary across users with varying levels of literacy and income. Text messages and longer voice calls were common among those with relatively higher income and greater literacy, while missed calls and abbreviated voice calls were found to be dominant forms of communication for individuals without abundant access to income and/or sufficient literacy. The formal education and literacy requirement for text-intensive ICTs is directly impacted by the gender disparity in Bhutan's formal education landscape (RGoB 2005; Wangmo 2004). As a result, Internet use at both sites was found to be skewed toward formally educated, English-speaking men.

As discussed in Chapter Two, Snowden (2000) and Geser (2004) contend the study of ICTs in the Third World has been blinded by a focus on text-intensive tools. Snowden argues this emphasis is a result of values associated with text in economic and intellectual arenas in First World settings, which consequently overlooks relevant and effective voice-intensive ICT alternatives in developing country contexts. In a similar vein, Geser points to the wider reach of voice-intensive ICTs, such as the mobile 
telephone, in developing countries when compared to predominantly text-intensive ICTs. Findings from this study echo analogous trends, as they point to the inclusive and transformatory nature of voice-intensive ICTs across gender lines. The advent of mobile telephones in developing countries - their mobility, flexibility and multifarious use and ownership models - have paved the way for a renewed look at text versus voice transmissions via ICTs. It is recommended that future studies interrogating the relationship between gender and ICTs in the Third World avoid assigning values to text versus voice intensive ICT use before truly understanding its reach, nature and purpose.

\subsubsection{Spectra of Users and Non-Users}

A limited body of research exists on understanding different types of ICT users and non-users in developing countries. Most of the current literature is focused primarily on different types of use in developed countries such as those in Europe (Smoreda \& Thomas 2001), the U.S. (Horrigan 2006) or Canada (Middleton \& Sørensen 2005). The simplified mandate of the user/non-user dichotomy conflates positive values with users and deficient values with non-users. ${ }^{108}$ However, some researchers such as Danny Butt (2004: 71) have examined the user/non-user dichotomy in the Third World context and posed the question of why non-users should want to become a user in the first place. This line of inquiry opens a range of research questions examining an individual's choice in becoming an ICT user, rather than assuming the value-laden position that becoming a user is necessarily beneficial to all.

\footnotetext{
${ }^{108}$ Steve Cisler (2000) draws an analogy between the user/non-user binary and the $19^{\text {th }}$ century European and American missionaries who traveled to the Third World to save all the 'unconverted lost souls'. The well-intentioned expeditions in both of these scenarios points to the embedded hubris that can accompany a relatively insular approach to understanding and empowering women and men living in the Third World.
} 
Exploring users and non-users of ICTs as rich and fluid states challenges the idea of leapfrogging from a 'non-user state' to a 'user state'. Instead, examining the positions that exist between the two extremes points of the dichotomy provides a nuanced interpretation of how different individuals physically and socially access various ICTs. To address this, Cisler (2000) suggests a "spectrum of connectivity" and Warschauer (2003) proposes a "gradation of use". These studies and data analyzed in this thesis contributed to my development of a revised taxonomy (based on a spectrum model) of use and non-use. These represent a wider range of positions within the two broad categories of 'users' and 'non-users'. The application of this taxonomy allows an individual's (non-)usage status for a specific ICT to be triangulated based on livelihood circumstances, resources, and strategies. The resulting position on the spectrum is subsequently reflected as an iterative, incremental and fluid situation on the corresponding user or non-user spectrum. The proposed spectra challenge the rigid, twodimensional and value-laden quest of converting non-users to users, and replace it with a responsive system that acknowledges both elements of physical and social access.

The proposed spectrum of use for each of the three ICTs derived from this study can facilitate future research into this issue. Recognizing that individuals can hover between fixed positions of user status and/or occupy more than one position, there are five defined states identified in the spectrum: i) individual with a significant amount of early exposure to and adoption of an ICT (early adopter); ii) individual who uses an ICT relatively frequently and is enthusiastic to use it more (keen user); iii) individual who uses an ICT relatively frequently but is not interested in increasing usage (satisfied user); iv) individual cautiously experimenting with the use of an ICT for the first time (initial 
user); and v) individuals who directly benefit from the ICT use of others (user-by-proxy). A number of these states, each constituting some form of ICT use, can be omitted when discussing a 'traditional ICT user'. ${ }^{109}$

A wide range of states was also observed with respect to non-users. These ranged from: i) individuals who are unaware of an ICT's existence (unaware); ii) individuals who are uninterested in learning how to use an ICT (uninterested); iii) individuals who are physically unable to use an ICT (physically unable); iv) individuals who are socially unable to use an ICT (socially unable); v) individuals who previously used an ICT but has since stopped (drop out); or vi) individuals who refuse to use an ICT, despite having the physical and social access available to do so (rebel). ${ }^{110}$ Although the user and nonuser taxonomies are based primarily on findings from Thimphu and Tangmachu, they can be generally applied and adapted across a variety of developing and developed country contexts.

\footnotetext{
${ }^{109}$ Although there is no definition for a 'traditional ICT user', I would argue most of the literature precludes initial users and users-by-proxy in their assessment.

${ }^{110}$ It should be reiterated that this spectrum model is applied to a single individual and a single ICT. Moreover, an individual can occupy multiple categories, hover between categories, and shift between different categories over time.
} 


\subsection{Conclusion}

The role of information and communication technologies in Bhutan's development on the subnational, national and international levels is widely recognized. As the country enters into a new era with its first democratic election in 2008 , there is considerable emphasis in policy and praxis being placed on connecting the populace with the means to exchange information and knowledge. However, there remains a lack of inquiry into the impacts of newly introduced ICTs - be they fixed telephones, mobile telephones or the Internet - on socio-economic and cultural aspects in different Bhutanese communities. In exploring the interaction between specific interactive ICTs and gender relations in Thimphu and Tangmachu, this thesis was able to uncover different dependencies, biases, correlations, and questions for future study. In addition to exploring the validity of the three assertions vis-à-vis data that were collected, the influence of text versus voice transmissions and different types of ICT users and nonusers were raised as pertinent issues to interrogate further. It is my recommendation that future research into gender and ICTs in Bhutan consider the assertions used to shape this study, as well as the two issues that emerged as part of the inductive research process. It is my hope that this work contributes to the growing body of literature on gender and ICTs in Bhutan, as well as to the broader literature on gender and technology studies in the Third World. 


\section{Appendix A: Household Survey}

Household Name/ID:

Interview \#:

Interviewer(s):

Date:

\begin{tabular}{|c|c|c|c|c|c|c|c|c|}
\hline NAME & AGE & $\begin{array}{c}\text { CENSUS } \\
\text { (DISTRICT) }\end{array}$ & $\begin{array}{c}\text { MARTTAL } \\
\text { STATUS }\end{array}$ & $\begin{array}{c}\text { \#OF } \\
\text { CHIIDRE }\end{array}$ & OCCUPATION & $\begin{array}{c}\text { LANGUGE (S) } \\
\text { (PRERERRED) }\end{array}$ & $\begin{array}{c}\text { RURAL-URBAN } \\
\text { MGRANT } \\
\text { (YN) }\end{array}$ & COMMENTS \\
\hline & & & & & & & & \\
\hline & & & & & & & & \\
\hline & & & & & & & & \\
\hline & & & & & & & & \\
\hline & & & & & & & & \\
\hline & & & & & & & \\
\hline & & & & & & & & \\
\hline & & & & & & & & \\
\hline
\end{tabular}




\section{Appendix B: Semi-Structured Interview Plan for Thimphu}

Preamble: Thank you very much for taking the time to participate in this research study - your involvement is very valuable to this study. This interview will take between 60 and 75 minutes. Its purpose is to learn about you and how you access and use the Internet and telephones. Please note that all the responses you provide should be directly related to you and your personal experience unless otherwise specified. Several questions provide you with a list of options to choose from.

Please feel free to ask for clarification or an explanation of any question throughout this interview. Do you have any questions before we begin?

Name: Household ID: Sex: Age:

\section{A. GENERAL}

1. Can you explain which income bracket this household falls within?

- _ Less than $1,000 \mathrm{Nu} /$ month

- $1,001-5,000 \mathrm{Nu} / \mathrm{month}$

- $\quad 5,001-10,000 \mathrm{Nu} / \mathrm{month}$

- _ 10,001-20,000 Nu/month

- _ 20,001-40,000 Nu/month

- _ More than $40,000 \mathrm{Nu} / \mathrm{month}$

2. a) How many people in this household earn an income? Total _

b) Do you earn a monthly income? (Y/N) If yes, how much?

- _ Less than $500 \mathrm{Nu} / \mathrm{month}$

- _ 501-1,000 Nu/month

- $1,001-5,000 \mathrm{Nu} / \mathrm{month}$

- _ 5,001-10,000 Nu/month

- _ 10,001-20,000 Nu/month

- _20,001-40,000 Nu/month

- _ More than $40,000 \mathrm{Nu} / \mathrm{month}$

3. Did you receive any formal education?

- _ _ Y Y If yes, how many years ? Are you currently enrolled?

- _ _ N; Did you receive non-formal education (NFE)?

4. Have you moved to this community within the last 10 years?

- ___ Yes; How many years ago? from rural/urban area?

-

5. Did you ever live in a rural community for over 5 consecutive years?

- _ _ Yes; If yes, how many consecutive years

- $\quad$ No

\section{B. AWARENESS: Internet and Telephone}

6. Have you ever heard about the Internet before?

- _ Y; When?

- _ Never heard of the Internet before; (have you heard of computers before)

7. Have you ever heard about telephones before?

- _ Yes; When?

- - No 
8. Have you ever heard about public access telephones (P.C.O.) before?

- _ Yes; When?

- $\quad$ No

9. Have you ever heard about mobile telephones before?

- __ Yes; When?

- _

10. According to your knowledge, how far is the nearest Internet connection from your house?

- _ At home

- W Within a 10 minute walk

- _ Within a 30 minute walk

- _ Within a 60 minute walk

- _ Not in walking distance

11. According to your knowledge, how far is the nearest fixed phone from your house?

- At home

- _ Within a 10 minute walk

- _ Within a 30 minute walk

- _ W Within a 60 minute walk

- _ _ Not in walking distance

12. According to your knowledge, how far is the nearest P.C.O. phone from your house?

- _ At home

- _ Within a 10 minute walk

- _ Within a 30 minute walk

- _ _ Within a 60 minute walk

- _ Not in walking distance

\section{Community Knowledge}

13. According to your knowledge of your community, where can one go in order to get Internet access? (Select more than one if appropriate)

- _ At home

- _ At work

- _ At a neighbour's house

- _ At school

- _ At a library

- _ At an telecentre (also known as knowledge centre - at BCCI)

- _ At an Internet café

- __ Other

14. According to your knowledge of this community, where can people go in order to use a fixed phone? (Select more than one if appropriate)

- _ Their own home

- _ Neighbour

- _ Work

- _ School

- _ Library

- _ _ Telecentre (also known as knowledge centre)

- _ Internet café

- _ _ STD/PCO booth

- _ Other 


\section{USAGE: Internet}

15. a) Have you ever used the Internet before?

- _ Y Y; when was the last time you used it?

- $\ldots \mathrm{N}$

b) If yes, what language do you usually use the Internet in?

c) If yes, for which of the following purposes do you usually use the Internet for?

- _ Reading about news and events in Bhutan

- _ Reading about news and events outside of Bhutan

- _ Reading email only

- _ Responding to email only

- _ Reading and responding to email

- _ Employment reasons - specify ...

- _ Conducting research

- _ Other

d) If no, which of the following explains why you don't use the Internet (Select more than one if appropriate)

- _ It is too expensive (prohibitive cost)

- _ _ It is too far away (distance makes it inaccessible)

- _ There is nothing I need the internet for (irrelevancy)

- I I don't understand the language of web pages very well (language)

- _ The type of information available does not interest me (content)

- _ I I feel shy to use the Internet in public places

- _ Other

16. a) Do you feel that you ever need to use Internet? (Regardless of usage level)

- $\mathrm{Y}$;

- _ N N why not?

b) If you don't use the Internet as much as you would like to, why? (Select more than one if appropriate)

- _ It is too expensive (prohibitive cost)

- _ It is too far away (distance makes it inaccessible)

- - There is nothing I need the internet for (irrelevancy)

- _ I I don't understand the language of web pages very well (language)

- _ The type of information available does not interest me (content)

- _ I I feel shy to use the Internet in public places

- _ Other

17. a) If you use the Internet, where do you use Internet access? (Select more than one if they apply)

- - At home

- - At work

- _ At a neighbour's house

- _ At a school

- _ At a library

- At a telecentre

- At an internet café

- _ Other

b) Where do you access the Internet most often (choose one of the above choices) 
18. If you use the Internet, how often do you use the Internet in one month?

- _ None (then indicate how often in 6 months:

- 1-5 times a month

- _ 6-15 times a month

- 16-25 times a month

- _ 25-50 times a month

- _ _ More than 50 times a month

19. If there was internet access closer to your home, would you use it more frequently

- _ _ much more frequently

- _ _ slightly more frequently

- _ _ would not affect my usage

- _ _ less frequently

20. If internet access cost less, would you use it more frequently

- _ much more frequently

- __ slightly more frequently

- _ _ would not affect my usage

- _ _ less frequently

21. If you have Internet access at home, how much does the household pay for it monthly?

22. If you use the Internet outside the household cost (i.e. Internet café etc), how much do

23. a) In your household, are there more female or male Internet users (to your knowledge)? Why do you think this is the case?

b) Which household member uses the Internet most? Why?

24. Do you have any general comments you would like to make about the Internet (access and use) in your life? (positive and negative)

\section{USAGE: Telephones}

25. a) Have you ever made or received a telephone call? (Show picture of a fixed/landline, mobile and public access telephone)

$-\quad-\mathrm{Y}$

b) If yes, who is the last person you called using a telephone? And what type of phone was it? For how long? From where?

- Person (Relation): ; Type of phone: ; Estimated time ; From where 


\begin{tabular}{|c|c|}
\hline $\begin{array}{l}\text { Which type of phone have you used in the past } 3 \\
\text { months? (Select more than one if appropriate) }\end{array}$ & $\begin{array}{l}\text { Which type of phone have you used most frequently } \\
\text { in the past } \mathbf{3} \text { months? (Select only one)? }\end{array}$ \\
\hline$\_$fixed & fixed \\
\hline mobile & _ mobile \\
\hline public access & _ public access \\
\hline none & _ none \\
\hline
\end{tabular}

26. Is there a fixed line phone in this household?

- _ $\mathrm{Y}$; Who has access to receive calls?

- $\quad \mathrm{N}$ to make calls?

27. Does anyone in this household own a mobile phone?

- _ _ Y Y How many people? who?

- $\mathrm{N}$

Probe: Does anyone share their mobile?

28. Do you use a public access (P.C.O.) phone?

- _ $\quad$ Y; how often in one month? $(1-5,6-15,16-25,26-50$, more than 50)

- $-\mathrm{N}$

29. a) Are there more female or male fixed phone users?

b) Which household member uses the fixed phone most? Why?

30. a) In this household, are there more female or male mobile phone users?

b) Which household member uses the mobile phone most? Why?

31. a) Are there more female or male P.C.O. phone users?

b) Which household member uses the P.C.O. most? Why?

32. If you have a mobile phone, how often have you changed it in the past 2 years? change your mobile phone? (Probe: functions, status, games, camera)

33. a) How often do you make a voice call on a fixed phone in one month?

- __ None (then indicate how often in 6 months:

- _ 1-5 times a month

- 6-15 times a month

- _ 16-25 times a month

- _ 26-50 times a month

- _ More than 50 times a month

b) How often do you receive a voice call on a fixed phone in one month?

- _ None (then indicate how often in 6 months:

- _ 1-5 times a month

- _ 6-15 times a month

- _ 16-25 times a month

- _ 26-50 times a month

- _ _ More than 50 times a month 
c) How often do you make a voice call on mobile phone in one month?

- _ None (then indicate how often in 6 months:

- _ 1-5 times a month

- _ 6-15 times a month

- 16-25 times a month

- 26-50 times a month

- _ _ More than 50 times a month

d) How often do you receive a voice call on a mobile phone in one month?

- __ None (then indicate how often in 6 months:

- _ 1-5 times a month

- _ 6-15 times a month

- _ 16-25 times a month

- _ 26-50 times a month

- _ More than 50 times a month

e) How often do you send a SMS message on a mobile phone in one month?

- __ None (then indicate how often in 6 months:

- _ 1-5 times a month

- _ 6-15 times a month

- _ 16-25 times a month

- _ 26-50 times a month

- _ _ More than 50 times a month

f) How often do you receive a SMS message in one month? (Including \& not including SPAM)

- __ None (then indicate how often in 6 months:

- _ 1-5 times a month

- _ 6-15 times a month

- _ 16-25 times a month

- _ 26-50 times a month

- _ More than 50 times a month

g) How often do you receive a "beep/flash/missed call" in one month?

- _ None (then indicate how often in 6 months:

- _ 1-5 times a month

- _ 6-15 times a month

- _ 16-25 times a month

- _ 26-50 times a month

- _ _ More than 50 times a month

h) How often do you send a "beep/flash/missed call? in one month?

- _ None (then indicate how often in 6 months:

- $\quad$ 1-5 times a month

- _ 6-15 times a month

- _ 16-25 times a month

- _ 26-50 times a month

- _ _ More than 50 times a month

26. If you could, would you use the following phones more than you currently do?

- _ Mobile ( $\mathrm{Y} / \mathrm{N}$ ); If No, what is limiting your use?

- _ Fixed (Y/N); If No, what is limiting your use? (cost, distance ...)

- _ P.C.O. (Y/N); If No, what is limiting your use? (access, cost ...) (cost, hours of operation) 
27. a) Which of the following describe the reasons for using a phone? (Select more than one if appropriate)

\begin{tabular}{|l|l|l|l|}
\hline Activity & Mobile & Fixed (Private) & Fixed (Public) \\
\hline Contact with family members or friends & & & \\
\hline Send a greeting (e.g. birthday) & & & \\
\hline Emergency & & & \\
\hline Business/employment related & & & \\
\hline Safety matters & & & \\
\hline Other & & & \\
\hline
\end{tabular}

28. If you don't have a fixed phone in your house, would having one increase your usage?

- ___ much more frequently

- __ slightly more frequently

- _ wouldn't affect my usage

- _ _ less frequently

29. If you have used a mobile phone in the last 3 months, what is the most common method of payment? (select only one)

- _ _ cash - who did you pay?

- _ p pre-paid voucher

- _ none (I didn't pay for it) - why not?

- _ Other

30. If you have used a fixed phone in the last 3 months, what is the most common method of payment? (select only one)

- _ _ cash - who did you pay?

- _ _ pre-paid card - where did you get the card?

- _ none (I didn't pay for it) - why not?

- Other

31. If you have used a PCO/STD phone in the last 3 months, what is the most common method of payment? (select only one)

- _ _ cash - who did you pay?

- _ _ none (I didn't pay for it) - why not?

- _ _ Other

32. How much do you spend (in one month) on: public phones; fixed line phones; mobile phones? Monthly income?

33. Do you have any general comments you would like to make about telephones (fixed and mobile phones) (access and use) in your life? - Positive and negative 


\section{INTRA-HOUSEHOLD DYNAMICS}

1. Can you briefly indicate who is responsible for the following tasks within this household? Please indicate more than one if the task is shared relatively equally among the different household members.

\begin{tabular}{|l|l|l|}
\hline List of tasks & $\begin{array}{c}\text { Responsible } \\
\text { Prime }\end{array}$ & Responsible Secondary \\
\hline Cooking & & \\
\hline Washing Dishes & & \\
\hline Cleaning the house & & \\
\hline Repairing the house & & \\
\hline Looking after the children & & \\
\hline Dropping children off at school & & \\
\hline Washing clothes & & \\
\hline Kitchen garden & & \\
\hline Other: & & \\
\hline Other: & & \\
\hline
\end{tabular}

37. Are decisions within the household and those relating to matters outside the household made by the same person or different people?

- _ single person

- _ different people; who?

38. If you had to choose one primary decision-maker in the household, who would it be? (choose more than one if the responsibility is relatively equally shared) And what kinds of decisions does he/she make most often?

39. Is the primary decision-maker also the primary income-earner?

- $\quad \mathrm{Y}$

40. Do you feel that his/her access to a mobile phone and/or the Internet impacts on their decision-making authority? Why or why not?

- $-\mathrm{Y}$

41. Any final comments?

\section{Concluding Comments}

- Thank you very much for your time

- Provide my contact information 


\section{Appendix C: Semi-Structured Interview Plan for Tangmachu}

Name:

Household ID:

Sex:

Age:

Preamble: Thank you very much for taking the time to participate in this research study - your involvement is very valuable to this study. This interview will take between 60 and 75 minutes. Its purpose is to learn about you and how you access and use the Internet and telephones. Please note that all the responses you provide should be directly related to you and your personal experience unless otherwise specified. Several questions provide you with a list of options to choose from. Please feel free to ask for clarification or an explanation of any question throughout this interview. Do you have any questions before we begin?

\section{A. General}

The following questions build on the information gathered in the household survey.

1. Can you explain which income bracket this household falls within?

- _ Less than $1,000 \mathrm{Nu} / \mathrm{month}$

- _ 1,001-5,000 Nu/month

- $5,001-10,000 \mathrm{Nu} / \mathrm{month}$

- _ 10,001-20,000 Nu/month

- _ 20,000-40,000 Nu/month

- _ More than $40,000 \mathrm{Nu} / \mathrm{month}$

2. a) How many people in this household earn an income?

b) Do you earn a monthly income? (Y/N)

- Less than $500 \mathrm{Nu} / \mathrm{month}$

- _ $501-1,000 \mathrm{Nu} / \mathrm{month}$

- $\quad 1,001-5,000 \mathrm{Nu} / \mathrm{month}$

- $\quad 5,001-10,000 \mathrm{Nu} / \mathrm{month}$

- $10,001-20,000 \mathrm{Nu} / \mathrm{month}$

- $\quad 20,000-40,000 \mathrm{Nu} / \mathrm{month}$

- _ _ More than $40,000 \mathrm{Nu} / \mathrm{month}$

c) How many people in this household that earns a paid income are?

- _ Female

- _ Male

3. Did you receive any formal or non-formal education?

- _ _ Y Y if yes, (F/NFE) how many years If yes, how much?

- $\quad$ N

4. Have you moved to this community within the last 10 years?

- _ _ Y Yes; How many years ago? from rural/urban area?

- $\quad$ No

5. Did you ever live in an urban community for over 5 consecutive years?

- _ _ Yes; If yes, how many consecutive years ?

- _ No

6. Have you moved back and forth (migrated periodically) from different areas of Bhutan in the last 2 years? (i.e. for studies, for harvest etc.)

- _ Y Yes; From where (city) for what purpose how frequently? 


\section{B. AWARENESS: Internet and Telephone (SHOW PICTURES)}

7. Have you heard about the Internet before? (Is not asking if they use, just heard of)

- Y Y; When? Where?

- _ _ Never heard of the Internet before

8. Have you heard about telephones before? (Is not asking if they use, just heard of)

- _ Y Y; When? Where?

- _ Never heard of the telephone before

9. Have you heard about mobile phones before? (Is not asking if they use, just heard of)

- _ Y Y When?

- _ Never heard of the mobile phone before

10. To your knowledge, how far is the nearest Internet connection from your house?

- _ At home

- W Within a 10 minute walk

- _ Within a 30 minute walk

- _ Within a 60 minute walk

- _ Not within walking distance

11. To your knowledge, how far is the nearest telephone from your house?

- _ At home

- _ Within a 10 minute walk

- _Within a 30 minute walk

- W Within a 60 minute walk

- _ Not in walking distance

12. To your knowledge, how far is the Tangmachu information centre from your house?

- _ At home

- W Within a 10 minute walk

- _ Within a 30 minute walk

- _ Within a 60 minute walk

- _ Not in walking distance

C. USAGE: Internet

13. a) Have you ever used the Internet before?

- _ Y Y when is the last time you used it?

- $\quad \mathrm{N}$

b) If yes, what language do you usually use the Internet in?

c) If yes, for which of the following purposes would you like to use the Internet for?

- _ Reading about news and events in Bhutan

- _ Reading about news and events outside of Bhutan

- _ Reading email only

- _ Responding to email only

- _ Reading and responding to email

- _ Looking for jobs

- _ Employment reasons - specify...

- _ Conducting research

- _ Other 
c) If no, which of the following explains why you don't use the Internet (Select more than one if appropriate)

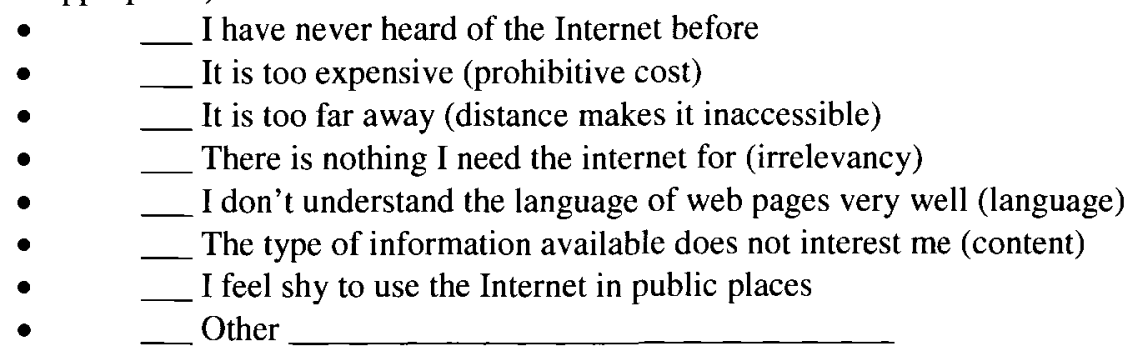

42. In this household, are there more female or male Internet users (to your knowledge)? Why do you think this is the case?

- _ Female

- _ Male

43. In this household, would you say that both female and male members have equal access to using the Internet? Explain briefly.

- $\quad \mathrm{Y}$

- $\quad \mathrm{N}$

The following questions are for respondents who have used the Internet before.

16. Did you ever access the Internet before the information centre was created in Tangmachu?

- _ Y Y where?

- $\quad \mathrm{N}$

17. How often do you use the Internet in one month?

- __ None (then indicate how often in 6 months:

- _ 1-5 times a month

- _ 6-15 times a month

- _ 16-25 times a month

- _ _ more than 25 times a month

18. If money, time, distance or language were not an issue, how often would you like to use the Internet in one month $\backslash$ ?

- __ None (then indicate how often in 6 months:

- 1-5 times a month

- 6-15 times a month

- 16-25 times a month

- _ more than 25 times a month

19. If there was internet access closer to your home, would you use it more frequently

- __ much more frequently

- __ slightly more frequently

- _ would not affect my usage

- _ _ less frequently 
20. If there was internet access that cost less, would you use it more frequently

- _ _ much more frequently

- __ slightly more frequently

- _ _ would not affect my usage

- _ _ less frequently

21. Do you have any general comments you would like to make about the Internet (access and use) in your life? (BOTH POSITIVE or NEGATIVE) and (ACTUAL or PERCEIVED) -i.e. usage is not an issue here. I want to know about what people associate with the Internet.

\section{D: USAGE: Telephone}

22. a) Have you ever made or received a telephone call? (SHOW PHOTOS)

- $-\frac{\mathrm{Y}}{\mathrm{N}}$

b) If yes, who is the last person you called using a telephone? And what type of phone was it? For how long? From where?

- Person (Relation): ; Estimated time __; From where ; What language did you speak in

c) What language do you speak in most often when using the telephone?

23. Is there a fixed line phone in this household?

- _ _ Y Y Who has access to receive calls? to make calls?

- $\quad \mathrm{N}$

24. Making calls within Tangmachu is free, however making calls outside costs money. Do you (only you - not the rest of the household) make calls outside of Tangmachu?

- _ _ Y Y Who do you call most often?

- $\quad \mathrm{N}$

25. To your knowledge, to other people in the household make calls outside of Tangmachu?

- _ _ Y Y Who do you call most often?

- $\quad \mathrm{N}$

26. To your knowledge, which household member uses the phone the most?

27. In this household, are there more female or male mobile phone users (to your knowledge)? Why do you think this is the case?

- __ Female

- _ Male

28. In this household, would you say that both female and male members have equal access to using the telephone? Explain briefly.

- $\quad \mathrm{Y}$

- $-\mathrm{N}$ 
The following questions are for those who use the telephone.

29. a) How often do you (not others in the household) make a voice call in one month?

- _ None (then indicate how often in 6 months:

- _ 1-5 times a month

- 6-15 times a month

- _ 16-25 times a month

- _ 26-50 times a month

- _ More than 50 times a month

b) How often do you (not others in the household) receive a voice call in one month?

- _ None (then indicate how often in 6 months:

- 1-5 times a month

- 6-15 times a month

- _ 16-25 times a month

- _ 26-50 times a month

- _ _ More than 50 times a month

30. If you could, would you use the telephone more?

- _ Y Y; what is stopping you?

- _ $\mathrm{N}$; why not?

31. If you answered (No) to the previous question, which of the following explains why you don't use the phone as much as you would like to? (Select more than one if appropriate)

- _ It is too expensive (prohibitive cost) - to make calls outside the loop

- L Lines are busy

- _ Too many people in the house want to use the phone at the same time

- _ _ I don't have anyone to call or receive calls from (irrelevancy)

- $\quad$ Other

32. a) Which of the following describe the reasons for using a phone? (Select more than one if appropriate)

- _ Contact with family members or close friends

- __ Emergency (illness, accident)

- _ Business/employment related

- __ Safety (informing upon arrival

- $\quad$ other

33. If you have used a phone in the last 3 months to call outside of Tangmachu, what is the most common method of payment? (select only one)

- _ I I did not call outside of Tangmachu in the last 3 months

- _ _ cash - who did you pay?

- _ voucher - where did you get the card?

- _ none (I didn't pay for it) - why not?

- _ Other

Do you have any general comments you would like to make about telephones in your life? (BOTH POSITIVE or NEGATIVE) and (ACTUAL or PERCEIVED) -i.e. usage is not an issue here. I want to know about what people associate with the Internet. 


\section{INTRA-HOUSEHOLD DYNAMICS}

34. Can you briefly indicate who is responsible for the following tasks within this household? Please indicate more than one if the task is shared relatively equally among the different household members

\begin{tabular}{|l|l|l|}
\hline List of tasks & Responsible Prime & Responsible Secondary \\
\hline Cooking & & \\
\hline Washing Dishes & & \\
\hline Cleaning the house & & \\
\hline Repairing the house & & \\
\hline Looking after the children & & \\
\hline Gathering firewood & & \\
\hline Fetching water & & \\
\hline Kitchen Garden & & \\
\hline Farm: Ploughing & & \\
\hline Farm: Planting & & \\
\hline Farm: Harvesting & & \\
\hline Other: & & \\
\hline
\end{tabular}

\section{E. TASKS AND RESPONSIBILITIES}

35. Can you please describe the types of tasks you do on a seasonal basis (i.e. in the fall and spring) - such as planting, ploughing, weeding, harvesting, etc.

Spring:

Summer:

Fall:

Winter:

37. a) Does the household receive much money from people living outside the community or even outside the country (remittances from family or friends)?

- $\quad \mathrm{Y}$

- $\quad \mathrm{N}$

b) If yes, how often is it received and how ?

38. Are decisions within the household and those relating to matters outside the household made by the same person or different people?

- _ _ single person

- _ _ different people; who?

39. If you had to choose one primary decision-maker in the household, who would it be? (choose more than one if the responsibility is relatively equally shared)

40. Is the primary decision-maker also the primary income-earner?

- $\quad \mathrm{Y}$

- $-\mathrm{N}$

\section{Concluding Questions}

- Thank you very much for your time

- Provide my contact information 


\section{Appendix D - List of Key Informant Interviewees}

\begin{tabular}{|c|c|c|}
\hline Name & Title & Institution \\
\hline Dr. Rinchen Chophel & $\begin{array}{l}\text { Executive } \\
\text { Director }\end{array}$ & National Council for Women and Children \\
\hline Dr. Francoise Pommaret & Advisor & $\begin{array}{l}\text { Institute of Language and Cultural Studies, } \\
\text { Royal University of Bhutan }\end{array}$ \\
\hline Tshering Tobgay & Director & $\begin{array}{l}\text { Department of Human Resources, Ministry of } \\
\text { Labour and Human Resources }\end{array}$ \\
\hline Tshering Yonten & Director & Department of Information and Media, MoIC \\
\hline Sangay Wangchuck & $\begin{array}{l}\text { Deputy } \\
\text { Director }\end{array}$ & Department of Information Technology, MoIC \\
\hline Karma Galay & Researcher & Centre for Bhutan Studies \\
\hline Mingbo Dukpa & $\begin{array}{l}\text { Managing } \\
\text { Director }\end{array}$ & Bhutan Broadcasting Service \\
\hline $\begin{array}{l}\text { Tenzin Choeda } \\
\text { Kunzang Choden }\end{array}$ & $\begin{array}{l}\text { Director } \\
\text { Author/Scholar }\end{array}$ & $\begin{array}{l}\text { Department of Information Technology, MoIC } \\
\text { Independent }\end{array}$ \\
\hline
\end{tabular}




\section{REFERENCES}

Abu-Lughod, L. (1993). Writing women's worlds. University of California Press Berkeley.

Aris, M. (1994). The Raven Crown: The Origins of Buddhist Monarchy in Bhutan. London: Serindia Publications.

Bartle, P. (1978). Modernization and the Decline in Women's Status. Paper presented to the Conference on Women and Ghanaian Development. National Council on Women and Development. Trinity College. Legon. Accra.

Bautsch, H., Granger, J., Karnjate, T., Khan, F., Leveston, Z., Niehus, G., et al. (2001). An investigation of mobile phone use: A socio-technical approach Socio-technical Systems in Industry, Summer Session 2001. Department of Industrial Engineering. University of Wisconsin-Madison.

Bayes, A., von Braun, J., and Akhter, R. (1999). Village Pay Phones and Poverty Reduction: Insights from a Grameen Bank Initiative in Bangladesh. Center for Development Research, No. 8, ZEF Discussion Papers on Development Policy, Bonn.

Benería, L., and Sen, G. (1986). Accumulation, reproduction and women's role in economic development: Boserup revisited in Leacock E, Safa H. Eds. Women's Work: development and the division of labour by gender. South Hadley, Mass: Begin and Garvey.

Blackwood, E. (1997). Women, land, and labor: negotiating clientage and kinship in a Minangkabau peasant community. Ethnology, Vol. 36

Boserup, E. (1970). Women's role in economic development. New York: St. Martin's Press.

Brauen, M. (1997). A Village in Central Bhutan. In C. Schicklgruber and F. Pommaret (Eds.) Bhutan: Mountain Fortress of the Gods. Serindia Publications: 85-100.

Butt, D. (2004). Class in the information society: Socio-economic reproduction in the new media environment. Master of Arts Thesis, Macquarie University, Sydney, 2004.

Buvinic, M., Gwin, C., and Bates, L. M. (1996). Investing in Women: Progress and Prospects for the World Bank. Policy Essay no. 19, Overseas Development Council in cooperation with the International Center for Research on Women (Washington, DC: Johns Hopkins University Press). 
Castells, M., Fernandez-Ardevol, M., Qiu, J. L., and Sey, A. (2006). Mobile communication and society: A global perspective. Cambridge, MA: The MIT Press.

CBS (Centre for Bhutan Studies) and IDE/JETRO (Institute of Developing Economies, Japan External Trade Organization) (2004). Economic and Political Relations Between Bhutan and Neighbouring Countries. Monograph 12, April 2004.

CEDAW (Committee on the Elimination of Discrimination against Women) (2003). An Updated Summary of the Report of the Kingdom of Bhutan.

Chadwick, R. J. (1991). Matrilineal Inheritance and Migration in a Minangkabau Community. Indonesia 51: 47-81.

Chant, S. (1998). Households, gender, and rural-urban migration: Reflections on linkages and considerations for policy. Environment and Urbanization 10 (1): 5-21.

Choden, K. (1997). Women in the City. In C. Schicklgruber and F. Pommaret (Eds.), Bhutan: Mountain Fortress of the Gods, Serindia Publications: 253-262,

Cisler, S. (2000). Subtract the digital divide. San Jose Mercury News (15 January).

Cockburn, C. (1983). Brothers: Male Dominance and Technological Change. London: Pluto Press Ltd.

. (1985). Machinery of dominance: Women, men and technical knowhow. London: Pluto Press Ltd.

(1986). Women and technology: Opportunity is not enough. Purcell, K.; Wood, S.; Waton, S.; Allen, S.(comp.).The changing experience of employment: restructuring and recession. London: MacMillan: 172-187.

Cockburn, C., and Ormrod, S. (1993). Gender and technology in the making. London: Sage.

Crehan, K. (1983). Women and Development in North Western Zambia: from Producer to Housewife. Review of African Political Economy 27/28: 51-66.

Crins, R. (2004) Religion and Gender Values in a Changing World. In K. Ura and S. Kinga (Eds.) The Spider and the Piglet - Proceedings of the First International Seminar on Bhutan Studies. Centre for Bhutan Studies: 581-596.

Croll, E., and Huang, P. (1997). Migration for and against agriculture in eight Chinese villages. The China Quarterly 149: 128-46. 
Dickerman, C. W., and Bloch, P. C. (1991). Land tenure and agricultural productivity in Malawi. Land Tenure Center, University of Wisconsin-Madison.

Dorji, T. (2001). Sustainability of tourism in Bhutan. Journal of Bhutan Studies, 3: 84104.

Dubgyur, L. (1999). Legal status of the Internet: Are there lessons to be learnt from domain names and trade marks disputes? Centre for Bhutan Studies 6: 89-122.

Everts, S. (1998). Gender and Technology: Empowering Women, Engendering Development. Amsterdam: Tool Consult and London, New York: Zed Books.

FAO. (1996). Non-Wood Forest Products of Bhutan, FAO Regional Office for Asia and the Pacific, Bangkok.

Fischer, N. (1999). In The Wired Diaries, January 1999.

Fortunati, L. (2002). Italy: Stereotypes, true and false. In J.E. Katz and M. Aakhus (Eds.) Perpetual contact. Cambridge: Cambridge University Press: 42-62.

Goode, W. (1963). World Revolution and Family Patterns, Free Press of Glencoe, New York.

Frissen, V., and Punie, Y. (2001). Present users, future homes-A theoretical perspective on acceptance and use of ICT in the home environment,

Gajjala, R. (2002). Cyberfeminist technological practices: Exploring possibilities for a women-centered design of technological environments. background paper prepared for the INSTRAW Virtual Seminars, June,

Gergen, K.J. (2002) The challenge of absent presence. In J.E. Katz and M. Aakhus (Eds.) Perpetual contact. Cambridge: Cambridge University Press: 227-241.

Geser, H. (2004). Towards a sociological theory of the mobile phone. University of Zurich. Accessed online: http://socio.ch/mobile/t geser 1.htm on June 3, 2007.

Giri, B. R. (2004). Bhutan: Ethnic policies in the dragon kingdom. Asian Affairs, 35(3): 353-364.

Gough, K. (1972). The Modern Disintegration of Matrilineal Descent Groups, Matrilineal Kinship, AH Wheeler and Co., Allahabad: 631-652.

Gray, A. (1987). Behind Closed Doors: Women and Video. In H. Baehr and G. Dyer (Eds.) Boxed-In: Women on and in TV. London: Routledge. 
Gupta, A., and Ferguson, J. (1997). Discipline and Practice: "The field" as Site, Method, and Location in Anthropology. In Gupta and Ferguson (Eds.) Anthropological Locations: Boundaries and Grounds of a Field Science. Berkeley: University of California Press: $1-46$.

Gurumurthy, A. (2003). Bridging the Digital Divide: Issues and Insights on ICT for Women's Economic Empowerment. New Delhi: UNIFEM.

. (2004). Gender and ICTs: Overview report', BRIDGE developmentgender. Institute of Development Studies, University of Sussex.

Gyatsho, L. (2004). Difficulty in Teaching Dzongkha in an English Medium System. In K. Ura and S. Kinga (Eds.) The Spider and the Piglet - Proceedings of the First International Seminar on Bhutan Studies. Centre for Bhutan Studies: 264-293.

Hafkin, N. J., and Taggart, N. (2001). Gender, information technology, and developing countries: An analytic study, Office of Women in Development, Bureau for Global Programs, Field Support and Research, United States Agency for International Development.

Hamelink, C. J. (1997). New Information and Communication Technologies, Social Development and Cultural Change. United Nations Research Institute for Social Development.

Haraway, D.J. (1985). A manifesto for cyborgs: science, technology, and socialist feminism in the 1980s. Socialist Review, 80: 65-108.

Harding, S. G. (1992). Subjectivity, Experience and Knowledge: An Epistemology from/for Rainbow Coalition Politics, Development and Change 23(3): 61-90.

Harding, S. G., and Hintikka, M. B. (2003). Discovering reality: Feminist perspectives on epistemology, metaphysics, methodology, and philosophy of science. Kluwer Academic Publishers.

Heeks, R. (2002). i-development not e-development: Special issue of ICTs and development. Journal of International Development 14: 1-11.

Horrigan, J. (2006). Tech Users: What They Have, How It Matters. in KMB Video Journal Conference. St. Petersburg Beach, Florida.

Huber, J. (1991). A theory of family, economy, and gender. In L. Rae (Ed.) Gender, family, and economy: The triple overlap. Blumberg. Newbury Park, CA: Sage.

Hugo, G. (1993). Migration Women in Developing Countries. In Department of Economic and Social Information and Policy Analysis, Internal Migration of Women 
in Developing Countries: Proceedings of the United Nations Expert Meeting on the Feminization of Internal Migration. New York: United Nations.

Hutt, M. (2003) Unbecoming Citizens: Culture, Nationhood and the Flight of Refugees from Bhutan. New Delhi: Oxford University Press.

Huyer, S. (1997). Supporting Women's Use of Information Technologies for Sustainable Development. WIGSAT submitted to the Gender and Sustainable Development Unit, IDRC.

Huyer, S., and Mitter, S. (2003). Poverty reduction, gender equality and the knowledge society: Digital exclusion or digital opportunity? Gender Advisory Board, UNCSTD.

Huyer, S., and Sikoska, T. (2003). Overcoming the gender digital divide: Understanding ICTs and their potential for the empowerment of women. Synthesis Paper-Virtual Seminar Series on Gender and ICTs.

Huyer, S., Hafkin, N., Ertl, H. and Dryburgh, H. (2005). Women in the Information Society, Chapter 6 In G. Sciadas (Ed.) From the Digital Divide to Digital Opportunities: Measuring Infostates for Development. Orbicom/ITU.

Kinga, S. (1999). The Status of Women in Traditional and Modern Bhutan. Prepared for the Centre for Bhutan Studies.

Lasen, A. (2002). A comparative study of mobile phone use in public places in London, Madrid and Paris. Digital World Research Centre, University of Surrey.

Liff, S., and Shepherd, A. (2004). An evolving gender digital divide?. Oxford Internet Institute, Internet Issue Brief No, 2, July 2004. Oxford: The University of Oxford.

Ling, R., and Yttri, B. (2002). Hyper-coordination via mobile phones in Norway. In J. E. Katz and M. Aakhus (Eds.) Perpetual contact. Cambridge: Cambridge University Press: 139-169.

Long, N., and Long, A. (1992). Battlefields of knowledge: The interlocking of theory and practice in social research and development. Routledge.

Lorber, J.(1994). Paradoxes of gender. New Haven, CT: Yale University Press.

MacKenzie, D. A., and Wajcman, J. (1985). The social shaping of technology. Open University Press.

Marcelle, G. (2000). Transforming information and communications technologies for gender equality. UNDP. 
Mathou, T. (2000). The Politics of Bhutan: Change in Continuity. Journal of Bhutan Studies, 2(2): 228-262.

Middleton, C. A., and Sørensen, C. (2005). How connected are Canadians? Inequities in Canadian households' Internet access. Canadian Journal of Communication, 30(4): 463-483.

Mies, M. (1982). In International Labour Office, World Employment Programme (Eds.), The lace makers of Narsapur: Indian housewives produce for the world market. Zed Press.

Mitter, M. S., and Rowbotham, S. (1995). Women encounter technology: Changing patterns of employment in the third world. Routledge.

Mitter, S. (2004). Globalization, ICTs, and economic empowerment: A feminist critique. Gender, Technology and Development, 8(1), 5.

Mohanty, C. T. (1991). Under Western Eyes: Feminist Scholarship and Colonial Discourses. In C. Mohanty, A. Russo and L. Torres (Eds.) Third World Women and the Politics of Feminism. Bloomington: Indiana University Press: 51-80.

Mohanty, C. T. 2003. Feminism without borders: Decolonizing theory, practicing solidarity. Duke University Press.

OECD. (2001). Understanding The Digital Divide. Paris: OECD. Accessed online: http://www.oecd.org/dataoecd/38/57/1888451.pdf on March 31, 2007.

Ormrod, S. (1994). "Let's nuke the dinner": Discursive practices of gender in the creation of a new cooking process'. In C. Cockburn and R. Furst-Dilic (eds.), Bringing Technology Home: Gender and Technology in a Changing Europe, 42-58. Buckingham: Open University Press.

Pain, A. (2004). State, Economy and Space in Bhutan in the Early Part of the $19^{\text {th }}$ Century. In K. Ura and S. Kinga (Eds.) The Spider and the Piglet - Proceedings of the First International Seminar on Bhutan Studies. Centre for Bhutan Studies: 160193.

Pain, A., and Pema, D. (2000). Continuing customs of negotiation and contestation in Bhutan. Journal of Bhutan Studies, 2(2).

Pain, A., and Pema, D. (2004). The matrilineal inheritance of land in Bhutan. Contemporary South Asia, 13(4): 421-435.

Parpart, J. L., Shirin, M. R., and Staudt, K. (2002). Rethinking em (power) ment, gender and development; an introduction. Rethinking empowerment in a global/local world London: Routledge: 3-21. 
Plant, S. (1996). On the matrix: Cyberfeminist simulations. Cultures of Internet: Virtual spaces, real histories, living bodies. London: Sage.

. (2002). On the mobile: The effects of mobile telephones on social and individual life. Motorola.

Pommaret, F. 1997. Ethnic Mosaic: the Peoples of Bhutan. In C. Schicklgruber and F. Pommaret (Eds.) Bhutan: Mountain-fortress of the Gods. London: Serindia Publications: 43-59.

Pommaret, F. (2004). Bhutan and research in Social Science. RESEAU Asie-Asia Network. August 1, 2004.

Pratt, G. (2000). Research performances. Environment and Planning D: Society and Space 18: 639-651.

Puro, J. P. (2002). Finland: A mobile culture. In J.E. Katz and M. Aakhus (Eds.) Perpetual contact. Cambridge: Cambridge University Press: 19-29.

Raiti, G. (2007). The Lost Sheep of ICT4D Research. The Massachusetts Institute of Technology, Information Technologies and International Development 3(4): 1-7.

Reeves H. and Baden S. (2000). Gender and Development: Concepts and Definitions. BRIDGE Report No 55, Institute of Development Studies, University of Sussex.

RGoB (Royal Government of Bhutan), United Nations (UNDP, UNICEF, WFP, Bhutan Country Office). (2001). Gender Pilot Study Report.

(2004). Bhutan Information and Communications Technology Policy and Strategies (BIPS). July 2004. Ministry of Information and Communications. . (2005a) Population and Housing Census of Bhutan 2005. Accessed online: http://www.bhutancensus.gov.bt/census overview.htm on March 31, 2007. (2005b). The Challenge of Youth Employment. Bhutan National Human Development Report 2005. . (2006) Rural-Urban Migration in Bhutan: Walking the Extra Mile. Ministry of Agriculture.

Roca, Z. (1994). Women, Population and Environment in Agricultural and Rural Development: Policy Challenges and Responses. FAO.

Rogers, B. (1980). The Domestication of Women: Discrimination in Developing Societies. London and New York, Tavistock. 
Roos, J. P. (1993). Sociology of Cellular Telephone: The Nordic Model. In Telecommunications Policy 17(6).

Rose, L. E. (1977). The politics of Bhutan. Cornell University Press.

Schicklgruber, C. 1997. Introduction. In C. Schicklgruber and F. Pommaret (Eds.) Bhutan: Mountain-fortress of the Gods. London: Serindia Publications: 13-27.

Schicklgruber, C., and Pommaret, F. (1997). Bhutan: Mountain fortress of the gods. Serindia Publications.

Schneider, D. and Gough, K. (1961). Matrilineal Kinship. Berkeley: University of California Press.

Simmons, E. (2002). Women in Agriculture. Remarks made at the Third International Conference on Women in Agriculture, Madrid, Spain, October 2-4.

Skog, B. (2002). Mobiles and the Norwegian Teen: Identity, Gender and Class. In J. E. Katz and M. A. Aakhus (Eds.) Perpetual Contact. Cambridge University Press, Cambridge: 255-273.

Smoreda, Z., and Thomas, F. (2001). Social networks and residential ICT adoption and use. EURESCOM P903 study" Cross-cultural attitudes to ICT in everyday life".www.eurescom.delftproot/webdeliverables/public/

Snowden, C. (2000). Blinded by text: Re-evaluating the oral imperative in communication. A paper presented at the Communications Research Forum 2000.

Sørensen, K. (2002). Love, duty and the S-curve: An overview of some current literature on gender and ICT. Digital Divides and Inclusion Measures.A Review of Literature and Statistical Trends on Gender and ICT, STS Report, 59: 1-36.

Steinmueller, W. E. (2001). ICTs and the possibilities for leapfrogging by developing countries. International Labour Review, 140(2): 193-210.

Terada, M. (2005). E-business piloting and readiness for rural women weavers in Bhutan: lessons learned. In S.J.R. Cummings, H. van Dam and M. Valk (Eds.) Gender, Society \& Development, Gender and ICTs for Development: A global sourcebook: $33-44$.

Tobgay, S. (2005). Agriculture Diversification in Bhutan. Ministry of Agriculture, RGoB: November 2005: 1-27.

Tobgyl. T. C. (2003). Bhutan: Wireless IP based Rural Access Pilot Project: Use of VoWLAN (Voice over WLAN) for the Provision of Rural Communications. ITU. 
Townsend, A. M. (2000). Life in the real-time city: Mobile telephones and urban metabolism. Journal of Urban Technology, 7(2): 85-104.

Turkle, S. (1988). Computational reticence: Why women fear the intimate machine. Technology and women's voices: 41-61.

van Driem, G. Van. (2004). Bhutan's Endangered Languages Documentation Programme Under The Dzongkha Development Authority: The Three Rare Gems. In K. Ura and S. Kinga (Eds.) The Spider and the Piglet - Proceedings of the First International Seminar on Bhutan Studies. Centre for Bhutan Studies: 294-326.

Wajcman, J. (1991). Feminism confronts technology. Pennsylvania: Penn State University Press. (2004). TechnoFeminism. Polity Press Malden, MA.

Wangmo, S. (2004). Country Case: Bhutan. In S. Wangmo, S. Violina and M.M. Haque (Eds.) Trend and Status of Gender Perspectives in the ICT Sector: Case Studies in Asia-Pacific Countries. ITU (International Telecommunications Union): 26-66.

Warschauer, M. (2003). Technology and social inclusion. MTT Press Cambridge, Mass.

Waverman, L., Meschi, M., and Fuss, M. (2005). The impact of telecoms on economic growth in developing countries. Africa: The Impact of Mobile Phones. The Vodafone Policy Papers Series 2.

Wilhelm, A. G. (2001). They threw me a computer... but what I really needed was a life preserver. First Monday, 6(4)

Wilson, M. (2003). Understanding the international ICT and development discourse: Assumptions and implications. The Southern African Journal of Information and Communication, 3.

Wright, C. (1995). Gender awareness in migration theory: Synthesizing actor and structure in southern Africa. Development and Change, 26(4): 771-791.

Yunus, M. (1998). Poverty Alleviation: Is Economics Any Help? Lessons from the Grameen Bank Experience. Journal of International Affairs 52(1), 48-65. 